\title{
Riot Dyke: \\ Music, Identity, and Community in Lesbian Film
}

\author{
by
}

Alana Kornelsen

A thesis submitted to the Faculty of Graduate and Postdoctoral Affairs in partial fulfillment of the requirements for the degree of

Master of Arts

in

Music and Culture

Carleton University Ottawa, ON

(C) 2016

Alana Kornelsen 


\begin{abstract}
This thesis examines the use of diegetic pre-composed music in three American lesbian feature films. Numerous trends can be noted in the selection of music in lesbian film broadlymusic is often selected to draw on insider knowledge of the target audience of these films, creating cachet. This cachet comes with accompanying "affiliating identifications" (Kassabian 2001) that allow music to be used in the films' construction of characters' identities. This is evident in the treatment of music in many lesbian films: characters frequently listen to, discuss, and perform music. This thesis focuses specifically on riot grrrl music and the closely linked genre of queercore (which together Halberstam ([2003] 2008) refers to as "riot dyke") in three films that focus on the lives of young women: The Incredibly True Adventure of Two Girls in Love (dir. Maria Maggenti, 1995), All Over Me (dir. Alex Sichel, 1997), and Itty Bitty Titty Committee (dir. Jamie Babbit, 2007). By examining how diegetic riot dyke music is used in these three films to build characters' identities and contribute to the films' narratives I argue that in these films, riot dyke music is presented as being central to certain queer identities and communities, and that this music (as well as the community that often accompanies it) is portrayed as instigating or providing opportunities for characters' personal growth and affirming characters' identities in adverse environments.
\end{abstract}




\section{Acknowledgements}

First and foremost, I would like to thank my supervisor, Dr. Anna Hoefnagels, for her guidance, support, and encouragement during the process of writing this thesis and over the duration of this program. Her input and critique has been invaluable and her reassurance and confidence in me have helped to guide me through this process.

Additional thanks to Dr. Alexis Luko who helped shape this thesis in its beginning stages. Thanks to Dr. Jesse Stewart and Dr. Carolyn Ramzy for their continual encouragement of those of us working in the Graduate Resource Centre and to Dr. Ramzy, Dr. James Deaville, Dr. Paul Théberge, and Dr. Amrita Hari for their exceptional teaching, which made the first year of the program an exciting and engaging experience.

A huge thank you to my colleagues, whose engaging conversation, suggestions, and commiseration were invaluable and appreciated, and to my family and friends for their continual support. 


\section{Table of Contents}

Abstract $\quad$ ii

Acknowledgements $\quad$ iii

Introduction 1

Methodology and Outline 4

Chapter 1: History and Theoretical Background 7

Definitions: "Lesbian Film" and "Queer" 7

A Brief History of Lesbian Film 9

$\begin{array}{ll}\text { Identity and Community } & 15\end{array}$

Links between Music and Queer Identities and Communities 20

Music in Film 22

Popular Music in Lesbian Film $\quad 24$

Chapter 2: Riot Dyke Music: History and Context for Its Use in Film 29

Riot Grrrl 30

Queercore $\quad 35$

Interactions between Riot Grrrl and Queercore: A Case for "Riot Dyke" 37

Riot Grrrl's Relationship to Race and Class 42

Conclusion 46

Chapter 3: Case Study: The Incredibly True Adventure of Two Girls in Love 48

Identities and Music in Two Girls in Love 52

Music, Social Milieu, and Community $\quad 53$

Music and Politics $\quad 55$

Music and Gender Expression $\quad 56$

$\begin{array}{ll}\text { Music and Class } & 57\end{array}$

Randy's Music Listening Choices $\quad 60$

$\begin{array}{ll}\text { Conclusion } & 67\end{array}$

Chapter 4: Case Study: All Over Me 69

Music, Social Milieu, and Community 72

$\begin{array}{ll}\text { Music and Politics } & 74\end{array}$

Music and Gender Expression $\quad 75$

Musical Listening and Performance in All Over Me 78

$\begin{array}{lr}\text { Conclusion } & 85\end{array}$

Chapter 5: Case Study: Itty Bitty Titty Committee $\quad 87$

Music and Politics $\quad 91$

$\begin{array}{ll}\text { Music and Gender Expression } & 94\end{array}$ 
Music, Social Milieu, and the Community of IBTC 95

Anna's Introduction to the C(i)A and Riot Dyke Music 98

Riot Dyke and the "Rebel Girl" 104

"White Girl": A Call for Change 107

$\begin{array}{ll}\text { Conclusion } & 109\end{array}$

$\begin{array}{ll}\text { Conclusion } & 110\end{array}$

$\begin{array}{ll}\text { Future Directions } & 113\end{array}$

Appendix I: English-Language Films Examined in Preliminary Research 116

$\begin{array}{ll}\text { Works Cited } & 125\end{array}$

$\begin{array}{ll}\text { Discography } & 130\end{array}$

Filmography 131 


\section{Introduction}

A quick glance at the soundtracks of a few lesbian films will quickly reveal to the viewer that although they may vary depending on the age and style of the film, most films with popular music soundtracks feature at least some music that is likely to appeal to an audience of queer women. Music plays an important role in many queer communities and in the lives of many individual LGBTQ people and as such is often central to portrayals of queer identities and communities in film. Anahid Kassabian, for instance, in her 2001 book Hearing Film: Tracking Identifications in Contemporary Hollywood Film Music, discusses how the lesbian film classic Desert Hearts (dir. Donna Deitch, 1985) uses music to appeal to a specifically lesbian audience. Kassabian does not focus in particular on lesbian film in this book, she simply finds Desert Hearts a compelling example of how a film's music can present different meanings for different audiences. Though Desert Hearts holds a unique position as being perhaps the most "classic" of all lesbian films, it is not unique in its use of music to appeal to lesbian audiences and to create realistic queer characters. While Desert Hearts primarily employs country and rock 'n' roll music, there is a wide range of genres that frequently appear in lesbian film soundtracks. This thesis focuses on another commonly used type of music is lesbian film, riot dyke music — that is, music by queer women in the riot grrrl or queercore genres, or that emerged in the overlap of these subcultures.

This thesis is concerned with portrayals of identity in American lesbian feature film as inflected by the use of riot dyke music. Specifically, I focus on how riot dyke music and specific songs within this genre are used in relation to characters' identities in a selection of thematically related films. I examine the music both in terms of its lyrics and extrafilmic associations, and 
explore the uses of the musical selections in the context of the films, looking at their relationship to plot, the identity of characters, and characters' development over the course of the films. Guiding questions include: What kinds of identities are linked to riot dyke music in these films; and What does riot dyke music contribute to the narratives of lesbian film?

In order to explore these questions, this thesis examines three films, The Incredibly True Adventure of Two Girls in Love (dir. Maria Maggenti, 1995), All Over Me (dir. Alex Sichel, 1997), and Itty Bitty Titty Committee (dir. Jamie Babbit, 2007), each of which engage with riot dyke music in different ways. Though these three films have similar themes of youth, selfconfidence, feminist ideologies, identity formation, and young love, each has a unique tone and style, and in each, the protagonists' life situations are remarkably different. In all of these films, the main character grows, matures, and becomes more independent, but this manifests differently in each film. Similarly, though all three films use riot dyke music, the music takes on both similar and contrasting purposes in each film. I discuss the three films in chronological order in part because the most recent film, Itty Bitty Titty Committee, which was produced more than ten years later than the other films, uses riot dyke music in a very different way than the earlier two films; in both The Incredibly True Adventure of Two Girls in Love and All Over Me, the main characters profess interest in performing this music, while in Itty Bitty Titty Committee, the main characters listen to and dance to riot dyke music but show no interest in personally making this music. Further, the use of music in All Over Me, the second film chronologically, serves as a good bridge between the relatively individual style of engagement with riot dyke music exhibited in The Incredibly True Adventure of Two Girls in Love and the almost exclusively communitybased listening in Itty Bitty Titty Committee. Following is a brief overview of each of these films' plots and soundtracks. 
The Incredibly True Adventure of Two Girls in Love (dir. Maria Maggenti, 1995) is the story of two high school girls in small-town USA: Randy Dean (Laurel Holloman), a tomboyish girl who works at the local gas station and is having a dead-end affair with an older married woman, and Evie Roy (Nicole Ari Parker), a well-off only child from a more "cultured" family. The two girls bond over their love of music, each introducing the other to the very different genres of music that they listen to, while their relationship is threatened by their differences in class and opportunity (though Randy is white and Evie is black, race is almost ignored in this film; Evie's well-off background seems to overwrite any discussion of race). Though their relationship is challenged when Evie's mother finds out that Evie is dating a girl and when Randy's aunt finds out that Randy is failing out of school, the film ends with a comic, somewhat optimistic moment. The soundtrack for Two Girls in Love relies heavily on music from in and around the riot grrrl scene, in particular "Cool Schmool" by Bratmobile, "Page Two" by Lois, “Wake Up, I’m Leaving” by Velocity Girl, and "Resist Psychic Death” by Bikini Kill. This music is associated with Randy, while Evie professes to enjoy classical music as evinced by her introduction of Randy to the Dies Irae from Mozart's Requiem Mass in D Minor.

All Over Me (dir. Alex Sichel, 1997) tells the story of Claude (Alison Folland), a teenage girl who lives in New York's Hell's Kitchen. The film follows Claude's volatile and emotionally/erotically charged relationship with her friend Ellen (Tara Subkoff), with whom Claude wants to start a band. Ellen's relationship with her bigoted and macho boyfriend creates tension in Claude and Ellen's friendship, making their creation of a band increasingly unlikely, so Claude's new acquaintance Luke (Pat Briggs), an openly gay punk musician, suggests that she check out a friend's club where "girl bands" often perform. There she encounters riot dyke-style music performed by another young woman, Lucy (musician and actor Leisha Hailey). Claude 
must grapple with her relationship with Ellen, whose boyfriend is implicated in murdering Luke, her own realization of her sexuality, and navigating her new friendship/romance with Lucy. All Over Me is the only film in my selection in which the main character is not already out at the beginning of the film. The film's soundtrack heavily features female fronted alternative/indie bands from the 1990s such as Helium, Babes in Toyland, Tuscadero, The Murmurs, The Amps, and 12 Rounds. The only definitively riot dyke music in the film, aside from music performed by Lucy’s band, is Sleater-Kinney’s “I Wanna Be Your Joey Ramone.” However, significantly, the film was partly funded by a grant to make a film about the riot grrrl music scene (New Line Productions 2005).

Itty Bitty Titty Committee (dir. Jamie Babbit, 2007) follows the exploits of the radical feminist group Clits in Action (C(i)A) through the eyes of Anna (Melonie Diaz), a relatively sheltered young woman who has been invited to join the group by Sadie (Nicole Vicius), the C(i)A's de facto leader. While Anna and Sadie struggle to negotiate their budding romantic relationship due to Sadie's perpetually on-the-rocks relationship with her older, more serious, girlfriend Courtney (Guinevere Turner), Anna and the other members of the C(i)A mastermind a plot to gain national attention. The film's soundtrack consists almost exclusively of music by riot dyke bands, including Sleater-Kinney, Bikini Kill, Heavens to Betsy, Team Dresch, Slant 6, and Le Tigre, with additional music composed by Radio Sloan of queercore band The Need.

\section{Methodology and Outline}

In order to explore how riot dyke music is used to contribute to characters' identities in these three films, I focus on music that the characters choose to listen to. Listening to this music falls into the category of "habit" as used by Thomas Turino (2008) to describe identity 
formation. Turino proposes that one way to describe identities is as a collection of "habits," the choices a person makes in everyday life to represent themselves to themselves and others, drawing on a Peircean conception of "habit." I discuss this idea in more depth in Chapter 2. In the case study chapters I examine the riot dyke music that characters listen to, both lyrically and in terms of the music's extratextual associations and affiliating identifications, in order to explore what the music represents about the characters' identities, how it contributes to the films' narratives, and how it is used to demonstrate the growth and maturation of these young characters.

In Chapter 1 of this thesis I present the theory and history that I draw on in the following chapters. I discuss the history of lesbian film, the importance of music in queer communities, and theories of music in film that explain the importance of music in LGBTQ film. I also discuss the theories of identity and community that I rely on in the later chapters. In addition, this chapter provides a summary of my preliminary research on music in lesbian film and how it led to my selection of the case study films. Chapter 2 provides an in-depth examination of riot dyke music as a genre (or confluence of genres). Here I explore riot grrrl and queercore musics' histories and their overlap, examine the links between riot dyke music and lesbian communities and identities, and discuss the affiliating identifications (and identity markers) that riot dyke music may bring to the films in which it is employed. Chapters 3, 4, and 5 examine this music as it is used in The Incredibly True Adventure of Two Girls in Love (dir. Maria Maggenti, 1995), All Over Me (dir. Alex Sichel, 1997), and Itty Bitty Titty Committee (dir. Jamie Babbit, 2007) respectively. In these chapters I explore the music that the characters are portrayed as listening to (that is, the music that they listen to as a "habit" that builds their identity) to discover what the music contributes to the identity being portrayed onscreen and how the music relates to the films' narratives and 
character development in order to demonstrate the connection between riot dyke music and protagonists' maturation and/or identity shifts. Each chapter focuses on three ways that "habits" and identities manifest in relationship to riot dyke music in the film under discussion: the creation of community, the cultivation of political identities, and characters' gender expression. Following this, the chapters explore characters' music listening choices and the music's relationship to character development, though the emphasis in each chapter varies due to each film's different use of music. In the conclusion, I explore the similarities and differences in this music's use in the three films, drawing conclusions about the role of riot dyke music in this small selection of films. I find that riot dyke music is linked to white lower- and middle-class queer young women who push against social expectations of femininity, and is frequently used to bring about a maturation or change in identity (related to politics or sexual orientation) in the films' main characters. 


\section{Chapter 1}

\section{History and Theoretical Background}

Due to this thesis's location at the intersection of several topics, including queer film, popular music, and theories of identity and community, this chapter positions the thesis in relation to these topics. I begin this chapter by exploring the meanings of the terms "lesbian film" and "queer" and how I use these terms in this thesis. Following this, I position the thesis and the films from which I selected my case studies within the context of the history of lesbian representation in cinema, leading into an exploration of the concepts of "community" and

"identity," theory which is central to this thesis. Next, I explore the intimate connections between queer individuals and communities with music that make music important to portrayals of queer women in film. In the final sections of this chapter I discuss the use of diegetic music and compiled scores in film before making some observations about popular music in lesbian film broadly, observations which informed my selection and analysis of films for this thesis.

\section{Definitions: "Lesbian Film" and "Queer"}

In this thesis I use "lesbian film" to mean films that focus on stories about women who experience same-sex attraction and which are aimed at (or have been claimed by) an audience of women who identify as lesbian, bisexual, or queer. My use of the label "lesbian film" is not meant to imply that the female characters in these films are necessarily lesbian; rather, the phrase follows the common vernacular used to refer to these films, based on a review of popular queer 
women's popular culture websites such as AfterEllen and Autostraddle. ${ }^{1}$ Another reason for this semantic choice is that one can easily argue that many popular "lesbian films" are not particularly "queer" except for in the sense of "queer" as an umbrella term for LGBTQ people. Lisa Henderson argues that "in a cultural universe where distributable 'gay films' are likely to be feature-length and to affirm gay and lesbian communities through coming-out stories, happy endings, and same-sex kisses, the depth and range of queer feeling and representation are compressed" $(2008,573)$. In contrast, Bob Nowlan asks "Does it continue to make sense to distinguish queer from non-queer varieties of gay, lesbian, bisexual, and transgender film?"; this question is particularly relevant since in recent years, scholars of LGBTQ film have started to use the term "queer" in a broader sense $(2010,10)$. However, to distinguish from the specific connotations of terms such as "New Queer Cinema," which refers to a specific group of queer films from the early 1990s discussed in more depth below, I refer to these films as "lesbian films" (though some films examined arguably do fall within the purview of New Queer Cinema as well).

In regards to the word "queer," I generally use it as an umbrella term for lesbian-, bisexual-, pansexual-, or queer-identified women or non-binary people as alluded to by Nowlan. Queer studies scholars provide myriad more specific definitions—-for instance, Eve Kosovsky Sedgwick defines queer as "the open mesh of possibilities, gaps, overlaps, dissonances and resonances, lapses and excesses of meaning when the constituent elements of anyone's gender, of anyone's sexuality aren't made (or can't be made) to signify monolithically" $(1994,8)$ and

\footnotetext{
${ }^{1}$ This parlance may be beginning to change; an Autostraddle article from August 11, 2015 entitled "The 100 Best Lesbian Movies of All Time" includes the disclaimer that "The term 'lesbian movies' is used in the headline because that is the most popular search term for people looking for films about women who like other women, but these movies feature women of all sexual orientations besides 'straight." AfterEllen often uses the phrase "lesbian/bi movies" as a descriptor.
} 
Nowlan proposes that the linkage of the term "queer" to a questioning of the efficacy of identity politics means that it is "often used both to denote and to refuse to denote identity" $(2010,4)$. However, Nowlan makes the important observation that "homosexuality is that which has tended to be and continues to tend to be widely regarded as the queerest kind of social behavior" (9). Along similar lines, both Sedgwick and Peraino emphasize that while academic definitions of "queer" can be broad and quite diffuse, seeming to include anyone and anything that questions social norms of gender and sexuality, same-sex desire and transgender identities remain central to queer theory (Sedgwick 1994, 8; Peraino 2006, 6). Though these scholars inform my understanding of the term queer, I primarily use it to refer to LGBTQ characters and communities in the films I examine since, as these scholars generally also emphasize, the term applies most readily to LGBTQ people. Given that the identities of both the audience members and the characters onscreen are rarely defined explicitly, "queer" becomes an important term to acknowledge non-straight orientations without making any more specific assumptions about identities. The following section examines how queer women have been portrayed on film throughout its history, leading to a broad exploration of "lesbian film" since the 1980s.

\section{A Brief History of Lesbian Film}

Lesbian feature film as examined here began in the early 1980s with movies such as Lianna (dir. John Sayles, 1983) and Desert Hearts (1984). This is not to say that lesbians did not exist in cinema prior to this era; before the 1980 s, feature films that depicted lesbians were not uncommon, but usually lesbians were portrayed in a negative light. Due to this thesis's focus on three American films, this section focuses on film in America-both American film and foreign 
films released in America — and the effects of the Motion Picture Production Code (a set of moral guidelines governing the American film industry from 1930 to 1968) on the representation of queer women in film. This section includes films from other parts of the world that were also released in the United States since European films also influenced and were affected by the code, which plays a large role in the history of the portrayal of LGBTQ people on film in North America.

Visual culture scholar Jamie Stuart (2008) has provided a brief overview of the history of lesbians in film, which I draw on here. In early cinema, until the late 1920s, lesbian characters were rare, though many examples exist of women cross-dressing in film. In general, the crossdressing characters did not evoke lesbianism, with the occasional exception, for instance the 1914 film A Florida Enchantment (dir. Sidney Drew), a film which scholar Laura Horak argues "was able to represent inverted characters and same-sex desire so literally without incurring a backlash because the production looked similar to cross-gender performances that were already the subject of nostalgia" $(2016,111)$. Beginning in the late 1920s with the silent film Pandora's Box (dir. Georg Wilhelm Pabst, 1929) and continuing through the 1930s, cinema frequently portrayed the lesbian as "monstrous" or "predatory and aggressive" (Stuart 2008, 45). Though the Motion Picture Production Code was instituted in $1930,{ }^{2}$ banning "sex perversion or any inference to it" (as well as many other topics subject to moral scrutiny) (quoted in Leff and

\footnotetext{
${ }^{2}$ Prior to the 1930s, particularly in the late 1800 s, portrayals of homosexuality in cultural production were aimed at the upper class, which was supposed to be able to comprehend the meaning of relatively subtle scenes of implied homosexuality. Horak (2016) finds that in the United States, until the 1920s, film critics did not engage with implied lesbianism in films (that is, "film critics were not yet motivated to use [this interpretive framework] to prove their sophistication" (107)). However, as newspapers in the 1920s began telling the public about scandalous portrayals of lesbianism, often on stage or in books rather than on screen, the general public learned the signals and codes of homosexuality employed in drama and cinema. As such, the understanding of portrayals of homosexuality was no longer confined to the educated and "discerning" elite, forcing regulatory agencies to censor homosexuality in film so as not to corrupt the general public (who, it was assumed, had not understood portrayals of homosexuality before) (223). The Motion Picture Production Code argues that while "most arts appeal to the mature," (quoted in Leff and Simmons 2001, 293) film "appeals at once to every class, mature, immature, developed, underdeveloped..." (293294) and as such, films have "larger moral responsibilities" (quoted in Leff and Simmons 2001, 295).
} 
Simmons 2001, 288), the code was not strictly enforced until 1934; the German film Mädchen in Uniform (dir. Leontine Sagan, 1931) and Queen Christina (dir. Rouben Mamoulin, 1933) each portrayed women's same-sex attraction clearly and with nuance and were released in the United States prior to this date (Horak 2016, 209). LGBTQ cultural history scholar Lillian Faderman argues that this stricter enforcement of the Code was in part due to the onset of the Great Depression, which caused increased "moralistic disapproval of lesbianism which seemed decadent during grim times" $(1991,101)$.

Thus, from 1934 until 1968 (when the Production Code was altered) filmic representations of both male and female homosexuality became more veiled, focusing on obsession or on butch women, the latter of which Halberstam argues was "the only way of registering sexual variance in the repressive environment of Hollywood cinema" $(1998,186)$. The strictness of the code is evident in that when earlier films that contained scenes of explicit or implicit homosexuality were rereleased, these scenes were excised (Horak 2016, 219). Films through the 1940s continued the representation of lesbians as dangerous and frightening (Stuart 2008 , 48). During the 1950s, lesbians and gay men came to be perceived as an increased threat to America due to homosexuality's new classification as a mental illness in the United States in combination with the era's Cold War McCarthyism which positioned homosexuals as suspected Communists (49). The films in this era tend to portray lesbians as "criminals or mental deviants" (51).

In 1961, the Production Code's position on homosexuality in film was altered to be slightly more lenient; the revised rule stated, "restraint and care shall be exercised in presentations dealing with sex aberrations" (quoted in Hayes 2009). Seven years later the Motion Picture Production Code was replaced by the Motion Picture Association of America (MPAA) 
film-rating system, ostensibly ending the overt censorship of homosexuality, though the MPAA ratings system is highly subjective and unpredictable. Many films of the 1960s and 1970s continued to depict lesbians as dangerous, predatory deviants, though some presented more nuanced portrayals (Stuart 2008, 53); Benshoff and Griffin argue that "Hollywood throughout the 1970 s tended to use its new license to denote more clearly the same homosexual stereotypes that it had employed connotatively in the past" $(2004,321)$. During the 1980 s a number of feature films, both independent and mainstream, portrayed queer women in a more neutral light, including Personal Best (dir. Robert Towne, 1982) and Lianna (dir. John Sayles, 1983) (Stuart 2008, 55). Stuart argues that independent films such as I've Heard the Mermaids Singing (dir. Patricia Rozema, 1987) and Born in Flames (dir. Lizzie Borden, 1983), which depicted out queer women in nuanced ways, "set the stage for later films that took as an opening premise that the women involved were already aware of and comfortable with their lesbian identities" $(2008,56)$. Stuart posits that Desert Hearts (1985), now considered a classic, was thought of by many lesbians as "the start of a new lesbian cinema" (56).

The 1990s did see an escalation in the production of independent lesbian films, in part tied to what B. Ruby Rich has termed "New Queer Cinema" (2013, xx). The term New Queer Cinema is generally used to describe a group of films emerging between 1989 and the mid-1990s that Jack Curtis Dubowsky, a scholar who has examined music and cachet in New Queer Cinema, describes as "a coincidental collection of works from an unapologetic queer perspective that put strong, iconoclastic images of lesbians and gays onscreen" while on the small budgets of independent and "outsider" cinema $(2014,26)$. The directors of these films did not strive for "positive" representations of LGBTQ people, instead aiming "to make creative and dynamic films" (Stuart 2008, 58). Though the majority of New Queer Cinema focused on the stories of 
gay men, there was a simultaneous increase in lesbian romantic comedies and dramas that do not fit neatly inside the box of New Queer Cinema. Since the early 1990s, the production of independent lesbian films has continued both in America (the area on which this thesis focuses) and in many countries around the world, creating a greater breadth in storylines, while also displaying a movement towards a mainstream romantic comedy style. For instance, Bob Nowlan argues that

"post-queer" "gay-lesbian-bisexual-and-transgender cinemas" soon displaced the distinctly "queer" impetus of the late 80s to early 90s New Queer Cinema. And this displacement ran parallel with the steady assimilation - throughout the 1990s and continuing into the 2000s — of "queer" difference into a still partially marginalized but also ever increasingly tamed, heteronormatized, once-more fixed-identity minority population...striving for acceptance on "straight terms" within a "straight society" that remains, at best, only very limitedly "queered." $(2010,14-15)$

Thus, from the late 1990s onward, though there is some variation from this norm, lesbian cinema is largely comprised of relatively formulaic romantic comedies or romantic dramas, for instance Better than Chocolate (dir. Anne Wheeler, 1999), Imagine Me and You (dir. Ol Parker, 2005), Nina's Heavenly Delights (dir. Pratibha Parmar, 2006), Loving Annabelle (dir. Katherine Brooks, 2006), Puccini for Beginners (dir. Maria Maggenti, 2006), Bloomington (dir. Fernanda Cardoso, 2010), and Elena Undone (dir. Nicole Conn, 2010). In addition, English-language lesbian film is overwhelmingly dominated by stories about upper-middle-class white women, with only a few exceptions such as Chutney Popcorn (dir. Nisha Ganatra, 1999), Nina's Heavenly Delights, Saving Face (dir. Alice Wu, 2004), Pariah (dir. Cheryl Dunye, 2011), and The Watermelon Woman (dir. Dee Rees, 1996), which focus on characters and communities of colour. The last 
two, which engage with African American communities, also tell the stories of lower class characters. Relatively few films about white characters engage with class; The Incredibly True Adventure of Two Girls in Love (dir. Maria Maggenti, 1995) is one of few exceptions. The film lists above are based on my own examination of well-known lesbian films.

Though there were many films prior to the 1980s that portrayed lesbians, my examination of music in lesbian film begins with those films in the 1980s that began the trend of making feature films that centralized the stories of queer women and portrayed these women in ways that appealed to audiences of queer women, as opposed to presenting sensationalized, stereotypical portrayals of lesbians for mainstream audiences. Some of these films were made with an audience of queer women in mind. The films that I initially examined for the purposes of studying music in lesbian film span the date range of 1982 to 2014 and are all English-language fictional feature films or television movies. I must acknowledge here that there is a strong history of LGBTQ documentary filmmaking and short film-making which predates these films, beginning in the 1970s with short films such as Barbara Hammer's Dyketactics (1974) and Women I Love (1976), and documentaries such as In the Best Interests of the Children (dir. Frances Reid, Elizabeth Stevens, and Cathy Zheutlin, 1977). In addition to these films, there are also films that have been claimed by queer women that precede this era-for instance, the 1931 film Mädchen in Uniform and its 1958 remake (dir. Geza Radvany). However, it is the films of the early 1980s that were the first feature films to be produced with a lesbian audience in mind, and that paved the way for the proliferation of lesbian cinema in the 1990s. 
Identity and Community

The proliferation of lesbian film in the 1990s created a new outlet for representations of and engagement with queer identities and communities. Throughout this thesis I engage with ideas of identity and community as represented in lesbian film. Music is often used in these films to affirm characters' queer identities or as a means of creating community. As such, an exploration of theories of identity and community and how I use these terms to apply to the characters and groups in the case study films is warranted. Identities and communities, including those of LGBTQ people, are often strongly linked to or influenced by music. Music has long had associations with the queer, as examined by Judith A. Peraino (2006) in her book Listening to the Sirens: Musical Technologies of Queer Identity from Homer to Hedwig, and is thus wellpositioned to be used as a symbol of queer identities broadly and, in accordance with this project, to portrayals of lesbian and queer women's identities on film. Susan Fast argues that "musical genre [has] everything to do with the social, with subjectivity, with belongings and exclusions" (2012, 287) - that is, musical genres can be central to communities, as well as to individual identities. As such, the use of particular genres, in this case riot grrrl and queercore, are inextricably linked with the identities that filmmakers build for their characters.

In order to explore how music is related to identity and community, I rely throughout this thesis on the work of Thomas Turino (2008) regarding the "habit" as it relates to identity formation. Turino draws on C. S. Peirce's conception of "habit" as a "general principle working in a man's nature to determine how he will act" $(1955,123)$. Habits are changeable over time; Peirce argues that "habit-change often consists in raising or lowering the strength of a habit," that "habits also differ in their endurance," and most importantly for this project, that "the effects of habit-change last until time or some more definite cause produces new habit-changes" (1955, 
278). In his book Music as Social Life: The Politics of Participation, Turino, following Peirce, defines "habit" as "a tendency toward the repetition of any particular behavior, thought, or reaction in similar circumstances or in reaction to similar stimuli in the present and future based on such repetitions in the past" $(2008,95)$. Turino argues that an advantage of using the concept of the habit in relation to identity and cultural formations is that "habits are both relatively stable and also dynamic and changeable," allowing for engagement with shifts that can occur in personal identities and in communities (95). Further, Turino proposes that the concept of the habit enables understanding of links between individual people's identities and their social milieu because "the attainment of habits...is realized through active learning from, as well as through the imitation of, those around us at different levels of focal awareness" (95). Using the concept of "habit" as a starting point, Turino defines identity as "the partial and variable selection of habits and attributes that we use to represent ourselves to ourselves and to others, as well as those aspects that are perceived by ourselves and by others as salient" $(2008,102$; emphasis in original); this is in contrast to self, which he defines as "the composite of the total number of habits that determine the tendencies for everything we think, feel, experience, and do" (101). That is, one's music listening/creating choices may or may not be central to one's identity/identities (though they are always part of the self) — for some people music may not be central to any of their identities, while for others, music may be central to some or most of their identities. However, many scholars, whom I discuss below, argue that music is frequently central to queer identities in particular, an element that is evident in the use of music in lesbian film. Turino's concept of "habits" is central to my thesis; I explore how characters' music listening "habits" contribute to their identities, resulting in development of new identities or affirming preexisting identities. 
Community is another theme with which I engage frequently in this thesis. Each of the three films examined in later chapters use music to create community — through live music at clubs, through creating or sharing music with peers, or by allowing an isolated character to engage with a community to which she does not have access in person. Community and identity are closely intertwined, an idea which is elaborated on by numerous scholars. A common theme in scholarly discussion of community is the fact that community is heavily dependent on individual members' understandings of that community; that is, while an outsider might not interpret a certain group as a community, its members may understand it as such. In Benedict Anderson's influential book Imagined Communities: Reflections on the Origin and Spread of Nationalism, he argues that communities (in this case, nations in particular) are "imagined because the members of even the smallest nation will never know most of their fellow-members, meet them, or even hear of them, yet in the minds of each lives the image of their communion" ([1983] 2006, 6, italics in original). Anderson goes on to posit that "all communities larger than primordial villages of face-to-face contact (and perhaps even these) are imagined. Communities are to be distinguished, not by their falsity/genuineness, but by the style in which they are imagined" (6). He resists the idea that communities are a "fabrication" or "falsity," instead forwarding the idea that communities are "imagined" or "created" (6). I emphasize this so as to open up possibilities of understanding collections of people in the films I examine as “communities," and to be able to examine characters' connections to LGBTQ or feminist communities. Given the nature of film, which allows the audience only a brief excursion into the lives (and rarely the minds) of characters, this broad and flexible understanding of community is necessary to enable the discussion of portrayals of community on film. 
Turino (2008) and Anthony P. Cohen (1985) both emphasize the intrinsic links between identity and community, though Turino prefers to examine what he calls "cultural cohorts" and "cultural formations" rather than "communities." Turino argues that "any general theories about artistic processes and expressive cultural practices would do well to begin with a conception of the self and individual identity, because it is in living, breathing individuals that 'culture' and musical meaning ultimately reside" $(2008,95)$. I would suggest that one could and should include consumption of the cultural products in the category of "expressive cultural practices." Our "habits" include which types of music we choose to listen to, and for many people musical listening habits are central within the array of habits that form the identities we present to the world and to ourselves, and which can contribute to community.

Whereas Turino emphasizes the individual's position in the formation of a cultural cohort, Cohen also emphasizes the reverse - that is, the importance of community to individuals' identity formation - arguing that members of a community often "find their identities as individuals through their occupancy of the community's social space" $(1985,109)$, which is where cultural productions such as music and film become important to identity and community. This idea is important to this thesis; characters in both All Over Me and Itty Bitty Titty Committee find and solidify new identities through engagement with new communities. Cohen also stresses the necessity of attempting to understand communities from the points of view of its members, positing that "we try to understand 'community' by seeking to capture members' experience of it... we ask, "What does it appear to mean to its members?"” (20) because community "is a matter of feeling, a matter which resides in the minds of the members themselves" (21). This understanding of community can be applied to queer musical gatherings. For instance, while Gill Valentine (1995) has asserted that k.d. lang's concerts do not create "real" lesbian community, 
Cohen's argument implies that if concert-goers feel that they experience community, or go to the concert to experience community, then this point of view is crucial to consider. That is, musics likely contribute to both individuals' queer identities as well as to conceptions of lesbian/queer communities, an idea central to this thesis that will be evident in the films I examine. In two of the three films I examine, live music is shown to be central to the communities portrayed.

Kay Kaufman Shelemay's (2011) discussion of different types of community formation also informs this thesis. Shelemay discusses community formation in terms of three different types of processes which lie on a continuum: processes of descent, based on "what are understood from within to be shared identities" (367); of dissent, "through acts of resistance against an existing collectivity" (370); and of affinity, which "emerges first and foremost from individual preferences, quickly followed for a desire for social proximity or association with other equally enamored" (373). I would propose that queer communities can span this entire continuum of descent, dissent, and affinity, depending on their emphasis on identity, on resistance to heteronormativity, and/or on desire to simply be among people with similar experiences respectively. While "descent" may seem like an odd way to describe communities not usually formed through familial ties, queer communities are often based on queer family formations, for instance, the idea of "chosen family" or of a "drag mother," and often place emphasis on having an understanding of the political and advocacy work done by previous generations. However, queer communities can also easily be framed in terms of affinity. All three of these different types of community formation are evident in the communities in the three case study films. It is important to note my intentional use of the plural, "communities." There is no unified LGBTQ community; rather, I use the word "communities" to acknowledge the 
diversity of ways in which LGBTQ people form groups of affinity, descent, and/or dissent with each other, based on location, race, gender identity, sexual orientation, class, ability, religion, political identity, and many other factors. The following section examines music as it relates to queer identities and communities.

\section{Links between Music and Queer Identities and Communities}

In the films that I examine, music is central to the main characters' identities and the communities they inhabit. This centrality of music to queer people and communities is supported by popular music scholar Jodie Taylor's assertion that music is central to "the fashioning of queer identities, the theatre of queer memory and the maintenance of queer culture more broadly" $(2012,49)$. Taylor argues that "because queerness lacks stylistic continuity and genre parameters, subcultural theory has tended to collapse examination of music and sexuality into pre-existing and cohesive logics of cultural style...merely placing the queer as an interjection or episode in otherwise heterocentric subcultural groupings" (50). One example of working to see and hear queer musical subcultures is Halberstam's ([2003] 2008) examination of queer female subcultures, in which Halberstam asserts, like Taylor, that queer subcultures, particularly queer women's subcultures, are frequently ignored. Halberstam argues that rather than positioning queer/lesbian groups as a minority in riot grrrl and queercore music scenes (which in fact are overlapping, non-distinct categories), many of these bands can be grouped together in a category of "riot dyke" music (30). Halberstam goes on to posit that if considered alone, this music "seem[s] to represent a queer edge in a larger cultural phenomenon," but that if considered together with other queer cultural producers such as drag kings and queer slam poets, "they add 
up to a fierce and lively queer subculture that needs to be reckoned with on its own terms"

(30). However, the fact that music can be central to identities, and queer identities in particular, is not restricted to musical subcultures; queers can find community and identity in music outside of the more structured context of a subculture. One thinks of the legions of lesbian, bisexual, and queer women who flock together to see k.d. lang, ${ }^{3}$ Tegan and Sara, or any number of other queer artists perform. However, I would argue that the extreme nature of the fandom that exists for artists like lang and Tegan and Sara is unnecessary for the music to contribute to one's queer identity. There are artists who are lesser-known, who have a more diverse fan-base, or who are not queer themselves who can fill a similar role for individual fans.

Music has long been used as a signifier of queerness, a topic explored in Peraino's book Listening to the Sirens: Musical Technologies of Queer Identity from Homer to Hedwig (2006). Peraino examines "how music functions as a technique in the conceptualization, configuration, and representation of queer subjectivity and identity" (5), since the earliest historical records of music. In addition, Philip Brett ([1994] 2006) has discussed the connections between the terms "musicality" and "homosexuality" over a shorter historical timeline, arguing that labels, or possibly identities, such as "musical" or "homosexual," or perhaps more frequently "musician," “music-lover," "lesbian," or "queer," are intimately entwined in individuals' subjectivities. Given that narrative films' meanings are generally less abstract than those of music, film seems to be a prime location in which to examine interactions between music and queerness. How are

\footnotetext{
${ }^{3}$ Gill Valentine (1995) provides a detailed exploration of the role k.d. lang and her music played in lesbian identity and community formation in the early 1990s. Valentine is hesitant to consider lang's concerts as communityforming, because she feels that the temporary gathering of queer women in this way does not constitute community, rather a "fleeting symbolic fiction of contrived intimacy and unity" (479) (I disagree with this position-I would argue that while a concert like lang's might not alone create community, it is a flawed argument to consider it in isolation as there are few cultural activities that, when considered alone, create a community). She does, however, argue that lang's music has the ability to transgress heterosexual spaces and to create lesbian space because of the sense of lang's music as "our music" for lesbians and queer women and due to recognition/appreciation of lang's music as a lesbian signifier (480).
} 
queer musical associations with identities and communities employed in such films? The following section provides a brief overview of music in film, focussing in particular on compiled scores.

\section{Music in Film}

In her 2001 book Hearing Film: Tracking Identifications in Contemporary Hollywood Film Music, Anahid Kassabian ascribes different types of audience identifications to compiled scores (scores comprised of music that pre-exists the film) in comparison to composed scores (scores written specifically for the film). Composed scores usually fall into what Royal S. Brown has termed a "classical" style, using the term's colloquial meaning of " "highbrow" music...that stands in opposition to the more popular forms of [music]," tends to be compositionally complex, and uses "the full symphony orchestra, with its choruses... of contrasting timbre" $(1994,39)$; that is, this music is generally reminiscent of Western art music. These "classical" scores have the ability to transport any listeners who are adept at understanding the conventions of traditional Western film scoring to roughly the same place, evoking particular emotions, locations, or historical time periods with ease, a characteristic that Kassabian calls the creation of "assimilating identifications," in which "there is no necessary relationship between film perceivers and the identity positions they take on" $(2001,2)$. In contrast, compiled scores, comprised of music (often popular songs from a wide range of genres) that pre-exists the film, evoke different associations for each audience member, who may connect previously heard songs with any number of different situations or life experiences. Thus, this creation of "affiliating identifications" "bring[s] the immediate threat of history" and broadens the range of 
possible responses to and understandings of the music, which may be an undesirable effect from the filmmaker's point of view (3). However, the flip side to this "threat of history" is the possibility of targeting specific audiences who may be familiar with the music and the ability to create realistic-seeming places in space and time when this music is used diegetically. That is, in the films I examine, part of the purpose of the riot dyke music employed is to evoke particular identities and time periods; I propose that in these films this music contributes to the representation of identities that will be familiar and legible to at least some of the films' queer audience.

Though the use of popular music in film has a number of downsides, for instance that "the evocative capacity of music...is culturally and historically relative" (Wright 2003, 11), that it may sound dated after only a few years (11), and that it can be distracting to the audience because it draws attention to itself, particularly if it has lyrics (Carey and Hannan 2003, 163), it also has certain advantages. For instance, in comparison to "classical" scores, popular music can more easily evoke extratextual and textual ideas outside of the dialogue or visual aspects of the film through its lyrics and its specific location in time (L. Anderson 2003, 114). Popular music evokes specific moments in time and space and is thus particularly useful in period films, especially when used diegetically. In addition, while "classical" scores often function to broadly underscore the emotional content of a scene, popular music lyrics can be used as a window into characters' thoughts, to establish character traits, or to further the film's narrative (112), techniques which are evident in the three films I examine. The following section examines the types of music frequently used in lesbian film, leading to my selection of films for this project. 


\section{Popular Music in Lesbian Film}

While extensive scholarship exists on compiled scores in film generally (that referenced above provides a very small sample of a large field of scholarly work), little scholarship has been done on music in LGBTQ film, and even less on music in lesbian film specifically, though Kassabian (2001) does examine some of the music selections in Desert Hearts, as mentioned earlier. Dubowsky (2014) has examined New Queer Cinema and the creation of cachet with queer audiences through music selection, drawing on Kassabian's concept of affiliating identifications. He argues that while popular music is often poorly employed in film - that is, it is often used in ways that do not contribute to the narrative or emotional mood of the picturepopular music does have the advantage of being an easy way to build cachet with the audience (29). Dubowsky defines cachet as "a quality of membership in, knowledge of, or significant resonance with a target audience or subculture" (29, emphasis in the original), which can be created by a filmmaker in a number of ways, such as "existing membership, insider knowledge, references, or allusions that are appreciated by a target audience" (32). Though Dubowsky focuses exclusively on films that examine the lives of queer men, his discussion of the creation of cachet within queer communities is equally applicable to lesbian film; he argues that "queerness itself has a potential for a special relationship with cachet. Because queers routinely form communities that are outside the mainstream culture, queerness readily creates heightened modes of cultural cachet" (35). Attempts to create cachet or targeted affiliating identifications through music in lesbian films are evident in an examination of their soundtracks and manifest in a number of different ways. Though this project is not specifically concerned with audience reception, music with cultural cachet or particular affiliating identifications for members of LGBTQ communities can be assumed to evoke specific meanings in relationship to characters' 
identities in film; that is, the use of music with cultural cachet helps to create realistic queer identities and communities. The following paragraphs explore some basic observations that I have made about popular music in English-language lesbian film.

I began this project by examining the soundtracks of 160 films from around the world. From this selection of films, I was able to compile a list of 62 well-known English-language lesbian fictional feature-length films (both feature films and TV-movies) released between the early 1980s and 2014; I examined the soundtracks of these films and looked for trends in the musical selections (see Appendix I). In particular, I looked for genres or artists who might hold particular meaning with queer audiences as opposed to genres that occur frequently in films due to their mainstream prevalence. For instance, the fact that most movies from the late 1990s onward use music that could be classified as indie rock or indie pop seems more indicative of the dominant forms of popular music of the era than of this music's particular significance to queer women. In contrast, the use of music by musicians with cachet within lesbian communities or of genres with particular subcultural meaning could allow for a meaningful exploration of the music's relationship to identity in lesbian films.

In my survey of these films, I found that genres such as punk, riot grrrl, queercore, country, folk, and a range of popular electronic musics occurred frequently, in addition to the more generic pop and rock mentioned above. In addition, musicians who are queer women, both well-known and more obscure, feature heavily in lesbian film soundtracks. Of the 52 films on my list with soundtracks that are at least partially compiled, 25 have music by at least one artist whom I would categorize as having a high degree of cachet in some communities of queer women, three films have music by less well-known, out, queer women, and 24 do not appear to have any music with particular cachet in lesbian communities. This is a notable trend; $54 \%$ of the 
films have music by out queer women; if the three films that feature no popular music are removed from the grouping, that number goes up to $57 \%{ }^{4}$

The trends that I have observed in lesbian film soundtracks can be summarized as follows: lesbian film soundtracks as a group frequently include music by lesbian, bisexual, or queer female musicians (for example, Ani Difranco, k.d. lang, Melissa Ferrick, Jen Foster, Jennifer Corday), genres associated with lesbian communities (for example, riot dyke music, or queer bands/musicians associated specifically with particular local music scenes), and music by other artists with large lesbian followings or cultural cachet (such as Patsy Cline, Johnny Cash, and Jane Siberry). I would argue that these trends are indicative of filmmakers' intent to create both cachet and particular affiliating identifications through their musical selections. The music selections are also sometimes indicative of the networking that goes into making low-budget film; Lisa Henderson (2008) has examined how queer filmmakers produce their films, focusing extensively on the unique networks of queer and non-queer people that allow the creation of lowbudget queer films. This style of networking is clear in the musical decisions in films such as And Then Came Lola (dir. Ellen Seidler and Megan Siler, 2009) and Elena Undone (dir. Nicole Conn, 2010), both of which employed lesbian rock/country artist Jennifer Corday as music director. Corday's work resulted in both films featuring music by almost exclusively lesbian/queer female artists (many based in California); the latter film also has a number of songs written specifically for the film by Corday. In this type of film, the line between the creation of affiliating identifications/cultural cachet and supporting (often local) queer artists becomes blurred — some films may succeed more at one than the other. Dubowsky $(2014,28)$ proposes

\footnotetext{
${ }^{4}$ These calculations are based only on my broad but not comprehensive selection of English-language lesbian films with compiled soundtracks and are used here as only a rough indicator of the frequency of the use of music by queer women in lesbian films.
} 
that using an original score by a recognized artist in this manner can be an ideal way to create a score that is both effective and has cachet with the desired audience.

Beyond the use of specific songs or artists in lesbian film, these films also frequently engage textually with music through characters' musical performances, discussions of music, or listening to music in the film. Listening to music often occurs in the context of bars or clubs (with music either live or not), as in If These Walls Could Talk 2 (dir. Jane Anderson, Martha Coolidge, and Anne Heche, 2000), Itty Bitty Titty Committee (dir. Jamie Babbit, 2007), Stud Life (dir. Campbell X, 2012), Pariah (dir. Dee Rees, 2011), and But I'm a Cheerleader (dir. Jamie Babbit, 1999), pointing to the importance of music to queer women's community formation. Many others involve a film's main character(s) performing music (or performing to music), as in films including Loving Annabelle (dir. Katherine Brooks, 2006), Better than Chocolate (dir. Anne Wheeler, 1999), Nina's Heavenly Delights (dir. Pratibha Parmar, 2006), The Guest House (dir. Michael Baumbarten, 2012), Tipping the Velvet (dir. Geoffrey Sax, 2002), The Gymnast (dir. Ned Farr, 2006), and When Night is Falling (dir. Patricia Rozema, 1995). Some films involve main characters listening to music, for instance in Mosquita y Mari (dir. Aurora Guerrero, 2012) and Puccini for Beginners (dir. Maria Maggenti, 2006), though most films in which characters listen to music outside of a bar or club also feature other modes of interaction with music as well. All Over Me (dir. Alex Sichel, 1997), Cloudburst (dir. Thom Fitzgerald, 2011), Desert Hearts (dir. Donna Deitch, 1985), and The Incredibly True Adventure of Two Girls in Love (dir. Maria Maggenti, 1995) all fall in this category, featuring both discussions of music and listening to music, and in the case of All Over Me, musical performance as well. The prevalence of interactions with music in lesbian film points to the importance of music in queer 
communities, and to the importance of using music in lesbian film to create realistic and relatable characters and communities.

Of the films I examined, three stood out as related in terms of both musical genre and thematic content, such as a focus on young characters and the importance of music to the films' characters or communities. All Over Me, The Incredibly True Adventure of Two Girls in Love, and Itty Bitty Titty Committee each follow the lives of young queer women, ranging in age from 15 (All Over Me) to early adulthood (Itty Bitty Titty Committee). Each of these films explores themes of young love, identity formation, and community. Musically, all three films employ music that can be described as falling under the umbrella of "riot dyke." Finally, in each of these films, music is shown to be important to the identities of either individual characters or to the communities that these characters inhabit. Thus, these three films are well suited to an examination of how their soundtracks contribute to their characters' identities and to the films' representations of character development. The following chapter examines the history of riot dyke music and the associations it is likely to evoke in lesbian film, providing background on this music crucial to the case studies in the following chapters. 


\section{Chapter 2}

\section{Riot Dyke Music: History and Context for Its Use in Film}

This thesis focuses on riot dyke music as defined by Halberstam ([2003] 2008) — that is, riot grrrl and queercore music by queer women - as it relates to characters' identities in lesbian film, as is examined in case studies of three films in the following chapters. However, a discussion of riot grrrl's and queercore's histories as cultures and communities and their possible affiliating identifications when used in film is essential to provide the reader with the necessary context prior to my examination of how this music is used in these three films. This chapter discusses both riot grrrl and queercore, but the majority of the chapter is devoted to the contextual exploration of riot grrrl culture due to the higher volume of scholarship on riot grrrl, the lack of scholarship on women in queercore (despite women's prominence in this scene), and the greater presence of riot grrrl-associated music in the films I will examine. This chapter aims to provide an understanding of the affiliating identifications that are linked to riot dyke music that are relevant to my discussion of individual films in later chapters. This will be achieved by examining the histories and politics of riot grrrl and queercore as well as exploring the interrelation of these two movements (what Halberstam ([2003] 2008) terms "riot dyke"), examining riot grrrl's link to lesbian communities (which makes its frequent deployment in lesbian film understandable), and examining issues present in riot grrrl around race and class. This exploration of the affiliating identifications linked to riot dyke music will allow for a more nuanced discussion of how this music is used in relation to characters' identities in the case study films. 
Queercore and riot grrrl are closely related genres, delineated by a fuzzy line but delineated nonetheless, particularly in academic scholarship and by the mainstream media; within the subcultures there is certainly some division, but there is also an awareness of the free flow of music and people between these groups and a rejection of labels (see for instance Brownstein 2015). Queercore and riot grrrl generally centre in different locations and though there is overlap in their politics, in general queercore's politics centre on LGBTQ issues while riot grrrl focuses on feminist issues. Musically, both queercore and riot grrrl frequently draw on punk roots, and there is overlap between musicians and bands in the two genres. Because most scholarship discusses them as separate entities - and there is certainly a valid case to be made for this, particularly in terms of non-musical subcultural practices-I open this chapter by providing a brief examination of each as distinct before I discuss how, particularly in relation to queer women's communities and music, it may be more useful to focus on their intersections.

\section{Riot Grrrl}

Gender theorist Sarah Dougher and musicologist Elizabeth K. Keenan define riot grrrl as "a politicised movement of young feminists in the early 1990s that organised around many different cultural formations - including music, art, writing, self-publishing, consciousnessraising and direct action" $(2012,259)$; it is "less a specific style of music than it was a sociopolitical identity that found expression in part through music" (259-260). The lyrics of riot grrrl music aimed to empower women and girls by discussing topics relevant to them in an engaging way and propagating feminist ideologies. For instance, songs on Bikini Kill's first album Revolution Girl Style Now (1991) discuss topics of domestic violence (“Liar"), rape and incest 
(“Daddy's L'il Girl," “Liar”), the treatment of women as sex objects (“Candy”), bodypositivity and the social control of women's bodies ("Feels Blind," "This is Not a Test"), and the idea that girls can and should push back against patriarchy ("This is Not a Test," "Double Dare Ya"). Similar topics were discussed in riot grrrl zines, many of which, especially in the beginning, were written by the women who were also in riot grrrl bands. Riot grrrl draws an emphasis on do-it-yourself (DIY) ethos from punk and earlier feminist cultures such as 1970s lesbian feminism, as evidenced in the production style of zines and music, and through activism (Kearney 1997, 218). It is important to note that 1990s riot grrrl subculture was not solely or even mainly a musical subculture; while riot grrrl music, such as that by bands including Bikini Kill, Heavens to Betsy, Bratmobile, and Huggy Bear, has certainly been the most audible element of the subculture, zines were, and continue to be, at least as prevalent a form of cultural production.

While riot grrrl's musical style is not entirely homogeneous, most riot grrrl music is punk-influenced, in part because early riot grrrl music was often a reaction of female punk musicians against sexism and misogyny in American punk scenes (Dougher and Keenan 2012, 259; Downes 2014, 101; Kearney 1997, 212). Punk music, though heterogeneous, broadly “reject[s] slick production values," and often involves "play[ing] in ways that imply a lack of proficiency with their instruments or lack of vocal training," "shout[ing] or speak[ing] rather than sing[ing]," and "mak[ing] use of distortion, deviant tunings, and stress-inducing tempos," that is, being "stridently disharmonious" (Prinz 2014, 586). Much of riot grrrl music followed in this vein; to be succinct, like most punk songs, many riot grrrl songs can be described as "loud, fast, and short" (587). Most riot grrrl bands followed the instrumentation of vocals, guitar, bass, and drums, or some variation on this (most often omitting the bass, or featuring two guitarists). 
Popular music scholar Marion Leonard (2014) describes riot grrrl music as a genre "denoting a particular style of politicized, punk inspired, overdriven indie rock performed by female-centred bands with shouted vocals." Riot grrrl music often follows a punk philosophy of placing an emphasis on musical participation and confrontational, political lyrics in lieu of musical mastery. The music rarely follows conventional popular music song structures, and usually features upbeat tempi, squealing or distorted guitars, vocals that could be characterized as pitched yelling, and relatively simple chord patterns.

Though much riot grrrl music and culture is punk-influenced, it is important not to oversimplify riot grrrl as simply an offshoot of punk. Due to its highly individual nature, riot grrrl can be a difficult movement to definitively describe. Rosenberg and Garofalo state that "many call [Riot Grrrl] punk rock feminism, even though Riot Grrrl has moved beyond punk circles" $(1998,809)$. The links between punk and riot grrrl have been extensively discussed, most notably by Mary Celeste Kearney (1997). Kearney argues that the discursive construction of riot grrrl exclusively as an offshoot (or even derivative) of punk obscures the influence of feminisms on the movement (208) and masks the diversity of the movement; that is to say, not all riot grrrls identify with punk (211). Discourses that present riot grrrls as "girl punks" or "punkettes" again reinforce the idea of punk's intrinsic masculinity and hide the long history of female punk musicians (212). Ultimately, she proposes that "the media reproduce the age-old narrative of female musicians as appropriating masculine forms of music-making without problematizing how punk's masculinisation has been socially (re)produced or how riot grrrl performers might be using traditionally masculine genres and performance styles in order to deconstruct the gendering of music" (212). 
Starting in the early 1990 s, riot grrrl music gave young women a new way to actively participate in music, both as performers and audience members. Many bands consciously worked to break down the hierarchical relationship between the performer and audience to allow for a more participatory experience. Common actions by performers working toward these goals included encouraging audience members to contribute to the performance, passing the microphone around the audience, performing on the floor rather than the stage, being available to the audience before and after the performance, and handing out zines at performances (Downes 2012, 222). Girls and women were encouraged to congregate near the stage, an area typically dominated by men in punk concerts, moshing was discouraged, and audience members' behaviour was often policed by the bands resulting in the public shaming of people (usually male audience members) who had behaved aggressively or discriminatorily (Downes 2012, 227; Marcus 2010, 265; Kearney 2006, 74). The goal of these practices was to foster an environment where girls and women felt safe and welcomed, as well as to offer "a supportive channel and strategy for young women and girls to speak out against and challenge the abuse they experienced in their immediate environments" (Downes 2012, 227). Many of these practices are evident in the live performances featured in two of the case study films, All Over Me and Itty Bitty Titty Committee.

Beyond practices implemented at performances, Downes and Kearney both argue that riot grrrl's musical style provided an opportunity to deconstruct gendered conceptions of music. Downes proposes that riot grrrl let young women perform punk-influenced music without falling into the punk tropes of the tomboy or the sex object, and "without resorting to the simplistic repression of the feminine and valorization of the masculine" (2012, 209); Kearney argues that riot grrrl music avoids the potential gender binaries reproduced by genres like womyn's music, 
which avoid traditionally masculine sounds and instrumentation, instead allowing for the demonstration of the construction of gender $(1997,221)$. Thus, riot grrrl theoretically allows for a wide range of gender expression from its participants and has the potential to work against conventional ideas of what styles of music women and men should perform. Academic and former riot grrrl Mimi Thi Nguyen describes the typical riot grrrl musical style in terms that foreground this resistance to binaries, conceiving it in terms of pop and punk musics, stating that "riot grrrl press-ganged punk and its discordant, splintered noise into an uneasy fit with pop and melodic froth ungrounding noise and froth from either negative delirium or cheerful myopia, and channeling both toward a dream of feminist futures" (2012, 173-174). Most importantly, "the formation of riot grrrl culture enabled the realization of a sonic community; riot grrrl produced a series of interactive moments and spaces for the realization of feminist, radical, and queer actions amongst young people" (Downes 2012, 213). This "sonic community" is clearly presented in the case study films through scenes of live music at clubs and the sharing of music between characters. This form of community resonates with Kay Kaufman Shelemay's ideas of communities formed through affinity, dissent, and descent-depending on the case study, this sonic community is formed through affinities towards certain types of music, musically expressed dissent with mainstream culture, and descent communities created by teaching new members about their forebearers through music.

Though much of the mainstream media has presented riot grrrl as a movement geographically- and time-bound to early-1990s Olympia, Washington, and Washington, D.C., by 1992, the riot grrrl movement, both in terms of zines and the creation of bands, had spread across North America and into Europe, particularly Britain (Downes 2012, 211; see also Dunn 2014; Kearney 1997 and 2006). However, the most well-known bands of the riot grrrl movement are 
from these two cities; their links to local punk scenes and music labels allowed them the privilege of pressing records, while most later riot grrrl bands only performed live (Kearney 2006, 75). These bands should not be seen as representative of the movement as a whole, but only a small segment of it. Further, though in North America riot grrrl music seems to be a thing of the past, riot grrrl culture continues to thrive through zines and community building (Kearney 2006); outside of North America, bands currently exist "in Malaysia, Brazil, Paraguay, Israel, Australia and across Europe,” and Brazil has a yearly riot grrrl festival (Dunn 2014, 325). In addition, riot grrrl "continues to live on within the cultural memory and curiosity of young queer girls" (Driver 2007, 211) — a new generation of young women has embraced this music. That riot grrrl music continues to be compelling is demonstrated by its use in the film Itty Bitty Titty Committee, a film set a decade and a half after the peak of the riot grrrl movement.

\section{Queercore}

Queercore, also known as homocore, began in the mid-1980s and came into its own in the early 1990s. The movement was initially centred in Canada, particularly in Toronto, and the United States, in San Francisco and Los Angeles (DeChaine 1997, 18; Shoemaker 2010, 299; Rauzier 2012, 238; Ciminelli and Knox 2005, 8). Like riot grrrl, queercore draws on the DIY ethos of punk, using music as well as other cultural media, such as zines, to spread a political message. DeChaine defines queercore as "a musical subformation which combines much of the aesthetic of punk rock music with radicalized perspectives on gay and lesbian politics and identity" $(1997,17)$. Schwandt proposes that the term "can be used to describe a number of subcultural and musical practices, but its most common usage... refers to the channeling of the 
underground, do-it-yourself ethics associated with punk music and style and their 'hardcore' offshoots in order to challenge both heteronormativity and more mainstream images of LGBT life and culture" $(2009,77)$. Because riot grrrl and queercore usually employ the stylistic conventions of punk music, they can be hard to audibly differentiate from each other and from punk music without referencing their lyrical content, which generally centres on feminism in riot grrrl and queerness in queercore. DeChaine argues for an understanding of queercore as a subculture that uses punk rock as its musical medium, rather than queercore as simply queer punk music (1997, 17). Riot grrrl music might well be described similarly-that is, as a movement that uses the medium of punk rock towards feminist ends, rather than as feminist punk music.

Perhaps most relevant to this examination of queercore music in lesbian films as it relates to characters' identities, queercore also presents itself as in opposition to, or as providing an alternative to, mainstream gay and lesbian subjectivities and politics, what might be called “homonormative” LGBTQ culture (DeChaine 1997, 20). Homonormativity has been defined as "a politics that does not contest dominant heteronormative assumptions and institutions, but upholds and sustains them, while promising the possibility of a demobilized gay constituency and a privatized, depoliticized gay culture anchored in domesticity and consumption" (Duggan 2003, 50). Homonormativity privileges "those practices and identities that receive social sanction” (Murphy, Ruiz, and Serlin 2008, 1), particularly “categories of sexuality...that are white, monogamous, gender-conforming, and middle-class" (4). Du Plessis and Chapman argue that through their names "queercore" and "homocore" "not only signalled their allegiances to post-punk subculture, but also positioned themselves as equally distinct from lesbian and gay culture and the masculinist tendencies of hardcore punk" $(1997,48)$. For girls and women, 
"queercore answered a need to extend beyond the heteronorms of riot grrrl, the lesbian invisibility of mainstream culture and rigid models of lesbianism in dominant lesbian and gay social movements" (Rauzier 2012, 248). Ideas of resistance to mainstream, homonormative LGBTQ culture are evident in both All Over Me and Itty Bitty Titty Committee; in the former, Lucy, a musician and the main character's love interest, expresses openness to non-monogamous relationships, while in the latter, the characters protest against the legalization of same-sex marriage, arguing that marriage is an oppressive institution that queer people should not buy into. Much like riot grrrl, queercore has allowed for the creation of community, in particular through live musical performance, but also through other means of cultural production, such as zines (Shoemaker 2010, 295). The similarities between riot grrrl and queercore are not a coincidence; the following section examines the links between the two movements.

\section{Interactions between Riot Grrrl and Queercore: A Case for "Riot Dyke"}

Though most of the music I examine in this thesis is riot grrrl music, there are also several queercore songs or songs by bands that straddle riot grrrl and queercore. Two main scholarly discussions are relevant to the contextual placement of riot grrrl and queercore music in lesbian film. The first revolves around the presumed separation between riot grrrl and queercore. This perceived separation may in part be due to the slight temporal separation of the movements' respective beginnings. While queercore as a movement is generally agreed to have preceded riot grrrl historically_most historical descriptions of riot grrrl mark its starting point as the early 1990 s in comparison to queercore in the mid- to late-1980s - the movements' musics came into being relatively concurrently (Shoemaker 2010, 299; Kearney 1997, 222). What is indisputable, 
but often overlooked, is the fact that many musicians participated in both queercore and riot grrrl. Further, David Ensminger describes the riot grrrl musical scene as “queer-saturated” (2010, 64). Mary Celeste Kearney was one of the first scholars to examine the issue of the supposed straightness of riot grrrl which made it possible to neatly categorize riot grrrl and queercore bands, observing that "in spite of the coterminous emergence in the United States of riot grrrl and queercore bands like Tribe 8, Random Violet, The Mudwimmin and Team Dresch, there have been relatively few links made by the mainstream press between lesbian feminism, queercore and riot grrrl" (1997, 222).

Ciminelli and Knox add to this discussion of the relationship between queercore and riot grrrl by positioning the zine-making element of queercore as preceding riot grrrl (for instance, the first queercore zine, J.D. 's, which was started in Toronto by Bruce LaBruce in 1985), while proposing that the "beginnings of what was to become the American queercore scene were rooted in the riot grrrl movement that began in the early '90s with bands like Bikini Kill, Bratmobile, and L7" $(2005,142)$. That is, queercore subcultural production existed mainly in the form of zines for several years; while queercore zines preceded and influenced riot grrrl zines (and queercore as a named movement precedes riot grrrl), riot grrrl music preceded and influenced queercore music. I will discuss one possible narrative of the emergence of queercore from riot grrrl in the following paragraph. Exchange between queercore and riot grrrl is also evident in the other direction; Kearney $(2006,178)$ argues that riot grrrl zines developed most directly from lesbian queercore zines, and Toronto-produced zine Bimbox straddled the line between queercore and riot grrrl (Ciminelli and Knox 2005, 10). The complexity of the different accounts of this era of riot grrrl and queercore history points to a close relationship between the two movements, particularly musically, even if this was ignored by the press. The mainstream 
media avoided associating riot grrrl with lesbianism, in part by ignoring riot grrrl's association with queercore; Kearney argues that "discursive formulations which position riot grrrl as emerging after and apart from the queercore scene help to reproduce the popular understanding of riot grrrl's members as predominantly straight" $(1997,222)$. Media accounts contemporary to riot grrrl present the movement's advocacy of "girl love" as "a form of childish play rather than adult sexuality" while emphasizing the importance of boys and heterosexuality in the lives of riot grrrls (233). In fact, riot grrrl was a place of refuge for queer girls from both mainstream society's homophobia and ageism within LGBTQ communities (Kearney 2006, 83) and riot grrrl's music and other cultural products have continued to inspire young queer girls in the new millennium (Driver 2007, 210). Many of the musicians in the best-known riot grrrl bands fall under the queer umbrella (Ciminelli and Knox 2005, 142). Riot grrrl has never been and is not today a primarily straight subculture, though its politics have principally highlighted feminist issues and not LGBTQ issues.

One possible narrative of the emergence of queercore from riot grrrl has been proposed by Ciminelli and Knox. Simultaneous to the overt heterosexualization of riot grrrl in the media discussed above, some media began to pejoratively label the genre "dyke rock"; Ciminelli and Knox posit that the frustration within the riot grrrl scene around being "dismissed" as such led to some queer musicians in the riot grrrl scene creating explicitly queer bands that were slightly distanced from riot grrrl and which became the beginnings of the queercore music scene (2005, 142). Val Rauzier argues that the common misconception of riot grrrl and queercore as two highly distinct music scenes stems from the fact that riot grrrl attracted a great deal of mainstream media attention in comparison to queercore $(2012,247)$ _ if both had been highly present in the media, or covered by overlapping media sources (queercore was discussed mainly 
in LGBTQ media), their strong and obvious connections may have been more apparent to scholars who wrote early accounts of the scenes. Thus, the high degree of overlap between the female queercore music scene and the riot grrrl music scene lead to Halberstam's ([2003] 2008) compelling argument for a consideration of these musics as belonging to a broader genre that Halberstam refers to as "riot dyke." The overlap of these two "distinct" music scenes is also evident in the frequency with which queercore and riot grrrl bands performed or recorded together or were featured on the same compilation albums. For instance, the compilation album Free to Fight! (1995) features songs by queercore bands Team Dresch, The Third Sex, and Excuse 17, as well as by riot grrrl-associated bands Heavens to Betsy, Lois, and Fifth Column. Queercore band Tribe 8 released the 1992 7" record There's a Dyke in the Pit with riot grrrl band Bikini Kill, as well as Lucy Stoners and 7 Year Bitch, while Excuse 17 toured with Heavens to Betsy (Rowe 2015). Deanna Shoemaker (2010) argues that although queercore band Tribe 8's lyrics focused explicitly on queer sexuality, the band also addressed topics common in riot grrrl music such as violence against women and frequently collaborated with riot grrrl bands. Thus, she proposes that Tribe 8 and their music "must be read in within the principles and practices of riot grrrl culture as well as queercore" (299).

The flip side of the heterosexualization of riot grrrl is scholarship that presents queercore as a predominantly gay male genre. For instance, Kevin Dunn $(2014,320)$ presents the two most famous lesbian queercore bands, Tribe 8 and Team Dresch, as riot grrrl bands. While these bands were certainly closely linked to riot grrrl (as discussed above), labeling them as riot grrrl bands negates the role they played in the formation of queercore, the genre to which they are more closely associated. The most comprehensive text about queercore, David Ciminelli and Ken Knox's Homocore: The Loud and Raucous Rise of Queer Rock (2005), also falls prey to this 
problem. Though they quote former Team Dresch guitarist/bassist Jody Bleyle, who states that "Lesbians have always been integral to the queercore movement" and goes on to say that "Queercore is girl-rooted. The bands that started the scene- they were all lesbians. There were almost no guys" (141), the authors go on to position queercore music as a direct descendent/offshoot from riot grrrl, in a condescending rather than respectful way, referring to riot grrrl as queercore's "humble beginnings" (142). Ciminelli and Knox position lesbian bands as relatively marginal, presenting male bands such as Pansy Division and Extra Fancy as the major players in the scene and queer women's bands as transient and short-lived (142), while isolating women's bands to separate chapters rather than integrating them into their broader narrative of queercore. Further, they refer to female queercore musicians as "grrrls," which emphasizes that the lesbian queercore and riot grrrl music scenes are closely interlinked, but also raises the question of whether the authors are dismissing these musicians as "girls" or whether this is a label these musicians claim for themselves. Both Rauzier and Schwandt are highly critical of Ciminelli and Knox's approach to female queercore musicians. Schwandt positions Ciminelli and Knox as perpetuating an understanding of queercore as a male space, arguing that a female band such as Tribe 8 is forced to "aggressively [assert] its authority to claim as its own a 'core' that has been conventionally understood as a 'male' space" $(2009,80)$. Rauzier positions her own work on queercore in opposition to accounts like Ciminelli and Knox's which she argues "tend to focus on predominantly white men and marginalise trans-individuals, lesbians and queer women" $(2012,240)$. Thus, just as scholarship and media coverage of riot grrrl has often marginalized the movement's queer members, explorations of queercore have not always served female participants well. The term "riot dyke" acknowledges queer riot grrrls and female queercore members and the fact that these people are often one and the same; Halberstam argues 
that "when considered together, they add up to a fierce and lively queer subculture" ([2003] 2008, 30).

Throughout this thesis, I primarily use the term "riot dyke" to refer to music in or between the riot grrrl or queercore genres, except when the provenance of the music and its affiliating identifications is important to my analysis (for instance, if the music's lyrics or the contents of a scene are particularly representative of riot grrrl or queercore politics). The exception to this approach is Chapter 3, in which I explore the film The Incredibly True Adventure of Two Girls in Love. In this chapter, my analysis focuses almost exclusively on riot grrrl music, which would make the umbrella term "riot dyke" broader than necessary and its use seem disingenuous.

\section{Riot Grrrl's Relationship to Race and Class}

While media coverage (and some scholarship) of the riot grrrl movement has often neutralized the threat of riot grrrls by presenting them as non-threatening, ineffectual, and heterosexual, in part by divorcing them from associations with queercore, as discussed above, the movement has also had internal problems. An issue that arose in riot grrrl and contributed to the decline (though not the end) of the community in the mid-1990s was the movement's difficulty in successfully dealing with diversity in terms of both race and, to a lesser extent, class. This section explores these issues to provide the reader with some of the affiliating identifications that riot grrrl music brings to the complex narratives of race and class that manifest in the three films I examine in the following chapters. Riot grrrl of the 1990s was by-and-large a white, middleclass phenomenon —-while women and girls of colour certainly participated in the movement, 
they were the minority and they did not always feel welcome. The demographic distribution of riot grrrl with regards to race is largely due to its close relation to punk, another very white subculture. Kearney points out that white female punk and riot grrrl participants had greater leeway to experiment with alternative forms of femininity than their non-white compatriots due simply to their racial, and often class, privilege $(2006,57)$. In addition, Kearney proposes that "the gender... trouble celebrated within Riot Grrrl may be the primary reason for its lack of appeal to poor female youth and girls of color, whose performances of gender... are structured quite differently as a result of their disenfranchised status and encouragement to achieve legitimacy within middle-class white society" (2006, 65-66). Further, middle-class white girls typically have greater access to education, means of cultural production, and have more spare time in which to use these resources to make zines, music, or simply participate in the riot grrrl scene (66).

Due to an awareness of the failures of the previous generation of feminists with regards to race, discussions of race and of white privilege in particular were central to riot grrrl ideology, at least in its early years (Schilt 2005, 40). Many of the initial "founders" of riot grrrl had taken women's studies or gender studies courses in university; riot grrrl zines by these women frequently attempted to provide nuanced discussions of race, white privilege, and the whiteness of riot grrrl (Kearney 2006, 59). These early riot grrrls were largely college-educated white women, including some working-class women (Schilt 2005, 56), but the movement subsequently attracted many middle-class teenagers and even pre-teens whose first exposure to feminism was through riot grrrl (45). Thus, the relatively infrequent discussions of race in later riot grrrl zines generally take the form of "racial awakenings"; that is, like the feminist awakenings that often precede them in white girls' zines, they describe moments of realization (of sexism, of white 
privilege) in relatively basic and often tokenistic ways. These explorations rarely approach what Kristen Schilt refers to as "race cognizance," in which the zines' authors and/or editors "recognize the power inherent in being white and engage in a critical analysis of white privilege" $(2005,48)$. While many girls and women of colour were drawn to riot grrrl because of its criticism of sexism in the punk scene, they often became disillusioned with white girls' unwillingness to engage with their critiques (44). Zines by girls of colour displayed a far greater awareness of issues surrounding race, as well as a conscious investment in making the voices of women and girls of colour heard (Kearney 2006, 155), while zines by white girls tended to assume a white audience and rarely showed interaction with non-white girls (for instance, through interviews or by including their work in the zine) (Schilt 2005, 46). Non-white and/or working-class girls and women often had a nuanced understanding of intersectionality through lived experience and were uninterested in reading about middle-class white girls' realizations of their racial and class privileges (46).

The main problem with regards to race in riot grrrl seems to be that most white riot grrrls are aware of their white privilege but have made few steps towards making riot grrrl more inclusive. Rosenberg and Garofalo (1998) state that while there has been extensive discussion about the homogeneity of riot grrrl, no practical solutions have been produced. Going beyond simple lack of representation in the riot grrrl community, former riot grrrl Mimi Thi Nguyen (2012) points out the obliviousness of riot grrrl politics to issues surrounding race and class, for instance noting that

women of color wondered out loud for whom writing 'SLUT' across their stomachs operated as reclamations of sexual agency against feminine passivity, where racisms had already inscribed such terms onto some bodies, and poor or criminal-class women argued 
that feminists 'slumming' in the sex industry (through stripping, for the most part) as a confrontational act implied that other women in this or other tiers of the industry were otherwise conceding to patriarchy. (179)

Kearney similarly notes the "the gender deviance displayed by riot grrrls is a privilege to which only middle-class white girls have access" $(2006,65)$. Just as earlier concepts of feminist "sisterhood" raised questions about the universality of women's experiences, Dougher and Keenan argue that "in placing their feminism in punk rock, riot grrrls' message of 'every girl is a riot grrrl,' raises questions about exclusions of race, class and sexuality" $(2012,269)$. The privilege held by many riot grrrls led to a privileged form of feminist politics, an element that is also apparent in the film Itty Bitty Titty Committee, discussed in Chapter 5.

Rifts formed in the riot grrrl community even as the mainly white participants actively worked to educate themselves about race. Nguyen argues that the problems continued to proliferate because "riot grrrl drew from liberal formulas that define racism as ignorance, and ignorance as the absence of intimacy" $(2012,181)$. While intimacy was in many ways a revolutionary element of riot grrrl, this insistence on intimacy with regards to racial experience "presented a series of problems about the violence of desires to be close to the other, as histories of colonialism and imperialism...demonstrate" (180); "the refusal [of women of colour] to be intimate was perceived as an act of bad faith, to insist upon continued presence was to further disturb the comfort of happiness of loving others" (185). Beyond the issues that plagued the riot grrrl movement in its prime, Nguyen points out that in riot grrrl histories, women of colour and issues of race are too often confined to single chapters or asides in riot grrrl histories, implying the resolution of these issues. As will be seen in Chapter 5, the 2007 film Itty Bitty Titty Committee, which tells a story of a more contemporary riot grrrl community and which was 
produced more than a decade after these issues were at their height in the riot grrrl scene, still struggles to deal with issues of race and class, making it clear that these issues are far from being successfully resolved within feminist and queer communities. The Incredibly True Adventure of Two Girls in Love and All Over Me, the films discussed in Chapters 3 and 4, respectively, each engage with class (and to a lesser extent, race) in different ways, the former through overt contrasts between characters and the latter through a gritty representation of working class life in New York.

\section{Conclusion}

In this chapter I have endeavoured to provide the reader with contextual information about the riot grrrl and queercore musics featured in lesbian films, their interrelation ("riot dyke"), and an idea of the time period and style of activism they evoke. These "affiliating identifications" will be referenced in the following chapters; the music used in the case study films comes freighted with the histories and issues discussed above. Mary Celeste Kearney aptly describes some of the associations riot grrrl brings with it when she states, "the songs of early Riot Grrrl musicians repudiated stereotypical constructions of girlhood by constructing a bold and unruly form of subjectivity historically discouraged in female adolescents" $(2006,60-61)$, manifest in queerness, body-positivity, and other forms of resistance towards social expectations of femininity. In addition to "bold and unruly" youth, riot dyke music's other likely affiliating identifications - for audience members aware of the music and its historical context — include the movements' overlapping feminist and queer ideologies, their DIY philosophies and welcoming nature to beginner musicians, and riot grrrl's links with white middle class women. These 
associations will be evoked, and sometimes complicated, in the three films I examine in the following chapters. The affiliating identifications that the music brings into the films are linked to the identities of the young women through their "habits" of listening to (and sometimes performing) this music. The following chapter examines the first of the three case study films, The Incredibly True Adventure of Two Girls in Love, a film created contemporaneously to the riot grrrl movement, examining how riot grrrl music is used to represent identity and character development in this film. 


\section{Chapter 3}

\section{Case Study: The Incredibly True Adventure of Two Girls in Love}

The 1995 film The Incredibly True Adventure of Two Girls in Love (hereafter referred to as Two Girls in Love) was directed by Maria Maggenti, a filmmaker "affiliated with and inspired by the Riot Grrrl movement" (Kearney 2006, 77). Two Girls in Love was made at the height of the riot grrrl movement in the mid-1990s and is one of the many lesbian films that make music, particularly discussions of music and listening to music, central to characters' identities and films' narratives. As discussed in the previous chapter, in this chapter I refer primarily to "riot grrrl" music rather than "riot dyke" music due to the film's use of riot grrrl music to the exclusion of other riot dyke music. Because Two Girls in Love strongly links riot grrrl music with one of its main characters, the film is well suited for an examination of how riot grrrl's affiliating identifications interact with characters' habits related to music listening, political orientation, gender presentation, and community. I use this exploration of affiliating identifications and characters' habits to link riot grrrl to particular identities and to explore how riot grrrl music acts as a source of affirmation for the main character, Randy.

Two Girls in Love, set in a semi-rural area of New York State, tells the story of the beginning of a romantic relationship between two high school students, Randy (Laurel Holloman) and Evie (Nicole Ari Parker). Randy is a white, tomboyish, "baby butch" character from a low-income family comprised of Randy, her aunt (Rebecca), and her aunt's girlfriend (Vicky). In addition, her aunt's ex-girlfriend (Lena), who is down on her luck and has nowhere else to stay, moves into the house at the beginning of the film. Randy struggles with school and works part-time at a gas station, where she has occasional liaisons with Wendy, an older married 
woman. At the beginning of the film, Randy has only one friend her own age, Frank, a Latino teenager who is implied to be gay throughout the film. Evie is a black girl from a higher-class background, who lives with her mother, Evelyn, an agricultural consultant for developing countries. Her father, who does not appear in the film, has remarried and works for a bank. Evie has a boyfriend from school, about whom she is ambivalent. She is popular at school, and has a group of three female friends with whom she frequently hangs out. Randy and Evie go to the same school, but have not met until Evie drops in at the gas station, unsure if her car's tires need air. Evie and Randy start spending more and more time together, and the relationship develops as Randy leaves a love note in Evie's locker and Evie gives Randy Walt Whitman's Leaves of Grass $^{5}$ to read.

The climax of the film comes when Randy's aunt finds out that she will be unable to graduate on time because she doesn't have enough credits, while Evie's mother almost simultaneously finds the two girls naked in her bed and the house completely trashed when she gets home early from a business trip. Faced by the wrath of Evie's mother, Randy and Evie flee to a hotel to escape their angry families. The film culminates with their friends and family forming an angry mob outside their hotel room; before Evie and Randy decide to "surrender" and leave the room, they vow to love each other forever. Two Girls in Love has been discussed as a groundbreaking film in the field of lesbian cinema (Driver 2007, 112) because it "refus[es] to focus on the 'problems' of being a young lesbian, instead allowing a working-class tomboy... to exist as an already out, proud, and politicized dyke from the start" (113).

\footnotetext{
${ }^{5}$ Leaves of Grass is a collection of poetry (first published in 1855, followed by numerous other editions with added material) known both for its position as classic American poetry and for its erotic content, which is often read as homoerotic due to Whitman's status as a homosexual or possibly bisexual man (see, for instance, Mulcaire 1993).
} 
This chapter focuses on how riot grrrl music is used as an identity marker and source of affirmation for Randy, an out, "baby butch” lesbian. In Two Girls in Love, the main characters' identities are repeatedly explored through contrast to each other, so I also examine Evie's identities and musical preferences, though to a lesser extent, in order to add nuance to the meaning of Randy's relationship with riot grrrl music. The film frames this contrast between Randy and Evie in terms of class: Randy comes from a working class family where money is tight, while Evie is from an upper-middle class home where money is never an issue. Their different class backgrounds are mirrored in their relationships to school, a location where Evie excels and Randy struggles, despite the strong value Randy's family places on education. These differences in their backgrounds are also narratively linked to their music listening choices; Randy is portrayed listening primarily to riot grrrl music, while Evie listens to classical music. Interestingly, even though Randy is white and Evie is black, race is generally treated as a nonissue in the film whereas class is openly explored (while race is highlighted by the contrast between the characters, the film does not engage directly with this contrast it presents). The explicit contrasts between the two characters' identities and music preferences create a clear delineation between particular identities (related both to class and to other aspects of identity) that the film links to certain musical genres. Focussing on Randy and her relationship to riot grrrl music, this chapter examines how particular affiliating associations of riot grrrl music are inscribed on Randy's character through her "habits," discussing the links the film makes between riot grrrl music and Randy's social milieu, her politics, and her gender presentation, traits that are amplified through contrast with Evie. In addition to these three aspects in common with the other two films, in this chapter I also examine how class is linked to musical habits since class is a central theme in Two Girls in Love. I argue that in Two Girls in Love, riot grrrl music is used as 
an aid in the representation of Randy as a young woman with an approach to the world that is queer, feminist, and defies gender stereotypes, while also contributing to the film's contrast of the class background of the two main characters. Riot grrrl political ideals such as resistance to social expectations of femininity and resistance to the male gaze are evoked by Randy's clothing and hairstyle habits. While the film challenges riot grrrl's association with the middle class by connecting working-class Randy and not upper-middle-class Evie with the genre, at the same time it reinforces riot grrrl's historical whiteness.

Of the three films I examine, Two Girls in Love has the shortest soundtrack of precomposed music. However, this pre-composed music serves a central role in the film; gender and media scholar Mary Celeste Kearney includes the film in a list of films inspired by the riot grrrl movement, arguing that Two Girls in Love "foregrounds [Randy's] admiration for... riot grrrl bands" $(2006,77)$. The film includes three riot girl songs, Bratmobile’s “Cool Schmool,” Bikini Kill's "Resist Psychic Death," and Lois's "Page Two.” Other popular music selections in the film include "Clock Song" by the post-punk band Scrawl (which pre-dates riot grrrl, but is often mentioned in relation to the movement), indie rock band Velocity Girl's instrumental piece “Wake Up, I'm Leaving,” and BETTY's “A Typical Love.” Notably, the film also features the Dies Irae from Mozart's Requiem Mass in D minor (K. 626), the only pre-composed art music piece in the film, and it also features a substantial amount of music composed for the film (by Terry Dame and Tom Judson) in a variety of genres, including country, rock, and "classical" musics, thereby meshing well with the compiled pieces in the film's soundtrack (though I do not discuss this music due to its position outside of the scope of this thesis). The soundtrack uses means beyond riot grrrl music to create cachet with queer audiences, for example through the use of “A Typical Love," which I do not discuss in this chapter since it does not fit within the riot 
dyke idiom. However it is worth noting that the selection of BETTY's music is significant because the band is known for engaging in LGBTQ activism and for later having composed the theme song of the television show The L Word (2004-2009), which focused on the lives of a group of queer women in Los Angeles and was likely the most prominent presentation of queer women in mainstream popular culture during the time that it was on the air. Aside from these other groups (BETTY, Scrawl, and Velocity Girl), Lois, Bikini Kill, and Bratmobile all fall solidly in the riot grrrl genre.

As in the other two films that I analyse, music plays an important role in defining characters' identities in Two Girls in Love, as well as in demonstrating characters' growth. In all three films, music is used to show these young characters' movement towards becoming women with confidence, agency, and personal autonomy. Focussing mainly on the portrayal of Randy in relation to riot grrrl music, in the first section of this chapter I examine the portrayal of Randy's identities, exploring how riot grrrl music is used to reinforce these identities and using contrasts with Evie to explore these identities more thoroughly. Following this, I examine the riot grrrl music that Randy listens to, how it is portrayed in relation to her identities, and the role it plays in affirming her identities in a relatively hostile small town environment.

\section{Identities and Music in Two Girls in Love}

In Two Girls in Love, music is closely linked with a variety of identities, particularly through the film's contrast of the characters of Randy and Evie. Randy listens to riot grrrl music and closely associated genres, while Evie listens primarily to classical music. The following sections examine how riot grrrl music relates to different aspects of Randy’s identity, largely 
through contrast with Evie; though the film links Randy's identities to riot grrrl music even without contrast with Evie, these links between Randy and riot grrrl are strongly solidified through the characters' juxtaposition. I examine Randy's social milieu, her political identity, her gender expression, and her class identity in relationship to the music she listens to, and through the contrasts made with Evie, drawing on Shelemay's (2011) ideas of community formation and Turino's (2008) concept of the habit as it pertains to identity formation. Though these identities certainly overlap and intersect, I discuss them below as relatively independent entities for the purpose of clarity.

\section{Music, Social Milieu, and Community}

The riot grrrl music that Randy listens to is not overtly connected to a subculture or community in the film - that is, though it is strongly connected to Randy's identity, Randy is not connected with a riot grrrl community in the physical sense of direct interaction with other community members (this contrasts from the use of riot grrrl music in the other two films to be discussed). Instead, listening to riot grrrl music is primarily an individual pursuit for Randy, usually accomplished on headphones, with the exception of one scene (which I discuss below) where she listens to riot grrrl music with her aunt's ex-girlfriend, Lena. Randy's interest in forming a band suggests a desire to create some kind of affinity-based community, but this aspiration does not seem feasible in her current location due to her isolation from her peer group; before she meets Evie, she has only one friend, Frank, who shows no indication of being interested in music. 
The film takes place in a semi-rural area; though the high school the characters attend seems like it could be in a small town, the gas station where Randy works is in a municipality named Barrier, which seems to be primarily rural and which Randy refers to as the "middle of nowhere" (0:08:23). As such, Randy is quite isolated from other queer and feminist youth who she might meet in a larger town or city, with the exception of Frank. Though she is surrounded by queer women at home (drawing on Shelemay, her queer community is formed more literally by descent than most queer communities), within the confines of the film, Randy does not seem to have the ability or opportunity to meet with other LGBTQ youth or to participate in riot grrrl subculture beyond listening to her CDs and expressing her queer identity. Two Girls in Love is set in a time period before home Internet access was commonplace, meaning that Randy does not have access to the online queer communities that abound today. As such, riot grrrl music appears to be one way in which Randy explores her queer identity even in the absence of a community of peers, along with reading books about queer youth (a 1994 book of short stories entitled Am I Blue? Coming Out from the Silence edited by Marion Dane Bauer is on her bed in one scene) and through outward expressions of her queer identity such as her clothing choices and her locker and bedroom decorations. Just as purchasing or renting lesbian films allows a queer woman to "invite a queer community into her own home" even if she is isolated from other LGBTQ people by location (Stuart 2008, 21), riot grrrl music creates a similar form of community in Randy's life. 
Music and Politics

Randy's separation from direct interaction with a riot grrrl community means that at first glance, she appears not to be particularly politically driven (especially in contrast to the characters of Itty Bitty Titty Committee, discussed in Chapter 5). However, Randy has grown up in an environment steeped in queer and environmental activist ideals. For instance, Lena has a hippy-like sensibility and obsesses about the ingredients in the food they buy. The family seems to avoid eating meat (they discuss tofu dogs in one scene) and they eat organic food. Randy appears very aware of queer politics/history and its specific vocabulary even though in other instances in the film she is shown to have a limited vocabulary in other areas. For instance, when she tells her family that she came out to a girl at school and her aunt expresses some concern that Randy should be careful, Randy retorts, "Why do you have to turn everything into a federal discrimination case?" $(0: 18: 26)$. This response makes sense only if she is both cognizant of the history and politics of LGBTQ rights and if it is a frequent topic of discussion in her household. The simple act of being a group of out lesbians in this small American town in the mid-1990s is political in and of itself.

Though Randy herself does not discuss politics with her peers at any point during the film, her locker and room are both plastered with zine pages, activist posters, and pins espousing a variety of causes and identities. In her school locker $(0: 10: 26)$ she has a pin with an environmentalist logo and others with LGBTQ signifiers on them, such as pink triangles and a lambda symbol, as well as a t-shirt with a pink triangle on it. She also has a poster from ACT UP (AIDS Coalition to Unleash Power), perhaps the most influential LGBTQ activist organization of the late 1980s and early 1990s. In her room at home (0:43:28) Randy has more LGBTQ rights posters and posters for LGBTQ community organizations, as well as music-related pictures (her 
locker also has a magazine spread of a female rocker). The second time Evie comes by the gas station (0:31:08), Randy is wearing a shirt with the statement, "Your body is a battleground." Taken together, these symbols that Randy has collected in the spaces that belong to her represent to the audience a young woman who is politically aware, mostly in relation to LGBTQ communities and LGBTQ rights, but also about feminist and environmental issues. Though she is not portrayed as being politically active in the sense of direct action or demonstrations, she clearly identifies with feminist and LGBTQ activism, and uses her "habits" of dress, decoration, and music listening to make these identities legible to herself and others. Thus, though the political elements of the film are more implicit than explicit—-they are rarely stated outright and their legibility depends on the audience's attention to scenes' backgrounds and the film's soundtrack - the film clearly sets up an association between queer and feminist politics and the riot grrrl music Randy listens to, confirming the political affiliating identifications most directly linked to riot grrrl music. As such, I would argue that riot grrrl music is used in Two Girls in Love to represent Randy's political identity as an out queer feminist.

\section{Music and Gender Expression}

Evie's gender expression largely falls in line with social conventions of femininity—she has long hair styled in braids, and wears dresses and ballet flats, while Randy keeps her hair cut short and unstyled, and mostly wears baggy clothes that obscure the shape of her body. As discussed in Chapter 2, riot grrrl brings with it strong associations with non-conventional expressions of femininity and resistance to the male gaze, which Randy exhibits through the choices she makes regarding her gender presentation. Randy's masculine style earns her the 
critique of the homophobic people in her town, while also marking her as queer. Though gender presentation and sexuality are separate aspects of identity and not necessarily associated, as gender and sexuality studies scholar Jean Bobby Noble points out, "female masculinity and/or butch identity in women is largely, but not exclusively, lesbian" (2003, xii). Randy presents herself as what many people in lesbian communities would call a "baby butch," invoking the long history of butch and femme identities in lesbian communities, but particularly in workingclass communities (xi). Though queer female masculinity has not always been associated with the working class, ${ }^{6}$ from the 1920 s onwards butch/femme subcultures have been primarily associated with working class women (Stuart 2008, 44). The butch/femme bar culture of the 1950s was central to the creation of unified lesbian communities during an era when lesbians "were considered both psychologically sick and a threat to the American way" (49). Thus, Randy's gender expression can be linked symbolically to both her working class upbringing and to her music choices.

\section{Music and Class}

While Two Girls in Love engages with queer and feminist politics primarily in non-verbal ways with only a few exceptions, the film's dialogue about class is much more overt. Due to the large role that class plays in the film's narrative, I discuss class here in addition to the three above habit-related topics. Class-related habits have the potential to be the result less of choice than of life experiences; Turino states that "Like facial expressions and body language when they are directly affected by the inner moods that they signify, signs of identity that result from one's

\footnotetext{
${ }^{6}$ For example, in the early twentieth century, upper-class lesbian Radclyffe Hall, the author of The Well of Loneliness (1928) and perhaps the most famous masculine lesbian of her era, provided confirmation of contemporary sexological theories of the "invert" as rich, educated, and upper-class (Oram 2007, 87; Wilson 1990, 70).
} 
actual experiences are what Peirce would call dicent indices_-identity signs that are actually affected by the social position, experiences, and ingrained habits that they signify" $(2008,107)$. The film engages with class in multiple ways, including through characters' consumption of music and other cultural products. Habits that are indicative of Randy's and Evie's respective working-class and upper-middle class affiliations are exhibited frequently throughout the film. Though I am focussing mainly on Randy and her relationship to riot grrrl music, because the film's examination of class is based largely on its contrast of Randy and Evie, this section will rely on the contrast between the film's two protagonists. The characters' class backgrounds are primarily distinguished through non-musical signifiers, dealt with at the end of the section.

Randy's and Evie's families are explicitly contrasted several times throughout the film. Early in the film, two consecutive scenes juxtapose Evie's and Randy's families making dinner, starting at Evie's home (0:27:54). We see an exterior shot of Evie's large, imposing brick house. Inside, in the kitchen, Evie's mother is drinking wine while Evie stirs the food, and she comments that Evie's father might be getting transferred to London by the bank he works for, which would give Evie the opportunity to travel to Europe and visit him. The two women are closely following a recipe that uses relatively upscale ingredients, and when Evie accidentally adds too much olive oil to the dish she panics, thinking that she has ruined dinner. In contrast, the following scene $(0: 29: 23)$ shows the chaos of Randy's house at dinnertime. The women are haphazardly assembling a pasta dinner in a kitchen that is clearly from an older era, snacking as they go. Later in the film when Evie comes over to Randy's house for dinner (0:44:22), Vicky comments "I hope you like pasta, Evie, because we eat it here a lot." A few scenes later we see Evie eating homemade sushi with her mother, sitting on the floor at a low table $(0: 50: 56)$. The 
tidiness and pristineness of Evie's home and the costlier and "cultured" food she and her mother eat is contrasted with the chaos of Randy's home and their frequent inexpensive pasta dinners.

Class differences beyond food choices are also articulated in the scene where Evie goes to Randy's house for dinner (0:44:22); Evie, feeling awkward in this unfamiliar environment, mentions that she gets to travel a lot because of her mom's job, making plain the distance between these two families in terms of finances. After dinner, Randy and Evie sit outside and Evie comments that she thinks Randy's aunt hates her, worried that it might be because she is black. Randy disagrees, saying that her aunt doesn't hate her at all, and if she seemed uncomfortable around Evie it was because she "just probably has a problem with people who can go to Paris for a week." The class differences between the characters are also demonstrated through the characters' modes of transportation. Randy rollerblades or skateboards wherever she goes, unless she is getting a ride with Frank in his old car, while Evie has a Range Rover that she was given by her father. This contrast is emphasized throughout the film by a running joke about Evie's car: whenever someone who hasn't met Evie yet sees Evie with her car for the first time, they comment "Nice car!" to Randy.

The film's demonstration of the class difference between Evie and Randy is also represented through the music they choose to listen to. While Evie listens primarily to classical music, as well as jazz when at home with her mother-both genres associated with the welleducated middle and upper classes - Randy's interest lies in riot grrrl and punk music. While the riot grrrl movement generally has middle-class associations, as discussed in Chapter 2, Randy does not fit into this mould, so it is an interesting choice to use in the film in relation to Randy's identity. The film's ongoing contrast of Evie and Randy in terms of class background and 
musical taste clearly links riot grrrl to Randy's working-class background and not to Evie's upper-middle class upbringing. All in all, by contrasting Evie's and Randy's identities through an exploration of their "habits," to use Turino's term, the film is able to explicitly link riot grrrl music to Randy's queer, feminist, working-class, and gender-nonconforming identities. The following section examines the music that Randy listens to in the context of the film's narrative, in order to explore the affirmative role that riot grrrl music plays in her life.

\section{Randy's Music Listening Choices}

At several points during Two Girls in Love we see Randy listening to riot grrrl music. The use of riot grrrl music and related genres is both a logical appeal to queer audiences who will appreciate the music as directly linked to their communities because of its affiliating identifications and as a way of crafting a realistic young queer woman in the mid-1990s, given the contemporary nature of the riot grrrl movement. In contrast to Randy, Evie is rarely shown listening to her own music, as many of Evie's scenes involve her meeting with friends in public contexts such as a local diner, providing fewer opportunities for her to make musical listening choices. Conversely, Randy has many scenes where she is alone at home or working at the gas station and listening to music by herself, perhaps pointing toward the importance of consumption of queer cultural products for LGBTQ youth, a theme echoed by Susan Driver who argues that “music [is] a vital tool in shaping queer youth self-perceptions, imaginative longings, and political commitments" $(2007,196)$. Most of the music that Randy listens to is concentrated in the film's first half — the music is used to introduce her and her identities to the audience. There are two examples of Randy listening to riot grrrl music in the film, as well as one example where it is unclear whether the music is diegetic (and thus, whether she is listening to it). Below, I 
discuss each of these uses of music in the order in which they appear in the film in order to illustrate how these songs fit into the film's storyline, focussing in more depth on the last two examples because in these examples Randy is clearly shown listening to riot grrrl music.

The first time Randy is shown listening to riot grrrl music is a scene in which it is unclear whether the music is diegetic. Randy is in her bedroom struggling to do her math homework; riot grrrl band Bratmobile's song "Cool Schmool" plays in the background (0:19:25). This is a very short scene-Randy gives up on her math homework and picks up her guitar to start practicing, at which point the film cuts to Randy practicing her guitar at the gas station, and "Cool Schmool" fades out. "Cool Schmool" is a sarcastic examination of the shallowness of popularity, the inanity of attempting to be "cool," and the superficiality of friendships based on listening to, talking about, and wearing the right things, regardless of what social group you are in. The song resonates with Randy's outcast status at school—Randy could be popular in some circles, but not in the small-town high school environment in which she finds herself. The song is upbeat and catchy, reinforcing its positive message of not compromising oneself to fit in with the right crowd, a message which Randy seems to have internalized: though it is made clear that her only friend at school is Frank, neither she nor Frank express any dissatisfaction with their relative lack of friends or with not being in the "in" crowd. Though most audience members would likely interpret the song's use as non-diegetic, its use in the intimate space of Randy's bedroom gives the sense that this is music that Randy listens to, even if she is not being shown listening to it in this moment, linking Randy explicitly to riot grrrl music for the first time in the film. The two other examples of riot grrrl music in the film are both clearly diegetic in nature; as such, I discuss them in more depth here. 
The next time Randy listens to music is also in her bedroom; Bikini Kill's "Resist Psychic Death" engages with issues of belonging and judgement, and is used in this scene to demonstrate how riot grrrl music serves an affirmative role in Randy's life. In relation to the film's plot, in the interim between the scene discussed above and this scene, Randy has broken up with Wendy, a scene that marks the beginning of Randy's maturation; Randy is no longer willing to be manipulated by her on-again, off-again paramour, although the breakup is quite childish on the parts of both women. This breakup scene also serves to demonstrate Randy's growing interest in Evie — she is willing to gamble on giving up her relationship with Wendy for the possibility of relationship with Evie. The scene in which Randy listens to "Resist Psychic Death" is directly preceded by one that sets the scene for the ideas espoused in the song. In this preceding scene, Evie is chatting with her friends in a diner (0:23:08). Evie's friends criticize her for hanging out with Randy, saying that Randy is "pretty much of a freak" because "she's a total pothead" and "a total diesel dyke" who should "fix herself up and not try to act like a man." This scene cuts to Randy in her bedroom with Lena, jumping up and down and playing her guitar in time to Bikini Kill's "Resist Psychic Death" (0:24:23). The song is at a moderate tempo, and features the distorted guitar, pitched yelling vocals, and feminist lyrics typical of riot grrrl music. This song's lyrics resonate particularly well with Evie's conversation with her friends in the previous scene, as well as with the taunts that Randy faces at school. The lyrics that the audience hears in this scene are from the third stanza of the song, which states:

There's more than two ways of thinking There's more than three ways of being There's more than four ways of knowing 
There's more than one way of going somewhere ${ }^{7}$

Thus, the song's placement in the film is a clear critique of Evie's friends' judgement of Randy as an unsuitable friend because she does not conform to their understanding of the world, as well as an endorsement of Randy and her family's unconventional life in this small town. Beyond the song's specific placement in the film, the song more broadly demonstrates that Randy's music of choice affirms her sexuality, gender expression, and family.

This is a very short scene, but it serves to cement a number of characteristics about Randy and her family. First, the scene emphasizes the significance of music in Randy's life. She is shown playing her guitar along with the song, demonstrating that both listening to and creating music are important to her. Not only does Randy choose to listen to riot grrrl music as one of her identity-defining habits, this genre of music is also that which she shows interest in performing, if only in her bedroom at this point. Though she is not particularly adept at playing the guitar, music and musicianship are shown to be important aspects of her identity. Riot grrrl's DIY impetus resonates well with this scene-Randy's present ineptitude at guitar (as seen in other scenes, for instance when she is practicing guitar at the gas station $(0: 19: 50))$ is not presented in a condescending way or shown to be indicative of her future musical skill. Instead, Randy is portrayed as using music to empower herself through the song's message of resistance to social norms (the song opens with the angry statement "Your world not mine / Your world not ours" followed by the averment "I'll resist with every inch and every breath / I'll resist this physic death"). This is a scene of joy and family, which confirms the values held by Randy and her family.

\footnotetext{
${ }^{7}$ I transcribed the lyrics of this song with the aid of http://www.lyricsfreak.com/b/bikini+kill/resist+psychic+death_20017741.html (accessed December 5, 2015).
} 
Secondly, Lena's presence in this scene emphasizes the non-conventional family setup in Randy's home, resonating with the song's lyrics, which speak to the multiple "ways of being" that should be welcomed in the world. This song and Lena's presence points to the family's inclusive lifestyle and practice of helping anyone in need. Riot grrrl music brings with it affiliating identifications of the movement's politics of inclusion and "girl love," making it an apt choice for this scene. The family's inclusive nature is also shown in how they welcome Randy's friend Frank to their meals on a regular basis because "his mom never cooks for him" (0:03:50). Finally, while this song emphasizes the diversity of ways of life in the world, it also points to the systemic erasure of people who do not follow social norms. The harassment that Randy faces because of her sexuality and unconventional family are clearly seen in other scenes where she is called a "freak," a "dyke," a "diesel dyke," and a "fucking dyke" by different people $(0: 05: 45$ and $0: 23: 33 ; 0: 53: 55 ; 0: 23: 33 ; 0: 15: 35)$, both to her face and behind her back. Though we do not see any discrimination against her family, aside from an early scene where some girls at school gossip that her family is all lesbians (0:05:45), based on the experiences that Randy faces as an individual it is safe to assume that a similar climate of homophobia exists in town in relation to her family. Riot grrrl music and its associated involvement in (or at least awareness of) feminist and queer activism fill a void in Randy's life in small-town 1990s America.

The final song that the audience sees Randy listening to is "Page Two" by riot grrrl musician Lois. "Page Two" is the B-side of her 1993 single "The Trouble with Me," and features queercore musician Donna Dresch on bass (reaffirming the overlap between riot grrrl and queercore explored in Chapter 2). The song is a laidback ode to a relationship filled with ambivalence on the part of the narrator, featuring a mixture of pitched speaking and singing but lacking the distortion and fast tempo so common in riot grrrl music. The song narrates three 
"pages" of a relationship, describing the initial infatuation, then the struggles of being in a relationship, and finally the relationship's end. However, the only part which is presented in the film is "page one," with the lyrics "Dear dearest one / This is what I've done / This is what I said / Like a flip of my head / Why do I stare at you? / Try to see a sign / Try to watch you move." ${ }^{8}$ This song differs markedly from the previous music we see Randy listening to in its musical elements (as discussed above), but also in its lyrical content. Instead of the focus on activism and encouragement of a variety of identities, this song is about a romantic relationship and the narrator's feelings and experiences of it. Thus, it comes with only the affiliating associations of riot grrrl politics, not the overt political or feminist nature of the earlier examples.

Like the earlier scene where Randy listened to Bikini Kill’s "Resist Psychic Death,” this scene takes place in Randy's bedroom. It follows a scene in which Randy and Frank drive by Evie's house and marvel at how rich her family must be $(0: 36: 23)$. While Frank insists that Evie must be spoiled, or at least "sheltered and privileged," Randy defends Evie against his claims, though Evie is shown throughout the film to be both sheltered and privileged. Randy's infatuation, set up for the audience in this scene, is reinforced through the music and Randy's actions in the following scene. Randy arrives at home in her bedroom, listening to "Page Two" on her headphones, seeming to be in a somewhat listless mood. She kicks at some of the miscellanea strewn on her floor, before noticing Leaves of Grass, which she picks up and opens. She moves her headphones to around her neck; a voiceover of her reading the book aloud begins as she lies down on the bed to read. ${ }^{9}$ The voiceover allows for a transition to a scene of her

\footnotetext{
${ }^{8}$ I personally transcribed the lyrics for this song.

${ }^{9}$ Randy reads from Leaves of Grass five times throughout the film, two of which are voiceovers with Evie. The passages selected are from sections 2, 19, 32, and 50 of "Song of Myself" and from "I Sing the Body Electric" (Whitman 1891). In general, the excerpts explore being physically present in one's body, physical (sometimes erotic) sensations, and the appreciation of the beauty of nature. Notably, this is not the only lesbian film to feature readings of Whitman's work. Loving Annabelle (dir. Katherine Brooks, 2006), another film in which music also
} 
reading the book to Regina at the gas station as the music fades out $(0: 37: 20)$. The scene uses both music and Randy's interest in the book to demonstrate her infatuation with Evie, particularly demonstrated through the song's lyrics, which describe the early state of a relationship where the two people are just beginning to get to know each other. The passage that Randy reads out loud is from section 32 of the poem "Song of Myself," a sensuous description of a horse, and it prompts Regina to state, "Jeez, what a homo that guy was" (referring to Whitman), when Randy pauses in her reading. Together, the music and Randy's interest in the poetry create a build-up of eroticism between the two main characters, which the audience encounters mostly from Randy's point of view, but also partly from the point of view of Evie, who had gifted Leaves of Grass to Randy. In this scene, riot grrrl music is explicitly linked to Randy's same-sex desire; Evie's same-sex desire is expressed through her gift of Whitman's book to Randy, once again emphasising the girls' different backgrounds as Evie's romantic interest is expressed through classic American poetry and Randy's is portrayed through contemporary popular music.

Overall, the riot grrrl music that Randy listens to is shown to be central to her life and to her identities. She listens to, discusses, and plays music frequently, pointing to its importance in her life. Riot grrrl music is used to enhance the narrative of the film, narrating Randy's same-sex desire and her position outside of the mainstream, as well as giving her a sense of power through motivational lyrics and by empowering her to play music herself. One final example demonstrates the importance that listening to riot grrrl music is given in the film's narrative. This

plays a substantive role, also features an excerpt from "Song of Myself" in a scene meant to demonstrate romantic/sexual tension between characters (0:07:06). This scene uses almost the exact same excerpt from section 19 of "Song of Myself" as The Incredibly True Adventure of Two Girls in Love with slightly different cuts. This use of Whitman's work in lesbian film perhaps demonstrates the work's popular currency as a signifier of queer sexuality, regardless of the gender of the characters or target audience. 
scene is particularly important in the film because it demonstrates the growth of both Randy and Evie as individuals and the widening of their personal musical worlds (and by implication, their broader worldviews). The scene is in a meadow, where Randy and Evie sit back-to-back listening to music on their individual headphones (0:49:29); a voiceover of Randy and Evie reading a slightly erotic excerpt from section 19 of Whitman's poem "Song of Myself" plays over the scene. Given the prior context provided in the film, the viewer assumes that Evie is listening to classical music and Randy is probably listening to riot grrrl music. Mid-way through the scene the two girls trade headphones with each other. Evie winces when she holds Randy's headphones near her ears, implying that Randy's music is loud and/or aggressive. Several different scenes of Evie and Randy in the meadow are spliced together, but when the scene returns to the girls sitting back-to-back listening to each other's music, both now seem to be enjoying the other's music. This scene demonstrates the broadening of both characters' worldviews as well as how they are attempting to bring their two different worlds together. By finding joy in the music of each other, the girls try to transcend some of the obstacles between them, most notably class, their differing levels of success at school, and family backgrounds.

\section{Conclusion}

In The Incredibly True Adventure of Two Girls in Love, riot grrrl music is used to resonate with the film's narrative as well as to build the identity of the character of Randy. By positioning music as central to the main characters' identities, the film allows the viewer to interpret elements of the characters' identities, as defined by their habits, through the lens of musical listening choices. In this film, riot grrrl music and its affiliating identifications resonate 
with Randy's queer, subtly feminist, perspective, and her nonconformity to gender stereotypes, while simultaneously contributing to the film's juxtaposition of the class backgrounds of the two main characters. My analysis of riot grrrl music in the film suggests that riot grrrl music is an outlet for Randy's emotions and provides affirmation for her queer identity in this conservative, small town environment. Furthermore, the characters' interactions with each other using music as a medium of commonality are used to demonstrate the characters' personal growth, mostly poignantly in the last scene discussed above. 


\section{Chapter 4}

\section{Case Study: All Over Me}

All Over Me is a 1997 film directed by Alex Sichel, starring Alison Folland, Tara Subkoff, and Leisha Hailey. The film tells the story of Claude (Folland), a teenage girl growing up in Hell's Kitchen in New York City. According to the film's production notes, All Over Me was partially funded by a grant from the Princess Grace Foundation to make a film about the riot grrrl scene (New Line Productions 2005). In All Over Me, music is central to the identities of most of the LGBTQ characters, demonstrated through the characters" "habits" of music listening, performance, and discussion. Like Randy in The Incredibly True Adventure of Two Girls in Love, Claude, the main character in All Over Me, is learning to play the guitar and hopes to start a band. Two other openly queer characters are already involved in local queer music scenes: Luke is in a punk or queercore band, while Lucy is in a riot dyke-esque group. Music is a topic of conversation between characters and characters listen to music together, paralleling Two Girls in Love. In this chapter I explore the role music plays in these characters' lives and how it is presented as central to their queer identities through their music-related habits. I examine how music is used to explore relationships between the characters and the role music plays in Claude's realization of her sexuality and her personal growth into a stronger, more independent young woman. I argue that through Claude's music-listening habits, riot dyke music and punkrelated genres are linked to Claude's emerging queer identity and her resistance to social norms of femininity (both possible affiliating identifications of riot dyke music), while also contributing to the film's exploration of Claude's personal development into a more independent and confident young woman. Claude's shifting identities recall Anthony P. Cohen’s (1985) 
observations on the strong effect community has on identity; Claude's coming to terms with her queer sexuality is closely linked to involvement with the local riot dyke scene, a community which seems to be based on musical and sexuality-based affinities. All Over Me's exploration of shifting identity in relation to a riot dyke community makes it an ideal film for the examination of habits of music listening, political orientation, gender presentation, and community. In this chapter, I explore how characters' habits link this riot dyke community to certain identities and how Claude's music listening choices narrate her personal growth.

All Over Me follows Claude, a fifteen-year-old high school student who lives with her mother and is just finishing school for the year. Claude has an intense friendship with a girl named Ellen (Subkoff), and is hoping to start a band with her, a plan impeded by Ellen's new romantic relationship with Mark (Cole Hauser), a misogynistic, homophobic man who encourages Ellen's drug and alcohol use. When Luke, a gay musician (played by Pat Briggs, in real life a glam rock/goth metal musician), moves into Claude's building, he suggests that she visit a local bar where "girl bands" frequently perform. At the bar, Claude meets Lucy (Hailey), a singer and guitarist in the band Coochie Pop (comprised of Hailey, Mary Timony, Vanessa Godson, and Jennifer Smith). When Luke is found murdered in the park outside Claude's apartment after an altercation the previous night with Mark and his friends, Claude must negotiate between maintaining her friendship with Ellen (who she finds out was present the night Luke died) and following her moral compass by going to the police. Meanwhile, Claude finds herself in the beginnings of a romantic relationship with Lucy and is forced to navigate her newly discovered sexuality. In comparison with Itty Bitty Titty Committee and The Incredibly True Adventure of Two Girls in Love, both comedies that err on the side of the fantastic, All Over $M e$ is a gritty depiction of a young woman's life in New York City and features themes of 
homophobia, drug use, and abusive relationships. More so than Two Girls in Love, All Over Me shows the dangers of being LGBTQ in this location in place and time through the harassment and physical danger that Luke and Jesse (a young gay man Claude works with at a pizza parlour) face from people like Mark; LGBTQ people are clearly portrayed as being part of a community formed in part through a form of dissent (to refer to Shelemay) that is threatening to mainstream society.

The soundtrack for All Over Me is less riot-dyke-punk-centric than the other two films examined in this thesis; where Itty Bitty Titty Committee features almost exclusively riot dyke music and Two Girls in Love had a majority of songs falling under that umbrella, All Over Me features a diversity of musical styles. The only riot dyke song in the film is Sleater-Kinney's "I Wanna Be Your Joey Ramone” from their 1996 album Call the Doctor. The film also features proto-riot grrrl band Babes in Toyland's song "Hello" as the non-diegetic title music. Beyond these two songs, the film includes a broad range of music, from lesbian favourites Ani DiFranco (a musician frequently employed in lesbian films) and The Murmurs (a duo which includes Hailey) to the punk music of Patti Smith, as well as some indie rock and alt country songs.

Compared with Randy in Two Girls in Love, the main character in All Over Me, Claude, has a slightly broader musical taste, though from the small sampling of her musical interests she is interested primarily in punk and punk-influenced music - she listens to Sleater-Kinney and is a serious Patti Smith fan (she has a large poster of Smith on her wall which she playfully strokes and kisses at one point early in the movie (0:8:17)). Lucy seems to gravitate towards femalefronted indie rock bands, listening to Alison Pipitone and Tuscadero. The song that her band performs in the film is by alternative rock/post-punk group Helium, a group that, though not a riot dyke band, is closely connected to riot dyke through associations between musicians. Band 
member Mary Timony is linked to riot dyke band Sleater-Kinney through her later participation in Wild Flag, a supergroup that also included Sleater-Kinney's Janet Weiss and Carrie Brownstein (Timony and Brownstein also created an EP as The Spells in 1999). Almost all of the popular music featured in the film is diegetic; as in Two Girls in Love, Claude and Lucy bond by listening to music together. As in Two Girls in Love, music is presented as central to the characters' identities, in particular those of LGBTQ characters - music is important to Luke, Claude, and Lucy. This chapter begins by exploring the representation of habits related to community, politics, and gender expression in All Over Me and their links to riot dyke music before examining how the music that Claude listens to is used to show her growth as a character.

\section{Music, Social Milieu, and Community}

As mentioned above, All Over Me has a soundtrack comprised of diverse genres, including punk and riot dyke, but also country and alternative rock, each of which bring very different sets of affiliating identifications to the film and to the characters with which they are associated. There is a substantial amount of diegetic music not related to the main characters: music Claude's mother listens to, music playing on the stereo at a corner store, and music at a bar Claude reluctantly visits at Ellen's pleading. The music that Claude and Lucy listen to and perform stands out from the rest of the film's soundtrack — while they listen to punk, riot dyke music, and women-fronted alternative rock, most of the other music in the film is country or male-fronted rock, linked to characters including Claude's mother and her boyfriend, and Ellen's boyfriend Mark. Thus, the diversity of the film's soundtrack connects particular music to the identities of queer characters through contrast with the music the film portrays as mainstream. 
The neighbourhood Claude lives in, Hell's Kitchen, is a primarily working-class area in New York City, historically populated by Irish and Puerto Rican immigrants, as well as artists and actors (Keller and Winslow 2010, 589). Both Ellen and Claude are presented as being from working class homes mostly by virtue of the roughness of the neighbourhood and the rundown nature of Claude's apartment building. Lucy seems to come from a more middle class familyher parents are away for the summer, which suggests access to enough money to travel, and her house is covered in paintings done by her father, suggesting access to a relatively large amount of leisure time. These differences are much more implied than explicit in comparison to Two Girls in Love, where the class differences are very clear-cut. However, they still imply a link between riot dyke music and lower- and middle-class young white women. Lucy's association with riot dyke music is also an association with queerness - Lucy wears a rainbow guitar strap when she performs, directly linking her music and her sexuality. Claude's position at the beginning of the film is contrasted with Lucy's: Claude wants to start a band but has so far been unsuccessful (while Lucy is in a successful band, by high school standards), and she starts the film in a state of denial about her sexuality (she is clearly not interested in dating boys, but is unaware of or unwilling to acknowledge her attraction to her best friend).

Throughout the film, Claude gradually transitions from a social milieu in which she does not fit — as demonstrated by her clashes with her mother and Ellen, both of whom are homophobic and critique Claude's habits of dress and eating (discussed below) — to a new community that is shown to have more potential for Claude to thrive. This new community is a queer community that centers on live music that is implied to be in the riot dyke genre. This transition is aided by Luke and Lucy, queer musicians who act as both friends and role models for Claude. Lucy represents the feminist, queer, body-positive nature of the riot grrrl movement, 
ideals which are shown to mesh well with Claude's worldview, even if she is not able to articulate these ideals out loud. The next section examines the particular politics of Claude's new community as depicted in the film.

\section{Music and Politics}

In comparison to both Two Girls in Love and Itty Bitty Titty Committee, All Over Me features the least explicitly political characters. Claude is not portrayed as having any particular politics - her actions stem from her desire to please and care for her friends and from her sense of right and wrong, not from an overtly feminist, queer, or other political stance. Unlike the protagonists of the other two films, Claude has neither grown up in a strongly feminist and queer environment (as in Two Girls in Love), nor is she portrayed as having been exposed to radical feminism (as in Itty Bitty Titty Committee). However, Claude does listen to punk and riot dyke music, which, as discussed in Chapter 2, are inherently political genres, at least in their roots, implying that she may have some internal feminist or punk-inspired politics. Claude is also the youngest protagonist of the films that I am examining; at only fifteen years old, Claude is likely at the point in her life where she is becoming more aware of politics and becoming more independent from the politics (or perhaps lack of politics) of her family. In contrast, Lucy and Luke are linked to queer politics - they both participate in punk or queer music scenes and are out as queer in the community, a position which is shown to be intrinsically political if only through the danger being out presents, particularly for queer men. Luke's choice to stand up to homophobic harassment is a political decision - a choice to be visible and to confront homophobia head-on. His murder makes clear the gravity of this political choice; as a queer man 
he would be well aware of the significance of his decision to be out, particularly in New York in the early 1990s near the height of the HIV/AIDS epidemic. Though gay men and trans women have historically born the brunt of the physical violence against the LGBTQ community, ${ }^{10}$ Lucy's decision to be out is no less political. Lucy also demonstrates knowledge about a particular strain of queer politics when she asks Claude about her relationship status, asking, "So, do you have a girlfriend? I mean, it's not like it matters in the way of monogamy or anything" (1:10:50). Though non-monogamous relationships certainly exist outside of LGBTQ communities, acceptance of a variety of forms of consensual non-monogamy is the norm in many LGBTQ communities, for some people as a form of resistance against patriarchal narratives that privilege monogamy. Thus, there is a particular political orientation connected to Lucy and Luke that Claude is introduced to over the course of the film.

\section{Music and Gender Expression}

The queer characters in All Over Me resist social expectations of normative gender performance, and unlike in Two Girls in Love, clear-cut butch/femme identities are not present. Both Claude and Lucy fit the gender-nonconformity associated with riot grrrl discussed in Chapter 2 in their own ways. Claude is comfortably androgynous, sporting baggy clothes but wearing her hair long. Her baggy clothing is critiqued by both her mother and by Ellen. She does

\footnotetext{
${ }^{10}$ For instance, the "Anti-Lesbian, Gay, Bisexual and Transgender Violence in 1998" report from the National Coalition of Anti-Violence Programs (the closest report I could find to the time of the film) found that $66 \%$ of reported hate crimes against LGBT people in the United States were against cisgender men and 5\% were against trans women (a large percentage considering the smaller number of trans women in the population relative to cisgender people). Rates of violence against trans women were more than 10 times higher than against trans men. Cisgender women reported hate crimes at $38 \%$ of the rate of cisgender men.
} 
not seem to mind when Ellen puts lipstick on her (1:05:25) but does not wear makeup herself. Claude is the epitome of awkward teenage-hood, often appearing self-conscious and uncomfortable in her body; her physical awkwardness is paralleled by her relative lack of agency in her life in comparison to Lucy. Claude's hair is dyed a colour of red that falls somewhere between the bright red associated with rebellious youth and the colour of naturally red hair. Lucy similarly embodies a riot grrrl approach to femininity. She is not androgynous like Claude, but instead has her short hair dyed bright pink, evoking both femininity and rebellion, and wears slightly baggy camouflage pants. Like many riot grrrls, she resists social norms of femininity without disavowing her femininity. Claude and Lucy are contrasted with Ellen, who worries obsessively about being thin and is always trying to appear sexy for her new boyfriend. Luke also does not fit into the box of normative masculinity. Though he wears typically masculine clothing - $\mathrm{t}$-shirts and jeans — he keeps his blonde hair long, paints his nails, and has a feminine swagger.

Claude also recalls some of the riot grrrl politics around body positivity and resisting social expectations of women discussed in Chapter 2 in other ways, most clearly through her unabashed consumption of food, particularly junk food, throughout the film (actions which would be unremarkable in real life, but are conspicuous in their representation in this film), a characteristic also associated with Lucy. Claude's unguarded relationship with food is emphasized by her first scene in the film, in which she and Ellen walk through the park that separates their apartment buildings. Claude is eating candy from a small paper bag, but when she offers some to her friend Ellen, who is very thin, Ellen refuses it, saying that she is on a diet. As they wander out of the park toward Claude's house, Ellen playfully (but cuttingly) criticizes Claude, saying, "Do you have to eat them like a fat pig?," a criticism that Claude laughs off, 
snorting like a pig. Claude's refusal to capitulate to social pressures to emulate the bodies of women in magazines and on television is demonstrated throughout the film as she happily munches on chips, eats ice cream out of the container, drinks pop, and eats chocolate bars (while some of Claude's eating might be classified as comfort eating, much of it is not). The subversive nature of Claude's eating is demonstrated by the fact that her eating behaviour is policed by Ellen, as described above, but also by her mother, who chastises Claude when she arrives home from the grocery store with a bag of chips and other food, saying, "When you're 600 pounds and no boy's going to give you the time of day, don't you come crying to me" $(0: 19: 32)$. The statement does not seem to stick to Claude - she has probably heard it many times in the past, and she shows no interest in the "boys" her mother refers to. Claude is contrasted with Ellen, who never eats in the film - the audience only ever sees her consuming alcohol and drugs, except from one scene where she drinks a soda to make her feel better after having drunk too much alcohol. Part of the film's resolution revolves around this dichotomy-in one of the last scenes we see Claude and Lucy walking together and sharing an ice cream cone, symbolically indicating their compatibility and similar worldviews (1:23:20). Similarly, Luke is also symbolically represented as aligned with Claude when he accepts the bag of candy from Claude when they first meet. Claude's relationship to food and her body is treated as an indicator of how she does not fit into certain aspects of the world in which she begins the film, as emphasized by her mother's and Ellen's different relationships with food and their bodies in comparison to Claude's. Her transition into a new, more accepting world is shown as she gradually leaves behind her emotionally abusive relationship with Ellen and finds a new connection with Lucy, whose feminist, queer, body-positive riot dyke politics resonates more with Claude's approach to life. 
Thus, overall the film connects riot dyke and other alternative female-front music with white, lower- or middle-class, queer women, as well as resistance to social gender norms. Music is essential to the queer community portrayed in this film—-music is central to Claude's, Luke's, and Lucy's interactions with each other and with their broader queer community. The following section examines the music that Claude listens to in All Over Me, exploring how the music is linked to her character traits and to her character development in the film.

\section{Musical Listening and Performance in All Over Me}

In this section I discuss three separate instances in which Claude and/or Lucy listen to (and in one instance, perform) music, each of which has a very different context from the others. In the first instance, Claude listens to riot dyke band Sleater-Kinney privately on her headphones; in the second, she listens to (and watches) a performance by Lucy and her band; and in the third, Claude selects a song by the Patti Smith Group to listen to with Lucy. These separate scenes are demonstrative of the different ways Claude uses music in her life: for personal listening, as a way of tentatively approaching the queer community, and as a way to form relationships with other individuals. These examples span a range from clearly linked to riot dyke to only tangentially related; what brings these examples together is Claude's (and Lucy's) interest in alternative music performed by women. This section demonstrates how these songs narrate Claude's personal growth and shifting identity.

The only riot dyke music in All Over Me is featured in a scene in which Claude is listening to it on her headphones. The scene $(0: 20: 10)$ follows shortly after the scene in which Luke suggests that Claude visit a club he knows where "girl bands" perform. Luke's 
participation in the local (likely queer) punk scene gives him an insider understanding of this local riot dyke scene. It is unclear whether Claude was introduced to Sleater-Kinney by Luke or if it is music that she discovered on her own, but the placement of this scene after the discussion about girl bands between her and Luke implies that he may have introduced her to this music. Regardless, the music serves a transitory purpose in the film—-marking a shift for Claude towards embracing her queerness. Listening to Sleater-Kinney is a step on her way towards visiting the club.

The scene is quite short, but the song's use nonetheless marks an important moment in the film. In the scene, Claude roller-skates down the road, listening to Sleater-Kinney's "I Wanna Be Your Joey Ramone" loudly on her headphones. She moves her headphones around her neck when she stops to talk briefly to Luke and Jesse. Luke is openly flirting with Jesse, and after saying hello, Claude puts her headphones back on and skates away. "I Wanna Be Your Joey Ramone" is from Sleater-Kinney's second studio album, Call the Doctor (1996). The song's lyrics are slightly obtuse but broadly discuss being a punk or rock musician; the song is closer to rock than punk in terms of its sound (more singing than speaking, a more complex guitar line, and less distortion than riot dyke usually has), though during the chorus there is some riot dykestyle screaming. The first and third chorus say "I wanna be your Joey Ramone / Pictures of me on your bedroom door / Invite you back after the show / I'm the queen of rock and roll" referencing Joey Ramone of the Ramones, while the second chorus references Thurston Moore of Sonic Youth fame, stating "I wanna be your Thurston Moore / Wrestle on the bedroom floor / Always leave me wanting more / Throw away those old records."11 The full lyrics of the song are unclear in their meaning - it is likely that the lyrics, particularly of the choruses, are meant to be

\footnotetext{
${ }^{11}$ These lyrics are a personally edited version of lyrics found at http://www.metrolyrics.com/i-wanna-be-your-joeyramone-lyrics-sleater-kinney.html (accessed May 28, 2016).
} 
ironic, while the rest of the lyrics are hard to interpret. However, the song is clearly discussing the punk rock lifestyle. It also has clear gender-bending elements - the female narrator identifies with two separate male punk musicians and professes to want to be idolized like them, including in a sexual way, presumably by women. Thus, even if the song is ironic or tongue-in-cheek, it still clearly connotes a queer orientation. The two people Claude is closest to, her mother and Ellen, both ignore or are disgusted by homosexuality, and it seems that Claude has not yet realized, or at least acknowledged, her own queerness. Thus, this song links to two important elements in Claude's life: her interest in becoming a musician, presumably in a punk or riot dyke genre since that is what she listens to, and her gradual realization of her sexuality. In a film where music must be carefully selected based on its affiliating identifications, this song clearly has a representational purpose.

The second example of Claude listening to music is a scene in which Claude goes to the bar Luke recommended to her. The scene (0:45:31) emphasizes the centrality of live music in this particular queer community (a theme which is also be present in Itty Bitty Titty Committee) - Claude, who lacks access to a queer community at the beginning of the film, is given access to this community through music. When Luke suggests that Claude visit his friend's bar to meet other young women who are interested in making music, he is intentionally introducing her to a community of both musicians and queer peers. That is, music is a creative outlet that Luke has found, and an outlet that he, possibly perceiving Claude's queerness before she recognizes it herself, knows will be invaluable for her, in part because of the community built around music. When Claude visits the club for the first time she is greeted with live music_Lucy and her band are performing the 1993 single "Hole in the Ground" by Helium, a band peripheral to the riot dyke music (though youth culture scholar Susan Driver describes 
Lucy’s music as "riot grrrl punk" $(2007,111))$. Initially Claude lingers outside the club, but is soon drawn inside to listen to the band, where an audience of young women crowds around the stage. The atmosphere is that of a lesbian bar, though it could also be a queer women's night at a bar, or perhaps Coochie Pop is a riot dyke group - the audience consists of young women, some of whom are clearly portrayed as queer, and the bartender's self-presentation is rife with lesbian signifiers. The audience seems welcoming to beginner bands; Lucy ends the band's set saying "So far we only have four songs, so I guess that's it" (0:48:52). The queer atmosphere of the event is emphasized when after the set an Ani DiFranco song ("Shy," from her 1995 album Not a Pretty Girl) is played over the sound system. ${ }^{12}$ The venue is implied to be all-ages, at least for this show_Claude and Lucy are both under-age. All these factors (the mostly queer audience, the all-ages venue, and the audience's and venue's welcoming attitude to inexperienced musicians) make the show seem to be in line with a riot grrrl or riot dyke music scene as discussed in Chapter 2. Additionally, this is the only scene of a large queer community presented in the film, making the fact that it features live music highly relevant; this community seems largely formed through affinity, towards riot dyke music and towards queer identities, to reference Shelemay. This is a space that Lucy feels comfortable in - she is relaxed and bubbly after her band's set.

The song that Coochie Pop performs at the club, "Hole in the Ground," by indie pop/postpunk group Helium, has lyrics that can be read as feminist and queer. The song has elements that link it musically to riot dyke style, most notably the vocals, which alternate between sung and

\footnotetext{
${ }^{12}$ Among the films that I examined prior to selecting the films for this project, Ani DiFranco was the most frequently used artist on lesbian film soundtracks in terms of the number of films in which her music was used (see Appendix I; DiFranco is featured in four of the films that I examined, while other artists featured in multiple films include Sleater-Kinney, Bikini Kill, Team Dresch, Goldfrapp, Lois Maffeo, and k.d. lang, each being featured in two films).
} 
spoken. Though the lyrics are not entirely transparent, my interpretation is that they describe a young woman learning to be independent of her (perhaps manipulative or overbearing) boyfriend and eventually realizing that she doesn't need or want him at all. That is, the lyrics mesh well with the "girl power" narratives of riot grrrl subculture, explaining why this song is used to represent the riot dyke scene represented in the film. The second verse states:

You've got to come out of under the ground,

You're like a seed, but right now you can't be found.

You could grow up, you could get bigger again.

This time you can do it without your boyfriend. ${ }^{13}$

The song's narrator is telling the protagonist that she would be better off without her boyfriend. The final few lines of the song state "You said 'There's a lot of things I'd like to do... / and boy one of them's not you," in reference to the boyfriend. The protagonist thus believes that she will accomplish more in life by gaining self-confidence through independence and by losing her dependence on her boyfriend.

In the context of the film, the song's lyrics are relevant broadly in that they speak to Claude's need to "come out of under the ground"; Claude is in a formative place in her life where the boyfriend of the song who is holding her back is represented by her friend Ellen, while Lucy holds the position of the song's narrator, encouraging Claude to escape her dependence on Ellen (it is perhaps not coincidental that the B-side of this single is titled "Lucy"). While she is singing the song, Lucy notices Claude in the audience and holds her gaze, smiling very intentionally at her-implying romantic interest, but also, given the song's lyrics, that the song has some special relevance to Claude. After meeting Lucy, Claude will undergo substantial

\footnotetext{
${ }^{13}$ I transcribed these lyrics with the aid of http://decoda.com/helium-hole-in-the-ground-lyrics (accessed May 28, 2016).
} 
personal growth, coming out of her shell, standing up for her personal morals, and beginning to come to terms with her sexuality. The music and the community to which it is linked prove central to Claude's shifting identity, recalling Cohen's assertion that people often "find their identities as individuals through their occupancy of the community's social space" $(1985,109)$.

The final scene in which characters listen to music, in this case the Patti Smith Group's "Pissing in a River" from the 1976 punk rock album Radio Ethiopia, follows shortly after this scene at the club. Claude has gone to hang out with Lucy at her house after the show. The two young women have been sitting on Lucy's bed listening to music [first Tuscadero's “Game Song" (0:50:42) and then Alison Pipitone's "Dynamite" (0:52:45, a song written for the film)] when Lucy suggests that Claude choose some music. Claude browses through Lucy’s CD collection and picks out the Patti Smith Group's influential punk album Radio Ethiopia (which belongs to Lucy's father and which Lucy has not listened to before), and with a bit of prodding from Lucy, puts on the song "Pissing in the River" (0:53:19). At first they sit down listening to the music, but soon Claude gets up and starts swaying to the music. Lucy eventually gets up and joins Claude, at which point she tells Claude "I'm really psyched you came over" and tentatively kisses her. The scene briefly cuts to a scene with Ellen and Mark before returning to Lucy's bedroom where Claude seems to be having some kind of panic attack or anxiety, swaying back and forth and holding her head while she sings along with the song. She walks over to the stereo and turns off the music and then sits down on the floor and starts crying. Lucy tries to comfort her, but Claude apologizes and says that she should go home.

"Pissing in a River" is an intense and angst-ridden song about a relationship the narrator is in; in the frank words of Lucy, "She seems really sad" (0:54:16). The song opens with solid, forceful piano chords, but once Smith's vocals enter the piano becomes more subdued. When the 
song's chorus-like section enters the song's instrumentation becomes much fuller, adding drums, organ, and electric guitar for the remainder (the electric guitar switches between chords on the chorus-like sections and arpeggiation on the verses). The lyrics portray a narrator struggling with a relationship, asking "What more can I give? Baby, I don't know / What more can I give you to make this thing grow?" ${ }^{14}$ Later in the song the narrator becomes resigned to the loss of the relationship, saying “You're gonna leave me / You don't need me / I can't live without you / I never doubted you," clearly resonating with Claude's internal and external struggles in her relationship with Ellen. Claude's panicked reaction to Lucy's kiss makes it clear that Claude is struggling with her sexuality and that this may be contributing to her breakdown, however, the lyrics of the song seem to speak more to Claude's relationship with Ellen. Not only is their friendship an unhealthy relationship in which Ellen neither returns her romantic feelings nor treats her as a friend, the relationship also faces the new issue of Ellen's focus on Mark and Claude's discovery that Mark is likely Luke's murderer. That is, I would argue that Claude's reaction to the song is primarily driven by her realization that her relationship with Ellen is likely irretrievable, though perhaps spurred by her discomfort about Lucy's romantic and/or sexual interest in her (or discomfort with her reciprocal feelings towards Lucy). The song's lyrics speak to Claude's dilemma about Luke's death — that is, how far should she go to protect her friend (and by extension, Mark)? One repeating section of the song asks "Should I pursue a path so twisted? / Should I crawl defeated and gifted? / Should I go the length of a river?” clearly resonating with Claude's moral dilemma. Though in this scene Claude seems emotionally broken and almost helpless, I would argue that this scene represents a moment of realization and growth for Claude — she is unable to begin a romantic relationship with Lucy without first dealing with

\footnotetext{
${ }^{14}$ Lyrics for this song retrieved from http://www.metrolyrics.com/pissing-in-a-river-lyrics-patti-smith.html and checked for accuracy (accessed May 28, 2016).
} 
her fraught relationship with Ellen. This realization is demonstrated in the following scene, the first in the film in which Claude stands up to Ellen, getting angry when she finds out that Ellen brought Mark to Claude's bedroom. This is the beginning of Claude's gradual distancing of herself from Ellen. Thus, the music facilitates Claude's growth and movement away from an unhealthy relationship towards a healthier one, and away from the homophobia and misogyny of Ellen's new boyfriend and his friends towards a community of young queer women.

\section{Conclusion}

Over the course of the film, Claude's development is frequently represented through the music she listens to. Claude starts the film in an unhealthy relationship with Ellen, unaware of or unwilling to acknowledge her non-straight sexuality, and having little chance of fulfilling her dream of being in a band. The music Claude listens to throughout the film shows her transition towards a realization of her sexuality and her transition away from her mostly-platonic relationship with Ellen toward a romantic relationship with Lucy. This transition is accompanied by the possibility of joining a band — near the end of the film we see Claude and Lucy playing their guitars together in Claude's bedroom (1:21:56). Importantly, the film uses characters' habits to link riot dyke music and the film's music-based community to queer sexualities, resistance to social norms of femininity, and white lower- and middle-class identities. While these first two case studies have examined films that use riot dyke music which were created at the height of the riot grrrl movement, in the last chapter I examine a more contemporary example of riot dyke music in film, looking at Itty Bitty Titty Committee, the film that of these three engages most directly with riot grrrl as a movement in spite of its temporal distance from the 
height of the movement. 


\section{Chapter 5}

\section{Case Study: Itty Bitty Titty Committee}

The most recent of the three films I discuss, Itty Bitty Titty Committee (hereafter IBTC) contrasts with the previous films due to its more explicit engagement with riot grrrl as a feminist political movement. In this film, the community is presented as one formed largely on the basis of dissent (to recall Shelemay) with both mainstream society and much of queer society. As in the previous chapters, riot dyke music is presented in this film as facilitating the maturation of the main character, as well as a shift in identity. IBTC was produced in 2007 by POWER UP, a not-for-profit organization in Los Angeles whose goal is "to promote the visibility and integration of gay women in entertainment, arts and all forms of media" through financing, producing, and distributing films and through providing educational filmmaking programs and other services (POWER UP Films 2006). Directed by Jamie Babbit, IBTC was POWER UP's first feature film. As in the films previously discussed, music is central to IBTC's portrayal of queer identities and communities, and in this film in particular, riot dyke music is the main genre of music that the characters listen to. The strong link that IBTC creates between riot dyke music and the political queer community it portrays makes the film well-suited for an examination of how riot dyke music's affiliating identifications interact with characters' habits related to music listening, political orientation, gender presentation, and community. By examining the links between the music's affiliating identifications and characters' habits I am able to link riot dyke to particular identities and to explore how this music is connected to the maturation of the main character, Anna. 
Compared with the previous two films discussed, the evocation of riot grrrl subculture is most direct in this film; the radical feminist group at the centre of the film, the C(i)A, is a riotgrrrl-like group, with many of the attendant problems discussed in Chapter 2. Though the film is set ten to fifteen years after the peak of the riot grrrl movement, ${ }^{15}$ riot dyke music is represented as central to both the radical feminist community the film portrays and to the growth of the main character, Anna, into an independent, confident young woman. Of the three films examined in this thesis, IBTC most explicitly links changes in music listening choices to changes in identity. This chapter explores the different identities the film links to riot dyke music through characters' habits, how this music is narratively tied to Anna's changing identity and personal growth, and the role riot dyke music plays in the community portrayed in the film. I demonstrate that the riot dyke music featured in the film becomes more audible, more political, and more personal as Anna's political identity changes; the music's clarity acts as a metaphor for the strength of Anna's links with this particular brand of radical feminist politics. Further, beyond her changing political identity (as evinced by her changing habits), Anna's participation in this radical feminist group and her engagement with riot dyke music is linked to an increase in her self-confidence and personal direction. In this chapter I distinguish between the riot grrrl politics that the C(i)A practices and the riot dyke music that they listen to. That is, though their politics are primarily concerned with feminist issues and are reminiscent of 1990s riot grrrl subculture, the music they listen to can be described more broadly as riot dyke, as can the broader music-based queer community in the film.

\footnotetext{
15 The film is set 125 years after "the erection of the Washington Monument" $(1: 12: 42)$. The ambiguity of this statement (this could mean the date the monument was completed, the date it was opened to the public, etc.) places the film in 2008 (based on the date construction ended), 2009 (based on the date the monument was dedicated), or 2013 (based on the date the monument was opened to the public).
} 
IBTC centres on the story of Anna, a young Latina woman who has recently graduated from high school and lacks direction in her life. Unlike Claude in All Over Me, Anna begins the film as an out lesbian. After joining a riot-grrrl-inspired radical feminist group, Clits in Action (C(i)A), Anna learns about and becomes an active participant in feminist activism, encounters riot dyke music, and grows into a confident, passionate person. The C(i)A carries out a number of feminist actions throughout the film, most involving vandalism of one kind or another, culminating in a takeover of a national television station so that they can blow up the Washington Monument on the 125th anniversary of its "erection." This occurs live on the air as an act of defiance against the phallocentricism of society; when one of the C(i)A members is trying to explain to Anna what the C(i)A is about, the first thing in her list of social problems is "that the public arena is entirely dominated by phallocentric imagery" (0:13:00). All of the members of the C(i)A are queer white women, with the exception of Aggie, a young trans man. The film features constant relationship drama, particularly between Anna and Sadie, the de facto leader of the C(i)A, who is known for the frequent affairs that she hides from her long-term girlfriend, Courtney. In comparison to Two Girls in Love and All Over Me, Itty Bitty Titty Committee is much more of an ensemble film, though the story still centres on Anna. The ensemble cast gives the film a much greater feeling of "community," and although the music is sometimes directly related to the narrative development of Anna's character, it is just as often used by other characters or heard in public places, such as the club featured frequently in the film. Music here is clearly central to "the maintenance of queer culture" as posited by Jodie Taylor $(2012,49)$. Further, the film demonstrates Cohen's idea of identity as shaped by community - it is Anna's involvement in this radical feminist community that leads to her identity shifts. 
$I B T C$ has a sizeable soundtrack, featuring music from several riot dyke bands and their successors. The soundtrack tends to feature large portions of single albums: six songs from Heavens to Betsy's 1994 album, Calculated, three songs from Bikini Kill's album Pussy Whipped (1993), and four songs from Le Tigre's 2001 album, Feminist Sweepstakes. Also included are two other Le Tigre songs, two songs by Sleater-Kinney, and single songs from The Need, Slumber Party, Slant 6, Peaches, and Team Dresch, all of which, aside from Slumber Party and Peaches, fit solidly within the umbrella of riot dyke. The music spans eleven years, from 1993 to 2003, and is used in diegetic contexts about half of the time. Additional music for the film is composed by Radio Sloan of The Need in a punk style - as such, there is some music in the film that sounds like riot dyke music, but is unrecognizable aside from its punk style because it does not pre-exist the film. This composed music is used in general for ambience and affect, and is clearly meant to blend in with the rest of the soundtrack - that is, it still evokes riot dyke style due to its positioning in a primarily riot dyke soundtrack.

Riot dyke music provides an almost constant backdrop to the C(i)A's activities. At the group's headquarters, riot dyke music is always playing. In addition, there are a number of scenes in a club that also feature diegetic music. This music is also used non-diegetically as a background to outdoor scenes, montages, and particularly as a backdrop to the group's political actions. The presence of riot dyke music in the C(i)A headquarters and in Anna's private listening makes it clear that the music the audience hears is a result of individual characters' listening choices. In $I B T C$, riot dyke music is presented as central to radical feminist identity, and in this case also with being lesbian or queer. For Anna, the main character of the film, being introduced to this music is closely tied to her introduction to the C(i)A's world and to coming into her own as a confident young woman. The following sections examine habits related to 
politics, gender presentation, and community as related to riot dyke music in IBTC. Because politics and community are inextricably linked in this film, I first discuss the politics of the community in the film, and in the later section about community, I primarily discuss the demographic make-up of the community.

\section{Music and Politics}

Like the previous two films examined, IBTC explores a range of identities in its characters. Most prominently, the film examines political identities and communities. The film's main characters all belong to the C(i)A: Shulie, a former lawyer and the brains of the group; a trans man named Aggie; Meat, a struggling artist; and Sadie, the charismatic de facto leader of the C(i)A. Anna joins the C(i)A early on in the film, and later the group recruits a woman named Calvin, an explosives specialist who was discharged from the military under 'Don't Ask, Don't Tell” and who is relatively apolitical, telling Shulie, "I don't care [why we're at war]. I just like to blow shit up. I'm a fucking adrenaline junkie" (0:43:30). At the end of the film, Calvin is not portrayed as a continuing member of the C(i)A. Many of the C(i)A's political stances and techniques mirror those of the riot grrrl movement, as discussed in Chapter 2. The C(i)A is contrasted with the more mainstream, law-abiding organization, Women for Change (WFC), which is headed by Sadie's older girlfriend, Courtney. WFC holds meetings in Courtney and Sadie's house; the conflict between the C(i)A and WFC is highlighted primarily by the conflict between both Sadie and Courtney. Sadie sneers at the rule-bound, bureaucratic, pie-chartintensive methods of Women for Change, while Courtney treats the C(i)A's activist techniques and obsession with phallic symbols with condescension. While the C(i)A believes that "the most effective way to effect change is to step outside the system and tear it down" (0:13:20), Courtney 
frowns at their obsession with phallic imagery, saying that they are "way out of control" $(0: 33: 32)$ and hypothesizing that in taking women's studies in college, "Sadie learned more about postmodern feminist theory than she did about how to effect real change" (0:34:29). Thus, the leaders of each organization think that the other is ineffective. By contrasting the radical feminism of the C(i)A with the more institutional form of feminism of Women for Change, the film is able to link various identity traits with radical feminism. First and foremost, the C(i)A's feminism is associated with youth and queer identities. The film contrasts the scorn that the C(i)A and Anna show towards the styles of feminism of women from other generations (the WFC's institutional, bureaucratic form of feminism and the low-key, inexplicit feminism of Anna's mother), though near the end of the film Anna is impressed to discover that her mother was once an intern for the feminist magazine $M s$. .

The C(i)A's politics revolve around a variety of related causes, including promoting body positivity by replacing thin mannequins with homemade mannequins moulded on real women's bodies and vandalizing the plastic surgery clinic Anna works at, reminding society of important feminist figures by placing homemade statues of Angela Davis and Emma Goldman in public places, protesting against same-sex marriage rights due to marriage's history as a patriarchal institution, and the destruction of a phallic monument. Many of these political stances mesh well with riot grrrl's politics as discussed in Chapter 2. The C(i)A's politics are very black and white: for instance, they are not interested in conceptualizing how marriage might be able to be subverted by feminists and LGBTQ people, and they scorn the strategies of less radical feminist organizations such as Women for Change rather than realizing that both organizations might have value. To a certain extent, the C(i)A's politics are meant to be hilariously clueless and over the top (this is a comedy film after all); the members are more interested in defacing public 
property than in taking concrete steps towards empowering women. The film essentially portrays a humorous reincarnation of riot grrrl subculture a decade or more after the movement's peak. However, as demonstrated in the following paragraphs, this new manifestation of riot grrrl culture has not learned from the earlier critiques of riot grrrl feminism discussed in Chapter 2, particularly about race and class issues within the movement.

The type of division between the C(i)A and Women for Change has existed between reallife feminists as well; Jamie Stuart describes this divisiveness, arguing that in the early twentyfirst century, many lesbian communities could "be seen to have split between...those who belong to the Human Rights Campaign and want to legalize gay marriage and...those who are performing as drag kings and challenging the category of "woman"” $(2008,59)$; that is, there is often a division between queer feminists with liberal goals and those with radical goals. In her discussion of IBTC, film scholar and critic B. Ruby Rich argues that the C(i)A's actions, which to some might seem like "off-kilter irrationality" or "infantile gestures," are actually "perfectly consistent with the language of groups shut out of systems of power" $(2013,210)$. She proposes that the C(i)A employs the carnivalesque as "a peacetime alternative to those whose demands are otherwise rendered mute and illegitimate, even in a porous, so-called democracy" (210). Rich points out that the film is an homage to Lizzie Borden's 1983 lesbian feminist science fiction movie Born in Flames; both films feature a group (or groups) of queer feminists deploying radical actions in opposition to a bureaucratic patriarchal society, with a catchy soundtrack, and a finale that involves blowing up a famous American building or monument. However, what Rich does not note is that while Born in Flames' characters dealt with issues of race and class, and participated in feminist actions that directly benefited other women, in Itty Bitty Titty Committee, the C(i)A does neither of these things. Thus, the C(i)A occupies an interesting position in terms 
of politics - the organization's politics are radical, but at the same time their politics seem narrow and inflexible.

\section{Music and Gender Expression}

Although the C(i)A is not an explicitly lesbian or queer organization, all of its members are queer or trans; Shulie, presumed straight by the other C(i)A members for the first half of the film, reveals her sexuality to be more fluid when she falls for Calvin. Though the C(i)A is initially described as only open to women, this is one area in which it has some flexibility as Aggie, a trans man, is welcomed into the organization; at the end of the film it is revealed that Aggie started up a new cell of the C(i)A for transgender people (1:21:36). Recalling the openness of riot grrrl culture to non-conventional gender presentation and resistance to the male gaze, the female characters in the C(i)A demonstrate a range of gender presentations, from Shulie's nerdy femininity and Sadie's punk femininity, to Meat's tattooed androgyny and Calvin's butchness. Anna's presentation of herself also shifts over the course of the film. As her association with the C(i)A strengthens, Anna's habits of gender presentation become more subversive, for instance through her dyed pink hair, and her clothing style shift away from frumpy office clothes toward clothing that suggests she is confident in her femininity.

\section{Music, Social Milieu, and the Community of IBTC}

In $I B T C$, music is shown to be central to the community represented. Riot dyke music is not only important to the identities of the individual characters who are portrayed as choosing to 
listen to it (Meat, Sadie, and Anna), but also to the broader queer punk feminist community of which they are a part. Live music, not just diegetic music, is central to Itty Bitty Titty Committee's depiction of this queer community, as evidenced by the multiple scenes at the club, usually accompanied by live music. The club is a place where the characters go when they are happy, angry, or upset — that is, it is portrayed a place they feel safe and supported, and where they go to find community based on affinities of musical preference and sexual orientation. The film uses live music to demonstrate the intensity of this community's connection with riot dyke music. The live nature of the music in the club is emphasized by featuring a shot of the band at or near the beginning of three of the four club scenes.

While IBTC closely links riot dyke music (particularly through listening and live performance), this music's affiliating identifications related to riot grrrl's position as a primarily white, middle-class movement are also evoked. Although characters' habits represent an abundance of different gender and sexual identities in IBTC and this diversity seems central to the film's queer activist community, the film's presentation of race and class difference is less nuanced; IBTC's riot grrrl community is experiencing many of the same issues around race as the 1990s riot grrrl movement did fifteen years earlier, as discussed in Chapter 2. While gender identity and presentation are central to the characters' identities, race and class are virtually ignored. The C(i)A's narrow politics perhaps obstruct their engagement with intersectional feminism and with issues with more day-to-day impact on women of all backgrounds and on women of colour more specifically, making the group unlikely to attract the participants of colour, particularly those not from middle- or upper-class backgrounds. In $I B T C$, none of the main characters, aside from Anna and her family, are members of visible minorities. While it is refreshing that the film's main character is Latina, the whiteness of the other characters makes 
Anna the exception that proves the rule; Anna's non-whiteness emphasizes the whiteness of the group. However, as in the case of Evie in The Incredibly True Adventure of Two Girls in Love, Anna's race is not presented as particularly relevant to her identity — she spends the movie surrounded by white characters (apart from her family) and race is never mentioned (even Two Girls in Love, which generally ignores race while emphasizing the other differences between the main characters, mentions Evie's race and the possibility of racism). The C(i)A's nonacknowledgment of its lack of diversity is particularly problematic in the context of feminist activism, which throughout its history has been troubled regarding inclusion of women of colour. Aside from Anna's family members, the only other person of colour in the film is Laurel (played by lesbian icon Jenny Shimizu), a minor character who actively dislikes the C(i)A. Thus, the C(i)A's lack of racial diversity echoes that of the riot grrrl movement of the mid-1990s.

Just as the C(i)A's membership is narrow in terms of ethnic background, they represent a similarly narrow set of class backgrounds. Unlike Two Girls in Love and All Over Me, in IBTC the characters are all comfortably_and for radical feminists, obliviously_middle class. The only reference made to class is Meat's angry questioning of Anna, which implies that Sadie will never leave her comfortable bourgeois life with Courtney: "You think [Sadie]'s going to leave her bungalow, her fancy summer house in P-town, for you?" (0:56:35); that is, the characters critique middle-class lifestyles while benefiting from their middle- or upper-middle class backgrounds. This statement emphasizes the middle-class status of the other characters. For instance, Shulie, who expresses agreement with Meat's comment, is a white, educated woman with a law degree, who has the privilege of choosing to live a less "bourgeois" lifestyle, a privilege not afforded to many lower class women or women of colour. Rather than Shulie, Meat, and the other C(i)A members acknowledging their own class privilege, they instead 
present Courtney as representing the middle class, privileged establishment which the C(i)A is rebelling against. However, the fact that all of the C(i)A's members are privileged with respect to class background (or current economic position) is ignored. In addition to Shulie, referred to as a "recovering lawyer" (0:11:15), Anna comes from a comfortably middle-class family and the other C(i)A members seem to be neither employed nor under financial stress, aside from Meat, a struggling artist (who cannot really be described as employed since no one is buying her paintings). Laurel, a jaded woman who lives in the C(i)A headquarters but is not a member of the group, goes so far as to rant that unlike the C(i)A members, she has a "real job" and pays "real rent," and the fact that she sublets the only bedroom in the place is what allows the C(i)A's "socalled political feminists to camp out on the floor for free" $(0: 28: 23)$. Thus, the only characters (aside from Courtney, whose job serves as a foil to C(i)A's political style) who are portrayed as having jobs are both people of colour-Laurel and Anna. As such, the film depicts some of the real-life conflicts in activist communities around white privilege and middle- or upper-class white activists "choosing to be poor" while their lower class compatriots (often members of ethnic minorities) do not have this choice, though the film does not draw attention to this trend it portrays.

Finally, as a composite of all the identities it portrays, IBTC portrays a queer feminist community formed in equal parts by affinity and dissent, at least as much as is possible within the limitations of a film. The C(i)A acts as a small community within a larger community of queer women; this larger sense of community is demonstrated through the film's characters' repeated excursions to the same club, a place where they obviously feel at home and surrounded by their peers. The following section examines how riot dyke music is connected with Anna's gradual integration into the $\mathrm{C}(\mathrm{i}) \mathrm{A}$ and the broader queer punk feminist community. 


\section{Anna's Introduction to the C(i)A and Riot Dyke Music}

Anna begins the film as a shy, unassertive, and slightly frumpy girl, lacking selfconfidence after having been rejected by the only university she applied to and dumped by her girlfriend. She has grown up in a world where being an out lesbian is not a political or even necessarily controversial decision — her parents fully support her lesbian identity, though, much to Anna's chagrin, her mother would like her to conform to social norms of femininity, at least for her sister Ellen's upcoming wedding. Anna works as a receptionist at a plastic surgery clinic and does not seem to have considered the implications of her decision to work at this establishment with regards to the objectification of women or societal standards of beauty; when Shulie, the most confrontational of the C(i)A members, challenges Anna about her job, Anna responds with a shrug, "You know, some women just want to look good" (0:11:55). Anna's initiation into the C(i)A's world is thus an introduction into feminism, radical activism, independence, and young adulthood, but not into lesbianism. Instead, Anna's participation in the C(i)A, and its concomitant exposure to riot dyke music, results in her becoming a confident young woman with direction in her life and with new politics-related habits.

At the beginning of the film, Anna's pre-C(i)A life is directly contrasted with the queer punk community around which the film revolves. With the exception of the title sequence, an abstract montage of which Anna is not a part, the scenes preceding Anna's introduction to Sadie and the C(i)A do not feature riot dyke music, and Anna is shown to be unsure of her direction in life and frustrated with and stifled by her family. The title sequence of the film features music by two politically-charged riot dyke songs: Le Tigre's “They Want Us to Make a Symphony Out of the Sound of Women Swallowing Their Own Tongues" and Heavens to Betsy's "Terrorist." The excerpt of the former song asks "What is it that they're, that younger women, are pushing up 
against? They would seem to have a list of options to choose on $[\mathrm{sic}], " 16$ while the latter song provides answers to this question, including street harassment and by extension, men's control of women and their bodies. During this sequence, scenes from a club (women dancing, a band performing) are interspersed with brief shots of the C(i)A members spraypainting slogans on buildings and skateboarding.

This music and its accompanying images of a lifestyle of partying and politically-inspired vandalism is juxtaposed with Anna's comparatively mundane life in the following scene, where she is being fitted for a bridesmaid's dress for her sister's wedding (0:02:24), a situation with which she is visibly annoyed. The music shift between the two scenes emphasizes the difference of these two worlds as the previous scene's angry riot dyke music is replaced by the wedding store's background music, Vivaldi's "Spring” from The Four Seasons. Though Anna is not choosing to listen to this music, the linkage of one of the most recognizable pieces of Western art music to Anna's position at the beginning of the film situates her in a place of normalcy. Later, at work, her co-worker Maude encourages her to get a "boob job" to cheer her up after her breakup with her girlfriend, a possibility which Anna seems to consider, or at least does not reject.

The point when Anna meets Sadie, the de facto leader of the C(i)A, creates a dividing line between this life and the new life she will have with the C(i)A. After Anna sees Sadie spraypainting anti-cosmetic surgery graffiti at her workplace, Sadie invites Anna to come to the C(i)A headquarters that evening. Though no music accompanies this scene, later, as Anna anticipates going to the meeting, non-diegetic distorted bass and guitar music begin in the background (0:10:32). Once she enters the headquarters the music becomes diegetic and vocals are added, directly associating riot dyke-style music with Anna's first willing encounter with the C(i)A.

\footnotetext{
${ }^{16}$ I personally transcribed these lyrics.
} 
This music is largely indecipherable. This may seem like an odd choice given that this scene is Anna's introduction to this new world, however, in combination with the following musical example, I would argue that the music's indecipherability and apolitical nature (aside from the generic associations) is tied to Anna's ignorance of feminist politics and lack of commitment to the C(i)A. As I show below, as Anna becomes more politically aware and involved in the C(i)A, the riot dyke music employed in the film becomes more decipherable and more politically charged.

During Anna's initiation into the C(i)A the audience hears the song "Hamster Baby" by Bikini Kill, again beginning in a non-diegetic context and later becoming diegetic. Her initiation is an action by the $\mathrm{C}(\mathrm{i}) \mathrm{A}$ in which she acts as a lookout while the others replace store mannequins with paper mâché models of real women (0:17:59). When a police officer happens by, Anna warns the C(i)A members and the song starts as the characters run away from the officer, yelling and screaming (0:19:22). When they arrive safely back at Sadie's house the music becomes diegetic. The lyrics of the song, which are about touring in a band, do not seem to have any relevance to the scene and, like in the previous example, are not political in nature. This follows the trend outlined above of Anna still not being very cognizant of feminist politics. However, the song and riot dyke music generally become clearly linked with youth and radicalism when Sadie promptly silences the music by closing the lid on her laptop when her older girlfriend Courtney, portrayed throughout the film as a conservative and stuffy killjoy, enters the room. Listening to riot dyke music is presented as one of Sadie's "habits" and not one of Courtney's. Courtney might in fact dislike or disdain this type of music; this scene demonstrates that riot dyke music is linked to queer identity for only a subset of lesbians. That is, appreciation of riot dyke music is linked to youth and anti-establishment politics, as compared to 
Courtney's style of political engagement, which the younger women in the film perceive as not radical enough.

Only when Anna has fully become a member of the C(i)A does the audience experience her (and other C(i)A members) listening to politically driven riot dyke music. This occurs with the film's use of Le Tigre's "FYR" (starting at 0:24:08), which ties together many aspects of the identities of the film's characters and of the C(i)A as a group. This moment in the film is the first time Anna is portrayed choosing to listen to riot dyke music rather than simply being in an environment in which this music is present - it is the beginning of her cultivation of a "habit" which contributes to her identities. This section of the film links her becoming a true part of the C(i)A (rather than being in a probationary position), her embrace of the C(i)A's politics, and her engagement with this style of music that is new to her. As with the previous two examples, "FYR" begins non-diegetically and then becomes diegetic. The song initially accompanies a home-video-style montage of some of the C(i)A's actions, such as putting up homemade statues of Angela Davis and Emma Goldman at the Los Angeles city hall and changing the gender signs on public washrooms. As the montage progresses, it foregrounds the importance of music to the characters, including shots of Sadie and Anna at a book and record store, where Sadie is showing Anna what she should read and listen to in order to cultivate her newfound feminist identity. The CDs and records shown include three different Sleater-Kinney albums, albums by Gossip, PJ Harvey, The Queers, and the Kill Rock Stars label compilation album Otis' Opuses (2006). With the exception of The Queers' and PJ Harvey's albums, which are contemporaries to riot grrrl's peak in the mid-1990s, the others are all either riot dyke-associated bands or, in the case of Gossip, highly influenced by riot dyke music. This scene is important because it explicitly links music listening habits to one's political identity, an idea more implicit than explicit in the 
previous two films discussed. In addition, the queer activist nature of most of these bands also links the music to sexual identity. That is, sexuality is portrayed as closely linked to politics; even though the C(i)A is participating mostly in feminist and not LGBTQ activism, the music Sadie suggests to Anna makes it clear that queerness is central to Sadie's feminist and activist identities and that she believes it should be for Anna as well.

The song that accompanies this montage, "FYR," from Le Tigre's 2001 album Feminist Sweepstakes, is important in the context of the film because, unlike the previous two musical examples, the song is explicitly political and fits thematically with the dramatic action. The influence of riot dyke music on Le Tigre's musical style is evident in this song in spite of the group's move away from punk-influenced riot dyke music towards electronic music. Like much riot dyke music, the song is upbeat, features lyrics that are chanted or yelled rather than sung, has distorted guitars (or synthesizers that sound like guitars), and features explicitly feminist lyrics. The song is a feminist call to arms: the chorus proclaims, "Feminists I'm calling you! Please report to the front desk!"17 The song's title and lyrics reference the chapter entitled "Fifty Years of Ridicule" in Shulamith Firestone's 1970 book The Dialectic of Sex: The Case for Feminist Revolution, a book that is referenced later in the film when Shulie explains that her name is an homage to Firestone. The importance of the song in the film is underscored by the fact that lyrics from the song are painted on one of the walls of the $\mathrm{C}(\mathrm{i}) \mathrm{A}$ headquarters. The song discusses the disconnect between political achievements such as Title IX and marriage equality with the onthe-ground realities of sexism, racism, and homophobia, through lines such as "Can we trade Title IX for an end to hate crime?," "While you were on vacation black people didn't get reparations," and "we really rocked the fucking vote with election fraud in poor zip codes." The

\footnotetext{
${ }^{17}$ I retrieved these lyrics from http://www.azlyrics.com/lyrics/letigre/fyr.html and edited them for accuracy (accessed December 9, 2015).
} 
song recognizes the importance of what has happened in "ten short years of progressive change" while pointing out systemic problems that should not be ignored or overlooked. The song's quick tempo and catchy rhythm keeps its tone upbeat and positive, fitting the mood of the montage.

After the montage ends, the song becomes diegetic as the film transitions to Anna listening to the song on headphones in her bedroom $(0: 26: 40)$. Since we last saw her room, she has redone the walls with spraypainted slogans, pictures from zines, and concert posters and record sleeves of bands including Le Tigre and Bikini Kill. The new style of her room, now prominently featuring these riot dyke bands, demonstrates her cultivation of new habits linked to queer activist identity. The lyrical content of the song is put in sharp relief by her sister, Ellen, who has been banging on the door, frustrated with Anna's neglect of her duties for the upcoming wedding. Anna, now thoroughly inculcated in radical feminist political ideals, retorts to Ellen's prodding on the subject that "marriage is a sexist institution designed by men to oppress women" (0:27:28). When Ellen comments on the new décor in Anna's room, Anna responds, "I no longer feel the need to surround myself with images of the misogynist tyranny." Anna's involvement in the C(i)A and her new taste for riot dyke music are thus tied both to an increase in her selfconfidence and to her new adherence to this specific type of feminist politics. Thus, the song "FYR" and its contextual use in IBTC connect riot dyke music directly to queer feminist politics and a rejection of mainstream social institutions such as a marriage. Anna has clearly made listening to this music part of her identity—she proudly displays record sleeves and concert posters on her walls - while disavowing her previous cultural habits and the identities they helped to build. This music is also linked with an increase in Anna's confidence — she is no longer willing just to go along with what her family wants her to do. 


\section{Riot Dyke and the "Rebel Girl"}

Once Anna's membership in the C(i)A is solidified, diegetic riot dyke music is employed extensively; in the following ten minutes the audience hears Le Tigre's "My Art" (0:27:43), Heavens to Betsy’s “Decide” (0:29:27), Slant 6’s “Ladybug Superfly” (0:34:50), and Bikini Kill's "Rebel Girl" (0:35:50). The songs all engage lyrically with the internal tensions in the $\mathrm{C}(\mathrm{i}) \mathrm{A}$ - now that Anna is a part of the group, the songs shift towards providing direct commentary on the characters and relationships in the group. Here I will briefly examine how the first three songs contribute to this end, building up the conflict between the group's members and contributing to the film's narrative, before focussing in more depth on the final song in this group, due to its direct link to Anna's character development.

The songs "My Art" and "Decide" accompany a scene at the C(i)A headquarters where Meat is working on her art while the music plays in the background. She warns Anna that Sadie is a fickle lover and will never leave her long-term girlfriend. Meat reveals that she was briefly in a relationship with Sadie and that Sadie has a new fling every month; Anna is just the next in a long line of affairs. Lyrically, the songs resonate with the scene. "My Art" describes the life of a jaded artist who feels threatened by a rival, which parallels Meat's feeling of being threatened by Anna, who is treated as an imposter in the C(i)A by Shulie and Meat. "Decide" presents a pessimistic image of marriage, with a character who says she is in control of her life but is really yearning for something more. The lyrics imply a critique of Sadie, who is reluctant to either leave the safety of her marriage-like relationship or to commit to it, in spite of the fact that neither she nor Courtney treats the other well. The latter two songs play in the club while Anna ignores Meat's advice and has a heart-to-heart conversation with Sadie; the lyrics of "Ladybug Superfly” emphasize Sadie's skills of manipulation and inability to commit to a relationship, 
saying "she knows she is your favourite vice / Be ready for the sacrifice / 'Cause you know she'll put your heart on ice." 18 Sadie tells Anna, "The way things are going with Courtney right now, I honestly don't think we'll make it to next week" (0:35:54), a statement given lie to by the music playing in the background. At that moment Meat asks Anna and Sadie to dance with her, in an attempt to defuse the romantic tension between them; Anna and Sadie agree to get up and dance but then promptly abandon Meat to dance with each other.

The final song in the group of diegetic riot dyke songs, "Rebel Girl” by Bikini Kill, begins shortly before Sadie tells Anna that she and Courtney will probably break up. Of these songs, "Rebel Girl” comments most directly on Anna's character. The song features a slower but still driving tempo, with heavy drums, distorted guitar, and a mixture of singing and yelling. The song's catchy melody is accompanied by guitar and bass lines that repeat without much variation, with the exception of a lead guitar part that has a brief solo. Unlike the previous song, which is diegetic but not live, this song is performed "live" at the club and despite its slightly slower tempo, it is still well within the realm of danceability, and has a catchier chorus and less aggressive singing style in comparison to some riot dyke music. Once the song begins and Sadie and Anna get up to dance, Sadie teaches Anna, who was initially reluctant to get up and dance, how to mosh. Following this, the music becomes non-diegetic and the film enters another montage, this time of moments in Anna and Sadie's budding relationship and of black and white club scenes, concluding as Shulie drives Anna home from the club, criticizing Anna for using the C(i)A as a dating service and not being devoted to its politics, continuing the critique of Anna as an imposter implied by the song "My Art" in the earlier scene described above.

\footnotetext{
${ }^{18}$ I retrieved the lyrics for this song from http://www.lyrics.com/ladybug-superfly-lyrics-slant-6.html and edited them for accuracy (accessed December 9, 2015).
} 
The song "Rebel Girl" is the only song in the film to specifically reference attraction between women - though the song avers "Love you like a sister, always / Come and be my best friend," non-platonic lyrics such as "I think I want to take you home," "In her hips, there's revolutions" and "In her kiss, I taste the revolution" pepper the song. ${ }^{19}$ The line "They say she's a dyke but I know / She is my best friend" sums up the song; the duality, intricacy, and seeming contradictions between various forms of love and attraction characterize the song's themes of ambivalence towards labels, as well as the youthful exploration of sexuality and identity. Though the song straddles the line between being about young love and friendship, taken as a whole, it speaks most strongly to the narrator's admiration of the "rebel girl," presented in the opening verse:

That girl thinks she's the queen of the neighbourhood

She's got the hottest trike in town

That girl she holds her head up so high

I think I want to be her best friend, yeah

In the context of the film, the song clearly narrates Anna's attraction to Sadie, which is at once based in admiration of her politics and rebellious image and in romantic or sexual attraction.

The song represents an ideal queer girl or woman who exhibits self-confidence, bravado, rebelliousness, sisterhood, political involvement, and a unique sense of style, all elements that describe Sadie well. These characteristics are also shown to be gradually coming to describe Anna as well, as evinced in part through this scene at the club, where Anna is dressed in more fashionable clothes and is learning to participate in queer feminist punk culture. In her examination of performance in lesbian films, Jamie Stuart observes that "a character's...

\footnotetext{
${ }^{19}$ I retrieved the lyrics for this song from http://www.lyricsfreak.com/b/bikini+kill/rebel+girl_20017775.html and checked them for accuracy (accessed December 9, 2015).
} 
involvement in a queer community, is sometimes accompanied by a change in appearance.

The character is recognizing that a shift in erotic identity, an internal construct, can mean a shift in the ways she is seen by others, an external consequence" $(2008,96)$. This observation aligns well with the portrayal of Anna's transition into this new group. Thus, while the song can be read as representing Anna's thoughts about Sadie, it can also be read to represent the idea of Anna's transition from her former reserved and shy disposition into a new confident, political, rebellious identity. In particular, the fact that Sadie teaches Anna how to mosh in this scene links "Rebel Girl" to Anna's personal growth and increasing active participation in this riot dyke community.

\section{"White Girl": A Call for Change}

The final example of diegetic riot dyke music in the film is also a live song performed in the club, a cover of Heavens to Betsy's "White Girl." This song is used to tie up the film's narrative about the C(i)A's internal strife, which was earlier acknowledged by the songs "My Art," "Decide," and "Ladybug Superfly." Much has happened since the previous scene discussed above: Anna and Sadie have begun and broken off a romantic relationship, the C(i)A has disbanded because of personal drama between the members, and following this dissolution Anna and Aggie have gotten drunk and slept together. However, Aggie had been harbouring feelings for Anna, and is hurt when he finds out, very publicly, that Anna does not have reciprocal feelings. In a last-ditch attempt to reunite the C(i)A sans Sadie, Anna hatches a plan that will get the group national media attention, but needs Aggie to help pull off the plan. The fact that they need Aggie forces Anna to face him and apologize; though she is clearly remorseful about the pain she caused him, she has either been avoiding him, or he has been avoiding seeing her. Thus, 
in this scene at the club, Anna has come to find Aggie in order to apologize to him. The scene is calm and introspective: the band's cover of "White Girl" is slow and heavy, and the audience at the club is mostly sitting on the floor listening. The lyrics are the only self-reflexive moment in the film with regards to race and the riot grrrl movement: the song discusses white privilege, and the narrator states, "I want to change the world / But I won't change anything / Unless I change my racist self." 20 Though the scene and the music do not directly align, in that the scene is not about racially-oriented issues, they both deal with themes of conflict within riot grrrl communities and the need for personal growth and self-reflection. The scene as a whole tries to represent growth of both the community and of the individuals within it, which is what enables the C(i)A to perform their final action that will earn them the national media attention they desire. Anna has reached a level of maturity, realizing that she needs to acknowledge and apologize for her mistakes because the interpersonal problems between the C(i)A members have been its downfall. Though Sadie earlier in the film represented herself as a mature leader, someone who will teach Anna the ways of radical feminism and the C(i)A, now Anna is presented as the mature one. At the end of the film, after the C(i)A has successfully pulled off their plan to gain national attention, Anna apologizes to Sadie for intruding on Sadie and Courtney's relationship and for sleeping with Aggie; Sadie reveals that she and Courtney have broken up but tells Anna, "I have a lot to learn," to which Anna responds cheekily, saying “Don’t worry, I'll teach you." Thus, the acknowledgement in "White Girl” that white riot grrrls need to address their racism parallels Anna's final acknowledgement that she must address the problems she has contributed to in the $\mathrm{C}(\mathrm{i}) \mathrm{A}$ and act more responsibly with regards to relationships in the future if the $\mathrm{C}(\mathrm{i}) \mathrm{A}$ is to succeed.

\footnotetext{
${ }^{20}$ I retrieved the lyrics for this song from http://songmeanings.com/songs/view/3530822107858507054/ and checked them for accuracy (accessed December 9, 2015).
} 


\section{Conclusion}

In $I B T C$, riot dyke music is strongly linked to Anna's personal growth. Not only does this music connect directly with her shifting political identity, the lyrics of the songs in the soundtrack narrate her growth to a confident young woman, and then her realization of the necessity of atoning for and altering her selfish behaviour which has contributed to the breakdown of the C(i)A. Further, riot dyke music, particularly "live" diegetic music, is closely linked to community in IBTC. In the introduction I cited Jodie Taylor's claim that music is central to "the fashioning of queer identities, the theatre of queer memory and the maintenance of queer culture more broadly" $(2010,49)$. In this chapter I have discussed riot dyke music in IBTC mostly in relation to her first point, "the fashioning of queer identities," but the deployment of this music in the film demonstrates all of these points, most intriguingly the middle point: the music used in this film is a constant remembering of earlier queer subcultural formations, whether through "live" performances of earlier riot dyke music, covers of riot dyke songs, or through the playing of recordings. The women in this feminist subculture are creating a queer history through their music-listening and -performing choices, constantly recalling earlier queer women's music while also creating their own new story. Regarding Taylor's final point, music is portrayed as central to the "maintenance" of this queer culture. All the activities that the C(i)A members are portrayed engaging in outside of their group involve going to the club and listening to and/or dancing to music. Riot dyke music is not only central to their individual identities as queer, radical feminists, but also to the community that they have formed. Riot dyke music facilitates Anna's transition into this new world and into her new feminist worldview, allowing her to find direction and independence in her life. 


\section{Conclusion}

Each of the three films I examined in the previous chapters explores young queer women's relationships with music and with identity formation in a slightly different way, both through these characters' habits and through songs' narrative contributions to the films. Though the characters are each in different situations in their lives, in each film riot dyke music acts as either an accompaniment to character maturation and identity shifts or as an affirmation of previously held identities. These functions of the music are demonstrated through characters' habits of music listening and performing as linked to habits of dress, political opinion, and sexuality, among others. The connections between particular habits and riot dyke music are solidified by the probable affiliating identifications of such music, as discussed in Chapter 2, many of which resonate with characteristics portrayed in these films, most notably feminist political stances, community formation, and resistance to normative expectations of femininity. By drawing primarily on Thomas Turino's concept of identity as formed by "habits," as well as Anahid Kassabian's idea of “affiliating identifications” and Kay Kaufman Shelemay’s conceptualization of modes of community formation, in this thesis I have explored the habits and identities linked to riot dyke music in these three lesbian films, how these films present this music as central to queer community formation, and how this music contributes to shifts in characters' identities.

In The Incredibly True Adventure of Two Girls in Love, Randy's interest in riot grrrl music is clearly linked with her already well-defined queer sexuality and serves primarily as source of affirmation in her life, a support in a small town where both she and her family are reviled by a significant portion of the population. Randy's interest in riot grrrl music is connected 
with habits of rebellion against social expectations of femininity as well as with workingclass identities, queer identities, and whiteness through contrast to the character of Evie, a young African-American woman who listens to classical music, comes from an upper- or upper-middleclass background and is more traditionally feminine. The relationship between Evie and Randy is in part built on the exchange of their musics of choice, leading to an implied mutual appreciation of the other's musical preferences and symbolically bridging the gap between their class backgrounds. In addition to listening to music, performing music is also intrinsic to Randy's identities. Though Randy is interested in performing riot grrrl-style music, her opportunity to do so appears limited at the moment due to her rural location and lack of like-minded peers. However, riot grrrl music gives Randy a sense of a larger community of queer youth, even if she is unable to directly access this community at present.

The film All Over Me takes a slightly different approach to its main character's relationship with music. In this film, the only case study film in which the main character does not have an established queer identity from the outset, Claude's exploration and realization of her sexuality are closely linked to her exploration of music. The local riot dyke music scene offers an escape from the world of homophobia and misogyny she increasingly finds herself in through her friend Ellen's relationship with her new boyfriend. As well, it functions to affirm her sexuality and her habits of resistance to social expectations of femininity, including norms of dress, food consumption, and body size. As in Two Girls in Love, music in All Over Me acts as a bridge between the two romantically involved characters; Claude and Lucy introduce each other to new music, but unlike Two Girls in Love, both listen to relatively similar styles of music. In All Over Me, non-mainstream music by female musicians, including riot dyke and punk music, is linked to challenging social norms of femininity, as well as to queerness, and working- and 
middle-class youth. Listening to and performing music are closely linked to Claude's identity formation and growth as a character, and are enabled in part by Claude's urban location —unlike Randy in Two Girls in Love, Claude may now have the opportunity to participate in her community's queer music scene. Further, the film closely links riot dyke music with queer community formed on the basis of dissent and affinity.

The final film I examined, Itty Bitty Titty Committee, differs in both its temporal placement (10-15 years after the other two films) and in the fact that its main characters do not perform or express interest in performing music. Like All Over Me, music in IBTC facilitates a transformation of identity, but in contrast to Claude's realization of her queerness, in IBTC, the transformation is from an apathetic disinterest in feminism to a radical feminist identity. In this film, music is used to explicitly intertwine feminist and queer identities, making them almost inextricable in the community portrayed. Further, though the film's main character is Latina, the fact she is introduced to this music through the white members of the C(i)A closely links riot dyke music to whiteness. The film links riot dyke music to the white middle class, to radical feminist identities, to queerness, and to youth. Older queer feminists are presented as disinterested in or scornful of riot dyke music and the politics to which it is linked. As in All Over Me, music is tightly linked with community, to both the C(i)A's small community and the broader queer punk community portrayed in the film, communities based on dissent and affinity, but also on descent to a certain extent. The local club is central to the main characters' lives, a place they visit regularly both as a group and alone. In both $I B T C$ and All Over Me, riot dyke music at live venues is central to youth queer community formation and by extension (following from Cohen), to the characters' identity formation as well. 
As mentioned at other points in this thesis, Jodie Taylor has argued that music is central to "the fashioning of queer identities, the theatre of queer memory and the maintenance of queer culture more broadly" $(2012,49)$. These three films demonstrate how the importance of music to queer communities, and certain musics in particular, crosses over into film, reaffirming Taylor's argument. In these films, which attempt to build realistic queer characters and communities by employing riot dyke music and its accompanying affiliating identifications, music is central to this endeavour while also providing an extra layer to the films' narratives and character development. Further, live music is integral to both All Over Me and Itty Bitty Titty Committee, facilitating the communities that go on to influence characters' identities. Each of these films portrays a character's identity formation or growth; in each case riot dyke music and its community are central to this formation or character development. Ultimately, in these films riot dyke music is linked to queer youth's growth and maturation, whether through first love, coming to terms with one's sexuality, or gaining direction in life. In addition, these films link riot dyke music to whiteness, youth, and working- and middle-class identities, as well as to queer and feminist political stances, forms of gender expression that resist normative expectations of femininity, and a range of queer identities. These identities mesh with the characteristics of the riot grrrl and queercore movements, though the linkage to working-class young women is interesting given the predominance of middle-class participants in the riot grrrl movement, as discussed in Chapter 2.

\section{Future Directions}

This thesis has been limited to select films containing riot dyke music, focussing particularly on movies about youth and self-discovery, but many other directions of scholarship 
on the topic of music and LGTBQ film are possible. Scholarship about popular music in LGBTQ film is quite slim at this point in time, consisting primarily of Anahid Kassabian's (2001) discussion of music in Desert Hearts, Jack Curtis Dubowsky's (2014) examination of popular music in New Queer Cinema films that focus on gay men, and Jamie Stuart's (2008) exploration of (frequently musical) performance in films about queer women. Beyond the specific artists and genres of music employed in lesbian film, to me one of the most intriguing aspects of lesbian film is the frequency with which these films engage with music, both in terms of listening and performance (a fact also noted by Stuart (2008)). Though this thesis has engaged with this idea to a small extent, more scholarship in this area is warranted. In addition, further scholarship on music — both musical genre and musical performance — in lesbian film would be valuable. For instance, an examination of country music in these films would explore an area of queer culture not often acknowledged, and would be timely given the recent publication of Nadine Hubbs' (2014) monograph Rednecks, Queers, and Country Music, the first in-depth examination of relationships between queerness and country music. I imagine that similar themes of resistance to gender norms may be linked to the use of this music in queer film soundtracks. Other areas of further study could include the use of music with lesbian cachet in these films and of particular musics in other forms of lesbian film, such as short film and documentary.

As LGBTQ cultures become increasingly mainstream, it will be interesting to see how the music featured in LGBTQ cinema will change. It is possible that this music will become increasingly mainstream as well and that the musical choices that I have argued have been unique to lesbian cinema may fade, particularly as LGBTQ cinema itself becomes more mainstream; indeed, the last few years have seen a proliferation of films about queer women in the mainstream, such as Blue is the Warmest Colour (2013), Pride (2014), Clouds of Sils Maria 
(2014), Carol (2015), Jenny’s Wedding (2015), Freeheld (2015), and Grandma (2015). Most

of these films do not have soundtracks with particular lesbian cachet or lesbian cultural associations. A quick glance at Appendix I demonstrates a similar trend in less mainstream lesbian films as well — whether this will continue to be a trend or whether this is just an outlying point in the evolution of LGBTQ film remains to be seen. LGBTQ cinema is excitingly dynamic, and its future directions will open new opportunities for both audience engagement and scholarship. 


\section{Appendix I: English-Language Films Examined in Preliminary Research}

This appendix provides a brief summary of the films whose soundtracks I examined in my preliminary research, in which I was looking for particular genres that occur frequently in lesbian film as well as for artists who have cachet. The table consists of Englishlanguage films that are both well known and for which I was able to find either the film or a listing of its soundtrack online. Earlier versions of this chart included all artists included in each film's soundtrack; artists who I felt lacked cachet with queer women are omitted in this chart for clarity. The films are arranged chronologically for clarity, and riot dyke music is in bold. In the genre column, "classical" refers to pre-existing Western art music used in compiled scores, not to "classical" style composed scores.

\begin{tabular}{|c|c|c|c|c|c|}
\hline Title & Year & Director(s) & Nationality & Genres & Artists with cachet \\
\hline Personal Best & 1982 & Robert Towne & USA & $\begin{array}{l}\text { soft rock } \\
\text { marching band }\end{array}$ & \\
\hline Born in Flames & 1983 & Lizzie Borden & USA & $\begin{array}{l}\text { punk } \\
\text { art rock } \\
\text { psychedelic rock }\end{array}$ & The Bloods \\
\hline Lianna & 1983 & John Sayles & USA & $\begin{array}{l}\text { folk } \\
\text { funk/soul }\end{array}$ & \\
\hline Desert Hearts & 1985 & Donna Deitch & USA & $\begin{array}{l}\text { classical } \\
\text { country } \\
\text { rockabilly/rock n roll } \\
\text { rock n roll } \\
\text { traditional pop } \\
\text { jazz }\end{array}$ & Johnny Cash, Patsy Cline \\
\hline I've Heard the Mermaids Singing & 1987 & Patricia Rozema & Canada & classical & \\
\hline Salmonberries & 1991 & Percy Adlon & $\begin{array}{l}\text { Germany/ } \\
\text { Canada }\end{array}$ & $\begin{array}{l}\text { classical } \\
\text { folk }\end{array}$ & kd lang \\
\hline Claire of the Moon & 1992 & Nicole Conn & USA & classical & \\
\hline Go Fish & 1994 & Rose Troche & USA & composed & \\
\hline $\begin{array}{l}\text { The Incredibly True Adventure of } \\
\text { Two Girls in Love }\end{array}$ & 1995 & Maria Maggenti & USA & $\begin{array}{l}\text { riot grrrl } \\
\text { classical } \\
\text { punk }\end{array}$ & $\begin{array}{l}\text { Bratmobile, Bikini Kill, Lois } \\
\text { Scrawl, Velocity Girl }\end{array}$ \\
\hline
\end{tabular}




\begin{tabular}{|c|c|c|c|c|c|}
\hline Title & Year & Director(s) & Nationality & Genres & Artists with cachet \\
\hline $\begin{array}{l}\text { The Incredibly True Adventure of } \\
\text { Two Girls in Love (continued) }\end{array}$ & & & & alt rock & BETTY \\
\hline When Night is Falling & 1995 & Patricia Rozema & Canada & $\begin{array}{l}\text { classical } \\
\text { singer songwriter }\end{array}$ & \\
\hline Bound & 1996 & $\begin{array}{l}\text { Andy and Lana } \\
\text { Wachowski }\end{array}$ & USA & $\begin{array}{l}\text { jazz } \\
\text { country/pop } \\
\text { alt rock }\end{array}$ & \\
\hline The Watermelon Woman & 1996 & Cheryl Dunye & USA & $\begin{array}{l}\text { classical } \\
\text { soul } \\
\text { house } \\
\text { acid jazz } \\
\text { R\&B } \\
\text { downtempo/electronic } \\
\text { pop } \\
\text { hip hop } \\
\text { folk }\end{array}$ & $\begin{array}{l}\text { Phyllis Hyman } \\
\text { Brooklyn Funk Essentials } \\
\text { Vanessa Daou } \\
\text { Sha-Key, Brooklyn Funk Essentials } \\
\text { Toshi Reagon }\end{array}$ \\
\hline All Over Me & 1997 & Alex Sichel & USA & $\begin{array}{l}\text { riot grrrl } \\
\text { punk } \\
\text { indie rock } \\
\text { indie pop } \\
\text { Americana } \\
\text { alt rock } \\
\text { alt country } \\
\text { indie folk }\end{array}$ & $\begin{array}{l}\text { Sleater-Kinney } \\
\text { Patti Smith, Babes in Toyland } \\
\text { Helium } \\
\text { The Murmurs, The Softies } \\
\text { Ani Difranco }\end{array}$ \\
\hline Gia & 1998 & Michael Cristofer & USA & $\begin{array}{l}\text { glam rock } \\
\text { rock } \\
\text { post-punk } \\
\text { jazz }\end{array}$ & \\
\hline High Art & 1998 & Lisa Cholodenko & USA & composed score & \\
\hline Better than Chocolate & 1999 & Anne Wheeler & Canada & $\begin{array}{l}\text { folk pop } \\
\text { rock }\end{array}$ & Bif Naked \\
\hline
\end{tabular}




\begin{tabular}{|c|c|c|c|c|c|}
\hline Title & Year & Director(s) & Nationality & Genres & Artists with cachet \\
\hline $\begin{array}{l}\text { Better than Chocolate } \\
\text { (continued) }\end{array}$ & & & & $\begin{array}{l}\text { house } \\
\text { indie folk } \\
\text { electronic } \\
\text { classical } \\
\text { pop }\end{array}$ & $\begin{array}{l}\text { Ani Difranco, Ferron } \\
\text { Sarah McLachlan }\end{array}$ \\
\hline But I'm A Cheerleader & 1999 & Jamie Babbit & USA & $\begin{array}{l}\text { riot grrrl } \\
\text { punk } \\
\text { rock n roll } \\
\text { indie rock } \\
\text { indie pop } \\
\text { dance/house } \\
\text { twee pop }\end{array}$ & Tattle Tale, Lois Maffeo \\
\hline Chutney Popcorn & 1999 & Nisha Ganatra & USA & $\begin{array}{l}\text { Indian folk } \\
\text { alt pop-rock } \\
\text { indie pop } \\
\text { queercore } \\
\text { indie rock }\end{array}$ & Longstocking, Team Dresch \\
\hline If These Walls Could Talk 2 & 2000 & $\begin{array}{l}\text { Jane Anderson; } \\
\text { Martha Coolidge; } \\
\text { Anne Heche }\end{array}$ & USA & $\begin{array}{l}\text { folk } \\
\text { rock } \\
\text { pop } \\
\text { electronic } \\
\text { pop } \\
\text { country } \\
\text { dance/house } \\
\text { rockabilly }\end{array}$ & $\begin{array}{l}\text { Indigo Girls } \\
\text { Melissa Etheridge } \\
\text { The Eurythmics } \\
\text { Cyndi Lauper, Club Nouveau }\end{array}$ \\
\hline A Family Affair & 2001 & Helen Lesnick & USA & composed & \\
\hline Kissing Jessica Stein & 2001 & $\begin{array}{l}\text { Charles Herman- } \\
\text { Wurmfeld }\end{array}$ & USA & $\begin{array}{l}\text { classical } \\
\text { jazz } \\
\text { soul jazz } \\
\text { R\&B, soul } \\
\text { folk rock }\end{array}$ & \\
\hline
\end{tabular}




\begin{tabular}{|c|c|c|c|c|c|}
\hline Title & Year & Director(s) & Nationality & Genres & Artists with cachet \\
\hline Kissing Jessica Stein (continued) & & & & $\begin{array}{l}\text { electronic/hip hop } \\
\text { country } \\
\text { new age }\end{array}$ & \\
\hline Lost and Delirious & 2001 & Léa Pool & Canada & $\begin{array}{l}\text { funk/soul } \\
\text { punk } \\
\text { indie folk } \\
\text { Latin mass }\end{array}$ & $\begin{array}{l}\text { Me'shell Ndegeocello } \\
\text { Ani Difranco }\end{array}$ \\
\hline The Hours & 2002 & Stephen Daldry & USA & classical & \\
\hline D.E.B.S. & 2004 & Angela Robinson & USA & $\begin{array}{l}\text { alt rock } \\
\text { pop-rock } \\
\text { electropunk/clash } \\
\text { electronic } \\
\text { dance/house } \\
\text { gothic rock } \\
\text { rap } \\
\text { singer songwriter } \\
\text { indie pop }\end{array}$ & Goldfrapp \\
\hline Girl Play & 2004 & Lee Friedlander & USA & singer songwriter & Jennifer Foster, Karyn Kuhl \\
\hline Mango Kiss & 2004 & Sascha Rice & USA & jazz & \\
\hline My Summer of Love & 2004 & $\begin{array}{l}\text { Pawel } \\
\text { Pawlikowski }\end{array}$ & UK & $\begin{array}{l}\text { electronic } \\
\text { classical } \\
\text { chanson } \\
\text { bossa nova } \\
\text { Christian songwriter } \\
\text { mambo } \\
\text { Bollywood } \\
\end{array}$ & $\begin{array}{l}\text { Goldfrapp } \\
\text { Edith Piaf }\end{array}$ \\
\hline Saving Face & 2004 & Alice $\mathrm{Wu}$ & USA & $\begin{array}{l}\text { jazz } \\
\text { singer songwriter } \\
\text { bossa nova } \\
\text { Taiwanese pop/folk } \\
\text { Buddhist anthem }\end{array}$ & \\
\hline
\end{tabular}




\begin{tabular}{|c|c|c|c|c|c|}
\hline Title & Year & Director(s) & Nationality & Genres & Artists with cachet \\
\hline Rent & 2005 & Chris Columbus & USA & musical & \\
\hline Gray Matters & 2006 & Sue Kramer & USA & $\begin{array}{l}\text { classical } \\
\text { singer songwriter } \\
\text { soul } \\
\text { alt country } \\
\text { Latin } \\
\text { disco } \\
\text { jazz } \\
\text { electronic } \\
\text { pop/folk pop } \\
\text { country }\end{array}$ & \\
\hline Loving Annabelle & 2006 & Katherine Brooks & USA & singer songwriter & Amy Cook \\
\hline Nina's Heavenly Delights & 2006 & Pratibha Parmar & UK & $\begin{array}{l}\text { Bollywood } \\
\text { bhangra } \\
\text { singer songwriter } \\
\text { dance/house } \\
\text { pop }\end{array}$ & $\begin{array}{l}\text { Lata Mangeshkar, Asha Bhosle, } \\
\text { Nazia Hassan } \\
\text { Alex Parkes }\end{array}$ \\
\hline Puccini for Beginners & 2006 & Maria Maggenti & USA & $\begin{array}{l}\text { classical } \\
\text { jazz } \\
\text { pop } \\
\text { indie folk } \\
\text { rock }\end{array}$ & \\
\hline The Gymnast & 2006 & Ned Farr & USA & singer songwriter & Jane Siberry \\
\hline Itty Bitty Titty Committee & 2007 & Jamie Babbit & USA & $\begin{array}{l}\text { riot grrrl } \\
\text { queercore } \\
\text { riot dyke } \\
\text { electropunk } \\
\text { indie rock }\end{array}$ & $\begin{array}{l}\text { Bikini Kill, Heavens to Betsy } \\
\text { Team Dresch, The Need, Slant } 6 \\
\text { Le Tigre, Sleater-Kinney } \\
\text { Peaches }\end{array}$ \\
\hline And Then Came Lola & 2009 & $\begin{array}{l}\text { Ellen Seidler; } \\
\text { Megan Siler }\end{array}$ & USA & $\begin{array}{l}\text { indie rock } \\
\text { country rock }\end{array}$ & $\begin{array}{l}\text { Sick of Sarah } \\
\text { Jennifer Corday }\end{array}$ \\
\hline
\end{tabular}




\begin{tabular}{|c|c|c|c|c|c|}
\hline Title & Year & Director(s) & Nationality & Genres & Artists with cachet \\
\hline $\begin{array}{l}\text { And Then Came Lola } \\
\text { (continued) }\end{array}$ & & & & $\begin{array}{l}\text { rap } \\
\text { indie pop }\end{array}$ & \\
\hline A Marine Story & 2010 & Ned Farr & USA & composed & \\
\hline Bloomington & 2010 & Fernanda Cardoso & USA & indie folk & Ani Difranco \\
\hline Elena Undone & 2010 & Nicole Conn & USA & $\begin{array}{l}\text { country rock } \\
\text { rap } \\
\text { indie pop/rock }\end{array}$ & $\begin{array}{l}\text { Jennifer Corday } \\
\text { God-des and She }\end{array}$ \\
\hline The Four-Faced Liar & 2010 & Jacob Chase & USA & $\begin{array}{l}\text { classical } \\
\text { electronic } \\
\text { indie rock } \\
\text { singer songwriter } \\
\text { indie pop }\end{array}$ & \\
\hline The Kids Are All Right & 2010 & Lisa Cholodenko & USA & $\begin{array}{l}\text { electropop } \\
\text { glam rock } \\
\text { folk } \\
\text { indie rock } \\
\text { Brazilian rock } \\
\text { soul } \\
\text { jazz } \\
\text { electronic } \\
\text { punk } \\
\text { Latin }\end{array}$ & Uh Huh Her \\
\hline Cloudburst & 2011 & Thom Fitzgerald & $\begin{array}{l}\text { Canada; } \\
\text { USA }\end{array}$ & $\begin{array}{l}\text { pop } \\
\text { country } \\
\text { folk rolk } \\
\text { reggae }\end{array}$ & kd lang \\
\hline $\begin{array}{l}\text { Codependent Lesbian Space } \\
\text { Alien Seeks Same }\end{array}$ & 2011 & Madeleine Olnek & USA & composed & \\
\hline $\begin{array}{l}\text { Jamie and Jessie Are Not } \\
\text { Together }\end{array}$ & 2011 & Wendy Jo Carlton & USA & $\begin{array}{l}\text { indie pop } \\
\text { hip hop } \\
\text { electronic }\end{array}$ & $\begin{array}{l}\text { Tegan and Sara } \\
\text { God-des and She } \\
\text { Anomie Belle }\end{array}$ \\
\hline
\end{tabular}




\begin{tabular}{|c|c|c|c|c|c|}
\hline Title & Year & Director(s) & Nationality & Genres & Artists with cachet \\
\hline $\begin{array}{l}\text { Jamie and Jessie Are Not } \\
\text { Together (continued) }\end{array}$ & & & & $\begin{array}{l}\text { indie pop } \\
\text { rock } \\
\text { singer songwriter } \\
\text { indie rock }\end{array}$ & Ripley Caine \\
\hline Pariah & 2011 & Dee Rees & USA & $\begin{array}{l}\text { pop-punk } \\
\text { indie rock } \\
\text { hip hop } \\
\text { soul/R\&B } \\
\text { folk/soul }\end{array}$ & Gossip/Tamar-Kali \\
\hline A Perfect Ending & 2012 & Nicole Conn & USA & classical & \\
\hline Jack \& Diane & 2012 & Bradley Rust Gray & USA & pop & \\
\hline Margarita & 2012 & $\begin{array}{l}\text { Dominique } \\
\text { Cardona; Laurie } \\
\text { Colbert }\end{array}$ & Canada & alt pop (Mexican) & \\
\hline Mosquita y Mari & 2012 & Aurora Guerrero & USA & $\begin{array}{l}\text { indie pop (Mexican) } \\
\text { indie rock (Spanish) } \\
\text { dance } \\
\text { electropop } \\
\text { (Venezuelan) } \\
\text { ska } \\
\text { Latin rock } \\
\text { Latin }\end{array}$ & \\
\hline Stud Life & 2012 & Campbell X & UK & $\begin{array}{l}\text { bhangra } \\
\text { dancehall }\end{array}$ & \\
\hline The Guest House & 2012 & $\begin{array}{l}\text { Michael } \\
\text { Baumbarten }\end{array}$ & USA & indie rock & \\
\hline Breaking the Girls & 2013 & Jamie Babbit & USA & $\begin{array}{l}\text { indie pop } \\
\text { electropop } \\
\text { indie rock } \\
\text { electronic rock } \\
\text { singer songwriter }\end{array}$ & Uh Huh Her \\
\hline
\end{tabular}




\begin{tabular}{|c|c|c|c|c|c|}
\hline Title & Year & Director(s) & Nationality & Genres & Artists with cachet \\
\hline Concussion & 2013 & Stacie Passon & USA & $\begin{array}{l}\text { pop } \\
\text { punk/glam rock } \\
\text { post-punk }\end{array}$ & Karyn Kuhl \\
\hline Contracted & 2013 & Eric England & USA & $\begin{array}{l}\text { alt rock } \\
\text { singer songwriter } \\
\text { electronica }\end{array}$ & \\
\hline Heterosexual Jill & 2013 & Michelle Ehlen & USA & pop-rock & \\
\hline Tru Love & 2013 & $\begin{array}{l}\text { Kate Johnston; } \\
\text { Shauna } \\
\text { MacDonald }\end{array}$ & USA & composed & \\
\hline Valencia & 2013 & $\begin{array}{l}\text { Peter Anthony, } \\
\text { Sharon Barnes }\end{array}$ & USA & $\begin{array}{l}\text { riot grrrl } \\
\text { queercore }\end{array}$ & $\begin{array}{l}\text { Bratmobile, Bikini Kill } \\
\text { Tribe 8, Pansy Division, Team } \\
\text { Dresch }\end{array}$ \\
\hline Who's Afraid of Vagina Wolf & 2013 & $\begin{array}{l}\text { Anna Margarita } \\
\text { Albelo }\end{array}$ & USA & $\begin{array}{l}\text { indie rock } \\
\text { electropop } \\
\text { jazz } \\
\text { pop }\end{array}$ & $\begin{array}{l}\text { Emily Wolfe, Love Darling } \\
\text { Hi Fashion, Love Darling }\end{array}$ \\
\hline Appropriate Behavior & 2014 & Desiree Akhavan & USA & $\begin{array}{l}\text { indie rock } \\
\text { soul } \\
\text { alt country } \\
\text { post-punk } \\
\text { Lebanese folk } \\
\text { Birjadi folk } \\
\text { Arabic dance } \\
\text { Persian folk } \\
\text { electronic } \\
\text { dream pop } \\
\text { dance-pop } \\
\text { folk } \\
\text { electropop } \\
\text { rock (Persian) }\end{array}$ & MEN \\
\hline
\end{tabular}




\begin{tabular}{|c|c|c|c|c|c|}
\hline Title & Year & Director(s) & Nationality & Genres & Artists with cachet \\
\hline Boy Meets Girl & 2014 & Eric Schaeffer & USA & $\begin{array}{l}\text { singer songwriter } \\
\text { pop }\end{array}$ & \\
\hline Girltrash: All Night Long & 2014 & $\begin{array}{l}\text { Alexandra } \\
\text { Kondracke }\end{array}$ & USA & musical & \\
\hline Life Partners & 2014 & Susanna Fogel & USA & $\begin{array}{l}\text { electropop } \\
\text { indie rock } \\
\text { electronic } \\
\text { singer songwriter } \\
\text { surf-punk } \\
\text { alt pop } \\
\text { punk } \\
\text { indie folk } \\
\text { indie pop }\end{array}$ & The Blow \\
\hline
\end{tabular}




\section{Works Cited}

Anderson, Benedict. (1983) 2006. Imagined Communities: Reflections on the Origin and Spread of Nationalism. 2nd ed. London: Verso.

Anderson, Lauren. 2003. "Case Study 1: Sliding Doors and Topless Women Talk About Their Lives." In Popular Music and Film, edited by Ian Inglis, 102-116. London: Wallflower Press.

Autostraddle. 2015. "The 100 Best Lesbian Movies of All Time." August 11. Accessed October 3, 2015. http://www.autostraddle.com/100-best-lesbian-queer-bisexual-movies-285412/.

Benshoff, Harry M., and Sean Griffin. 2004. America on Film: Representing Race, Class, Gender, and Sexuality at the Movies. Malden, Mass.: Blackwell.

Brett, Philip. (1994) 2006. “Musicality, Essentialism, and the Closet." In Queering the Pitch: The New Gay and Lesbian Musicology, edited by Philip Brett, Elizabeth Wood, and Gary C. Thomas, 2nd ed., 9-26. New York and London: Routledge.

Brown, Royal S. 1994. Overtones and Undertones: Reading Film Music. Berkeley: University of California Press.

Brownstein, Carrie. 2015. Hunger Makes Me a Modern Girl: A Memoir. New York: Riverhead Books.

Burt, Stephen. 2015. "Scrawl—Punk Rock for Grown-Ups: A Retrospective." At Length Magazine. Accessed December 1. http://atlengthmag.com/music/scrawl-punk-rock-forgrown-ups-a-retrospective/

Carey, Melissa, and Michael Hannan. 2003. "Case Study 2: The Big Chill.” In Popular Music and Film, edited by Ian Inglis, 162-177. London: Wallflower Press.

Ciminelli, David, and Ken Knox. 2005. Homocore: The Loud and Raucous Rise of Queer Rock. Los Angeles: Alyson Books.

Cohen, Anthony P. 1985. The Symbolic Construction of Community. London and New York: Routledge.

DeChaine, D. Robert. 1997. "Mapping Subversion: Queercore Music's Playful Discourse of Resistance." Popular Music and Society 21 (4): 7-37.

Dougher, Sarah, and Elizabeth K. Keenan. 2012. "Riot Grrrl, Ladyfest and Rock Camps for Girls." In Women Make Noise: Girl Bands from Motown to the Modern, edited by Julia Downes, 259-291. Twickenham: Supernova Books. 
Downes, Julia. 2012. “The Expansion of Punk Rock: Riot Grrrl Challenges to Gender Power Relations in British Indie Music Subcultures.” Women's Studies 41: 204-237.

- 2014. "“We Are Turning Cursive Letters into Knives': The Synthesis of the Written Word, Sound and Action in Riot Grrrl Cultural Resistance." In Litpop: Writing and Popular Music, edited by Rachel Carroll and Adam Hansen, 89-105. Farnham: Ashgate.

Driver, Susan. 2007. Queer Girls and Popular Culture: Reading, Resisting, and Creating Media. New York: Peter Lang.

Dubowsky, Jack Curtis. 2014. "Musical Cachet in New Queer Cinema." Music, Sound, and the Moving Image 8 (1): 25-56.

Duggan, Lisa. 2003. The Twilight of Equality? Neoliberalism, Cultural Politics, and the Attack on Democracy. Boston: Beacon.

Dunn, Kevin C. 2014. "Pussy Rioting: The Nine Lives of the Riot Grrrl Revolution." International Feminist Journal of Politics 16 (2): 317-334.

du Plessis, Michael, and Kathleen Chapman. 1997. "Queercore: The Distinct Identities of Subculture.” College Literature 42 (1): 45-58.

Ensminger, David. 2010. "Redefining the Body Electric: Queering Punk and Hardcore.” Journal of Popular Music Studies 22 (1): 50-67.

Faderman, Lillian. 1991. Odd Girls and Twilight Lovers: A History of Lesbian Life in TwentiethCentury America. New York: Penguin Books.

Fast, Susan. 2012. “Michael Jackson's Queer Musical Belongings.” Popular Music and Society 35 (2): 281-300.

Halberstam, Judith. 1998. Female Masculinities. Durham and London: Duke University Press.

- (2003) 2008. "What's That Smell? Queer Temporalities and Subcultural Lives." In Queer Youth Subcultures, edited by Susan Driver, 27-50. Albany: State University of New York Press.

Hayes, David P. 2009. “The Motion Picture Production Code.” Accessed August 16, 2016. http://productioncode.dhwritings.com/multipleframes_productioncode.php.

Henderson, Lisa. 2008. Queer Relay. GLQ: A Journal of Lesbian and Gay Studies 14 (4): 569597. 
Horak, Laura. 2016. Girls Will Be Boys: Cross-Dressed Women, Lesbians, and American Cinema, 1908-1934. New Brunswick, New Jersey, and London: Rutgers University Press.

Kassabian, Anahid. 2001. Hearing Film: Tracking Identifications in Contemporary Hollywood Film Music. New York and London: Routledge.

Kearney, Mary Celeste. 1997. "The Missing Links: Riot Grrrl—Feminism—Lesbian Culture.” In Sexing the Groove: Gender and Popular Music, edited by Sheila Whiteley, 207-229. London: Routledge.

. 2006. Girls Make Media. New York and London: Routledge.

Keller, Lisa, and George Winslow. 2010. “Hell's Kitchen.” In The Encyclopedia of New York City, edited by Kenneth T. Jackson, 2nd ed., 589-590. New Haven and London: Yale University Press.

Leff, Leonard J., and Jerold L. Simmons. 2001. "Appendix: The Motion Picture Production Code." In The Dame in the Kimono: Hollywood, Censorship, and the Production Code. 2nd ed., 285-300. Lexington, KY: The University Press of Kentucky.

Leonard, Marion. 2014. "Riot Grrrl.” In The Grove Dictionary of American Music, 2nd ed. http://www.oxfordmusiconline.com.proxy.library.carleton.ca/subscriber/article/grove/mu $\mathrm{sic} / \mathrm{A} 2257186$

Marcus, Sara. 2010. Girls to the Front: The True Story of the Riot Grrrl Revolution. New York: Harper.

Mulcaire, Terry. 1993. "Publishing Intimacy in Leaves of Grass.” ELH 2 (60): 471-501.

Murphy, Kevin P., Jason Ruiz, and David Serlin. 2008. “Editors' Introduction.” Radical History Review 100: 1-9.

National Coalition of Anti-Violence Programs. 1999. Anti-Lesbian, Gay, Bisexual and Transgender Violence in 1998. Written by Ken Moore. New York: NY. Accessed May $19,2016$.

http://www.avp.org/storage/documents/Reports/1998_NCAVP_Bias_Report.pdf.

New Line Productions. 2007. “All Over Me Production Notes.” Archived November 11. Accessed September 11, 2016.

http://web.archive.org/web/20071111123053/http://www.finelinefeatures.com/alloverme/ prodnote.htm and http://web.archive.org/web/20071112073740/http://www.finelinefeatures.com/alloverme/ prodnte 2 .htm. 
Nguyen, Mimi Thi. 2012. "Riot Grrrl, Race, and Revival." Women \& Performance: A Journal of Feminist Theory 22 (2-3): 173-196.

Noble, Jean Bobby. 2003. Masculinities Without Men?: Female Masculinity in TwentiethCentury Fictions. Vancouver: UBC Press.

Nowlan, Bob. 2010. "Queer Theory, Queer Cinema." In Coming Out to the Mainstream: New Queer Cinema in the 21st Century, edited by JoAnne C. Juett and David M. Jones, 2-19. Newcastle upon Tyne: Cambridge Scholars.

Oram, Alison. 2007. Her Husband Was a Woman! Women's Gender Crossing in Modern British Popular Culture. London and New York: Routledge.

Peirce, C. S. 1955. Philosophical Writings of Peirce. Edited by Justus Buchler. New York: Dover.

Peraino, Judith A. 2006. Listening to the Sirens: Musical Technologies of Queer Identity from Homer to Hedwig. Berkeley: University of California Press.

POWER UP Films. 2016. “About POWER UP.” Accessed Jan 10. http://www.powerupfilms.org/index.php?option=com_content\&view=article\&id=11.

Prinze, Jesse. 2014. “The Aesthetics of Punk Rock.” Philosophy Compass 9 (9): 583-593.

Rauzier, Val. 2012. “Queercore: Fearless Women.” In Women Make Noise: Girl Bands from Motown to the Modern, edited by Julia Downes, 238-258. Twickenham: Supernova Books.

Rich, B. Ruby. 2013. New Queer Cinema: The Director's Cut. Durham and London: Duke University Press.

Rosenberg, Jessica, and Gitana Garofalo. 1998. "Riot Grrrl: Revolutions from Within.” Signs 23 (3): 809-841.

Rowe, Amy. 2015. “Sleater-Kinney's Carrie Brownstein Will Make You Laugh and Cry in 'Hunger Makes Me a Modern Girl': Book Review." New York Daily News, November 4. Accessed January 17, 2016. http://www.nydailynews.com/new-york/carrie-brownsteinhunger-modern-girl-review-article-1.2421933.

Schilt, Kristen. 2005. “The Punk White Privilege Scene': Riot Grrrl, White Privilege, and Zines." In Different Wavelengths: Studies of the Contemporary Women's Movement, edited by Jo Reger, 39-56. Routledge: New York and London. 
Schwandt, Kevin. 2009. "The Erotics of an Oil Drum: Queercore, Gay Macho, and the Defiant Sexuality of Extra Fancy's Sinnerman.” Women \& Music 13: 76-87.

Sedgwick, Eve Kosovsky. 1994. Tendencies. London: Routledge.

Shelemay, Kay Kaufman. 2011. "Musical Communities: Rethinking the Collective in Music." Journal of the American Musicological Society 64 (2): 349-390.

Shoemaker, Deanna. 2010. “Queer Punk Macha Femme: Leslie Mah's Musical Performance in Tribe 8." Cultural Studies $\leftrightarrow$ Critical Methodologies 10 (4): 295-306.

Stuart, Jamie. 2008. Performing Queer Female Identity on Screen: A Critical Analysis of Five Recent Films. Jefferson, NC and London: McFarland.

Taylor, Jodie. 2012. Playing It Queer: Popular Music, Identity and Queer World-Making. Bern: Peter Lang.

Turino, Thomas. 2008. Music as Social Life: The Politics of Participation. Chicago: University of Chicago Press.

Valentine, Gill. 1995. "Creating Transgressive Space: The Music of k.d. lang.” Transactions of the Institute of British Geographers 20 (4): 474-485.

Whitman, Walt. 1891. Leaves of Grass. Philadelphia: David McKay.

Wilson, Elizabeth. 1990. "Deviant Dress.” Feminist Review 35: 67-74.

Wright, Robb. 2003. "Score vs. Song: Art, Commerce, and the H Factor in Film and Television Music." In Popular Music and Film, edited by Ian Inglis, 8-21. London: Wallflower Press. 


\section{Discography (by band and date)}

Ani DiFranco. 1995. Not a Pretty Girl. Righteous Babe Records. CD.

Babes in Toyland. 1995. Nemisisters. Reprise Records. CD.

BETTY. 1996. Limboland. Intersound. CD.

Bikini Kill. 1991. Revolution Girl Style Now! Self-released. Cassette.

Bikini Kill. 1993. Pussy Whipped. Kill Rock Stars. CD.

Bikini Kill/Huggy Bear. 1992. Yeah Yeah Yeah Yeah/Our Troubled Youth. Kill Rock Stars. LP.

Bratmobile. 1993. Pottymouth. Kill Rock Stars. CD.

Compilation. 1992. There's a Dyke in the Pit. Outpunk Records. 7'.

Compilation. 1995. Free To Fight! Candy Ass Records. CD.

Heavens to Betsy. 1994. Calculated. Kill Rock Stars. CD.

Helium. 1993. "Hole in the Ground." Pop Narcotic. 7”.

Le Tigre. 1999. Le Tigre. Mr. Lady. CD.

Le Tigre. 2001. From the Desk of... Mr. Lady. Mr. Lady. CD.

Le Tigre. 2001. Feminist Sweepstakes. Mr. Lady. CD.

Lois. 1993. "The Trouble with Me"/"Page Two." K Records. 7”.

The Need. 1998. Karaneedoke. Kill Rock Stars. 2x7”.

The Need \& Nomy Lamm. 2000. The Transfused. Yoyo Records. CD.

The Patti Smith Group. 1976. Radio Ethiopia. Arista. LP.

Scrawl. 1991. Bloodsucker. Feel Good All Over Records. CD.

Slant 6. 1995. Inzombia. Dischord Records. CD.

Sleater-Kinney. 1996. Call the Doctor. Chainsaw Records. CD.

Team Dresch. 1994. "Hand Grenade." Kill Rock Stars. 7".

Team Dresch. 1995. Personal Best. Candy Ass Records/Chainsaw Records. CD.

Tuscadero. 1994. The Pink Album. TeenBeat Records. CD.

Velocity Girl. 1994. ¡Simpatico! Subpop. CD. 


\section{Filmography (including TV shows and TV movies/miniseries)}

All Over Me (dir. Alex Sichel, 1997)

And Then Came Lola (dir. Ellen Seidler and Megan Siler, 2009)

Better than Chocolate (dir. Anne Wheeler, 1999)

Bloomington (dir. Fernanda Cardoso, 2010)

Born in Flames (dir. Lizzie Borden, 1983)

But I'm a Cheerleader (dir. Jamie Babbit, 1999)

Chutney Popcorn (dir. Nisha Ganatra, 1999)

Cloudburst (dir. Thom Fitzgerald, 2011)

Desert Hearts (dir. Donna Deitch, 1985)

Dyketactics (dir. Barbara Hammer, 1974)

Elena Undone (dir. Nicole Conn, 2010)

A Florida Enchantment (dir. Sidney Drew, 1914)

Girl Power (short, dir. Sadie Benning, 1992)

The Guest House (dir. Michael Baumbarten, 2012)

The Gymnast (dir. Ned Farr, 2006)

I've Heard the Mermaids Singing (dir. Patricia Rozema, 1987)

If These Walls Could Talk 2 (dir. Jane Anderson, Martha Coolidge, and Anne Heche, 2000)

Imagine Me and You (dir. Ol Parker, 2005)

In the Best Interests of the Children (dir. France Reid, Elizabeth Stevens, and Cathy Zheutlin, 1977)

The Incredibly True Adventure of Two Girls in Love (dir. Maria Maggenti, 1995)

Itty Bitty Titty Committee (dir. Jamie Babbit, 2007)

The L Word (created by Ilene Chaiken, 2004-2009)

Lianna (dir. John Sayles, 1983)

Loving Annabelle (dir. Katherine Brooks, 2006)

Mädchen in Uniform (dir. Leontine Sagan, 1931)

Mädchen in Uniform (dir. Geza Radvany, 1958)

Mosquita y Mari (dir. Aurora Guerrero, 2012)

Nina's Heavenly Delights (dir. Pratibha Parmar, 2006)

Pandora's Box (dir. Georg Wilhelm Pabst, 1929)

Pariah (dir. Dee Rees, 2011)

Personal Best (dir. Robert Towne, 1982)

Puccini for Beginners (dir. Maria Maggenti, 2006)

The Punk Singer (dir. Sini Anderson, 2013)

Queen Christina (dir. Rouben Mamoulin, 1933)

Saving Face (dir. Alice Wu, 2004)

Stud Life (dir. Campbell X, 2012)

Tipping the Velvet (dir. Geoffrey Sax, 2002) 
The Watermelon Woman (dir. Dee Rees, 1996)

When Night is Falling (dir. Patricia Rozema, 1995)

Women I Love (dir. Barbara Hammer, 1976) 